\title{
Water management, hydrological extremes, and society: modeling interactions and phenomena
}

\author{
Maurizio Mazzoleni $^{1,2}$, Vincent O. Odongo $^{2,3}$ Elena Mondino $^{1,2}$ and Giuliano Di Baldassarre $^{1,2,4}$
}

\begin{abstract}
We present a system-dynamics model to simulate the interplay between water management, hydrological extremes (droughts and floods), and society. We illustrate the potential and limitations of the model with an example application to the Brisbane river basin (Australia). In particular, we test its capability to explain various phenomena that have been empirically observed, including the levee paradox, (mal)adaptation, and supply-demand cycles. To illustrate, we consider four water-management strategies: no actions, in which no measures are adopted to mitigate droughts and floods; fighting floods, in which a levee system is built and raised to cope with flooding; water conservation, in which demand management is implemented to cope with drought; and water exploitation, in which the water supply is increased to cope with drought. Our findings show that changes in flood and drought awareness can help contribute to the emergence of multiple phenomena. Moreover, the outcomes from the proposed coupled-modeling framework indicate that water-management strategies aimed at specific hydrological extremes can in turn shape the severity of opposite natural hazards. Given its explanatory value, the model can contribute to a better interpretation of changes in drought and flood risk and the role of alternative water-management strategies.
\end{abstract}

Key Words: Brisbane flooding; maladaptation; Millennium Drought; system dynamics; water-management strategies

\section{INTRODUCTION}

Humans have significantly affected most river basins around the world, thereby leading to alterations in the hydrological regime (Falkenmark and Rockström 2008, Destouni et al. 2013, Vörösmarty et al. 2013). For example, hydrological droughts can be substantially exacerbated by irrigation or groundwater exploitation (AghaKouchak et al. 2015, Van Loon et al. 2016, de Graaf et al. 2019), while the construction of levees can significantly change the spatio-temporal distribution of flooding patterns (Heine and Pinter 2012, Blöschl et al. 2013, Gralepois et al. 2016). It is therefore necessary to explicitly consider the complex dynamics generated by the interplay between humans, floods, and droughts to understand how hydrological risk changes over time and across space (Krysanova et al. 2008).

Different management strategies have been adopted to reduce the negative impacts of hydrological extremes (Pande and Ertsen 2014, Thieken et al. 2016, Sterle and Singletary 2017, Kreibich et al. 2019, Sterle et al. 2019). Structural measures that address the problem in the short term often generate unintended consequences in the long term because of the feedback mechanisms operating in coupled human-water systems (Garcia et al. 2019). In this context, different types of phenomena have been empirically observed and reported in different parts of the world by a number of scholars. In relation to flood risk, "adaptation" occurs when learning factors following a flooding event help reduce the negative impacts of a flooding event occurring shortly after (Kreibich et al. 2017, Mård et al. 2018), whereas the "levee paradox" occurs when structural riskreduction measures enable intense urbanization of flood-prone areas that subsequently leads to reduced levels of flood-risk awareness (Montz and Tobin 2008, Di Baldassarre et al. 2013, Viglione et al. 2014, Yu et al. 2017). This process may lead to catastrophic losses when structural measures eventually fail, as it was experienced in New Orleans (Kates et al. 2006). Other sociohydrological phenomena have been observed in relation to drought: supply-demand cycles and reservoir effects. They are related to the construction or expansion of existing reservoirs or water-supply infrastructure to cope with droughts (Winder et al. 2005, Scott 2011). Supply-demand cycles occur when increasing water supply enables growing water demand, which can eventually lead to an unsustainable consumption of water (Kallis 2010, Gohari et al. 2013). Reservoir effects occur when over-reliance on large water infrastructures escalates society's vulnerability (Di Baldassarre et al. 2018), potentially leading to large economic losses when major droughts take place. Another phenomenon described in the literature is maladaptation (Juhola et al. 2016), which can occur in water management when the response to drought has the unintended effect of exacerbating future flood losses (Van den Honert and McAneney 2011, Albertini et al. 2020). This maladaptive response to drought is termed here as "sequence effect." Figure 1 shows the location of the aforementioned human-water phenomena that will be considered in this study.

Traditional methods for assessing hydrological risk (e.g., Shahid and Behrawan 2008, Jongman et al. 2014, Winsemius et al. 2016) do not explicitly account for the feedback mechanisms operating in human-water systems and thus cannot capture any of the above phenomena. This leads to an incomplete understanding of past hydrological risk changes, as well as unrealistic projections of future scenarios (Di Baldassarre et al. 2015, Schlüter et al. 2019). To fill this gap, numerous scholars have developed sociohydrological models exploring human-water interactions over the past few years (see, e.g., reviews by Blair and Buytaert 2016, Pande and Sivapalan 2017, Lu et al. 2018, Hall 2019, Brelsford et al. 2020).

${ }^{1}$ Department of Earth Sciences, Uppsala University, Uppsala, Sweden, ${ }^{2}$ Centre of Natural Hazards and Disaster Science (CNDS), Uppsala, Sweden, ${ }^{3}$ Stockholm Environment Institute, Stockholm, Sweden, ${ }^{4}$ Department of Integrated Water Systems and Governance, IHE Delft Institute for Water Education, Delft, The Netherlands 
Fig. 1. Examples of phenomena observed in various parts of the world by numerous scholars from different disciplines: levee paradox (or effect; Kates et al. 2006, Montz and Tobin 2008, Ludy and Kondolf 2012), flood adaptation (Penning-Rowsell 1996, Wind et al. 1999, IPCC 2012, Mechler and Bouwer 2014, Kreibich et al. 2017, Wens et al. 2019), supply-demand cycle (Kallis 2010, Dumont et al. 2013), reservoir effect (Gohari et al. 2013, van Dijk et al. 2013), sequence effect, i.e., flood after drought (Van den Honert and McAneney 2011, Bohensky et al. 2014, Mateo et al. 2014). Note that these authors did not necessarily use the same terms when describing these phenomena.

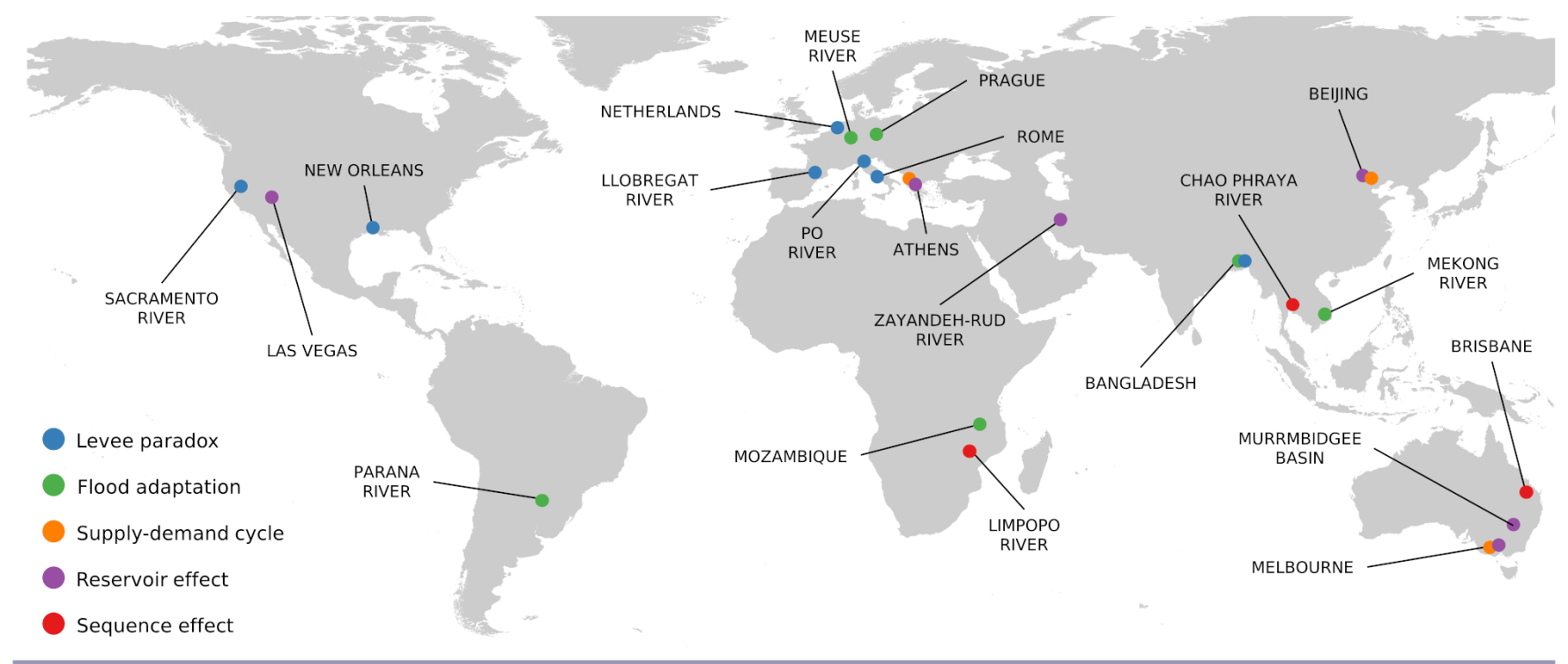

Di Baldassarre et al. (2013) proposed a system-dynamics model of human-flood interactions that uses the concept of flood memory as a primary mechanism explaining the emergence of flood adaptation and the levee paradox. Following this work, similar models with varying degrees of complexity were developed (e.g., Viglione et al. 2014, Di Baldassarre et al. 2015, Grames et al. 2016, Ciullo et al. 2017, Sarmento Buarque et al. 2020). Among them, Yu et al. (2017) included additional societal processes in their system-dynamics model to better represent the connection between flood awareness and collective actions. The effect of different types of society on flood-risk perception and management was recently investigated by Ridolfi et al. (2020). Barendrecht et al. (2019) used empirical data to estimate the parameters of a socio-hydrological flood model by means of Bayesian inference. In parallel with the development of systemdynamics approaches, agent-based modeling frameworks have been extensively used to gain a deeper understanding of the spatial, physical, and societal processes interacting with hydrological extremes (Janssen and Ostrom 2006, Filatova 2015, Dubbelboer et al. 2017, Haer et al. 2017, 2019, Tonn and Guikema 2018). In a recent study, Michaelis et al. (2020) showed that their proposed agent-based model was able to explain flood adaptation and the levee paradox.

Besides models of human-flood interactions, other sociohydrological models (based on system-dynamics or agent-based modeling frameworks) have been recently proposed to investigate intended and unintended effects of water management on humanwater systems (Happe et al. 2006, Srinivasan et al. 2010, Elshafei et al. 2014, Liu et al. 2014, van Emmerik et al. 2014, Sahin et al. 2016, Bakarji et al. 2017, Gohari et al. 2017, Mashhadi Ali et al. 2017, Konar et al. 2019, Li et al. 2019, Pouladi et al. 2019, Wens et al. 2019, Albertini et al. 2020). With respect to urban water- supply systems, Garcia et al. (2016) investigated the interactions between water supply, demand, and population's awareness of water shortages under different reservoir operating policies in a synthetic context. Using a similar approach, Gonzales and Ajami (2017) designed a system-dynamics model to represent urban domestic water demand as a function of both structural and societal factors in the San Francisco Bay area. They found a rebound effect emerging when a period of sustained low demand was followed by an increase of water use during hydrologically wet conditions. Similarly, Freire-González (2019) discovered a rebound effect in Spain when improving water resources productivity, using a general equilibrium dynamic modeling approach. Mateo et al. (2014) developed an integrated modeling approach to investigate the impacts of reservoir operations on downstream flooding. Similarly, Wallington and Cai (2020) modified an existing mathematical framework to incorporate feedbacks from downstream floodplain development in reservoir operations decisions. Kuil et al. (2016) developed a systemdynamics model to conceptualize the evolution of agricultural drought among the ancient Mayan society and uncovered reservoir effects. The model suggested that although reservoirs alleviated minor droughts and enabled agricultural expansion, they also promoted over-reliance on water resources that eventually exacerbated the negative impacts of a major prolonged drought, which contributed to the eventual collapse of the Mayan society (Aimers and Hodell 2011). Similarly, supply-demand cycles and dependency on infrastructure measures were observed and simulated with a holistic socio-hydrological model in Beijing, China (Li et al. 2019).

Although these socio-hydrological models have provided significant insights and contributed to advancing our understanding of human-water interactions, they directly focused 
on one specific hydrological extreme. However, droughts and floods do not always occur in isolation because they are interconnected and governed by the same underlying climatic and hydrological processes. Prolonged drought periods followed by extreme floods are increasing in frequency in many regions worldwide. These consecutive events can lead to dramatic impacts that are greater than the sum of the impacts produced by each individual extreme (Marzocchi et al. 2012). The occurrence of drought-to-flood events can be driven by a combination of various natural hydroclimatic processes (Coumou and Rahmstorf 2012, Van Loon et al. 2016). Unfortunately, only a few studies have modeled the human-water interactions in cases of consecutive droughts and floods. Di Baldassarre et al. (2017) proposed a new approach to explicitly account for the interactions between human and water with both drought and flood events under changing reservoir operation rules. Dadson et al. (2017) proposed a system-dynamics model that represents the national wealth, water-related productivity, and losses from water-related hazards such as floods and droughts (even though these were not explicitly included in the model structure). Recently, Albertini et al. (2020) developed a socio-hydrological model of human-flood interactions for understanding the influence of reservoirmanagement strategies and societal responses.

In this study, we propose a new system-dynamics model that captures multiple phenomena (Fig. 1) by simulating the way in which humans influence and respond to both droughts and floods under different water-management strategies.

\section{SYSTEM DYNAMICS MODELING}

\section{Modeling rationale}

Socio-hydrological models are often built to formalize hypotheses about the macroscopic (or generic) behavior of human-water systems by schematizing the feedback mechanisms that generate multiple phenomena, risks, and/or unintended consequences ( $\mathrm{Yu}$ et al. 2020). As such, they are different from: (1) predictive quantitative models (more common in hydrology), usually based on physically based equations, but often lacking an explicit representation of human behavior and social dynamics; (2) prescriptive optimization models used for the study of waterresource systems that often assume that people in a real system will make rational and optimal choices (Sterman 2002); and (3) descriptive qualitative methods (more common in social sciences), typically based on the critical analysis of political, cultural, and social processes around specific case studies.

In this study, we developed an explanatory model of the macroscopic (or generic) behavior of human-water systems with a focus on the interplay between floods, droughts, and human society. Our fundamental hypothesis is that multiple phenomena, which were identified by numerous scholars from various disciplines in different places around the world (Fig. 1), can be explained by the accumulation and the decay of (flood and drought) awareness. Because our model has no predictive purpose, there was neither calibration nor validation involved. Observations and model results were compared in a qualitative way with a focus on the capability of the model to explain macroscopic trends and emerging phenomena. Model parameters were defined based on empirical studies about the various processes, such as the way in which drought awareness decays over time (Gonzales and Ajami 2017).

\section{Modeling framework}

The model explicitly incorporates and links droughts, floods, and water-management strategies within a unified modeling framework, considering the dynamics of a human-water system in which a reservoir is used for both water supply and flood control (Fig. 2). Its structure is based on four systems:

- Reservoir system: It accounts for the water supply, flood control, and required environmental flow released by the reservoir using a linear hedging rule approach. The release is influenced by many variables such as the availability of water, the inflow to the reservoir, the downstream water demand, and the flood and drought awareness of the reservoir operator.

- Drought system: We calculated the water demand based on water shortage conditions and consequent society's awareness.

- Flood system: The flood wave propagation of the release from the reservoir and the consequent downstream flooding were modeled in this system. The human-flood interaction in the downstream area was modeled using sociohydrological approaches proposed in the literature.

- Population system: This system models the demographic dynamics of the downstream society. It is the direct link between the drought and flood systems.

Fig. 2. Schematic representation of a generic case study conceptualized in the proposed system-dynamics model.

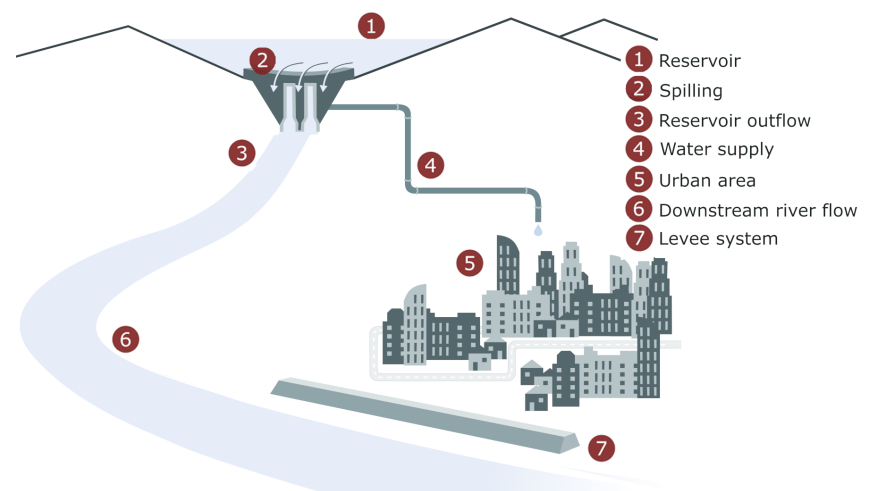

Figure 3 shows the causal loop diagram of our socio-hydrological model, representing the feedback mechanisms between the components of the four main systems. In each system, both the physical components and the decisions that affect the system were modeled at a monthly time scale. In our modeling framework, we assumed that humans respond to the occurrence and severity of hydrological extremes by implementing one of the following four water-management strategies:

- No actions: no strategies or actions to reduce the effects of droughts and floods.

- Fighting floods: building or reinforcing a levee system as a response to downstream flooding involving population in the floodplain area. 
- Water conservation: reducing per-capita water demand and using more conservative reservoir release policies during drought periods.

- Water exploitation: increasing the capacity of the dam compartment used for water supply when facing a water shortage period.

Fig. 3. Causal loop diagram of the model where arrows are feedbacks between state variables (bold text) and fluxes, and the symbols + and - represent positive and negative feedbacks, respectively.

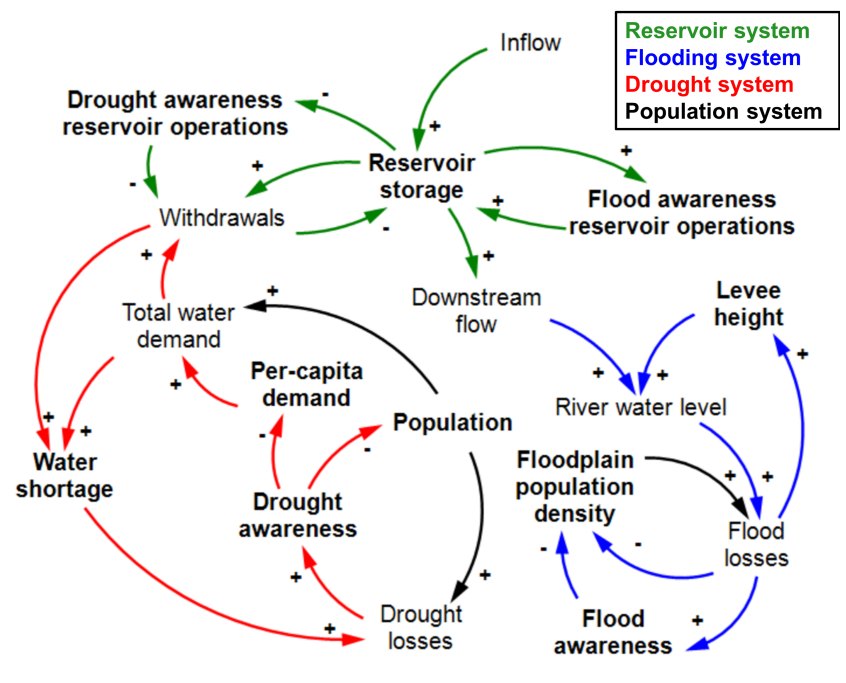

\section{Model structure}

Reservoir system

The reservoir system schematizes the reservoir release for water supply, flood control, and required environmental flow. The reservoir volume $V$ at time $t+1$ was calculated as:

$V_{t+1}=V_{t}+Q_{t}^{I} \Delta t-W_{t} \Delta t-Q_{t}^{S} \Delta t-Q_{t}^{E} \Delta t$

where $Q^{\mathrm{I}}$ is the mean monthly inflow to the reservoir, $W$ is the water withdrawals flow used for water supply by the downstream area, $Q^{\mathrm{S}}$ is the spillway release flow from the reservoir, $Q^{\mathrm{E}}$ is the environmental flow, and $\Delta t$ is the monthly temporal discretization of the model simulation. In our model, we neglected losses to evapotranspiration and gains/losses through groundwater flow.

The decision to release water for supply purposes can be affected by many factors, such as changes in future inflows, per-capita water demand, and population growth (Garcia et al. 2016). Nevertheless, water utilities must guarantee a water supply that can meet all demands of the system in an efficient way (Shih and ReVelle 1994, Draper and Lund 2004). The two main operational policies, commonly used to assess the release of water and address the aforementioned decision problem, are the standard operational policy and the hedging rule.

The standard operational policy graph (Fig. 4 in case of $K_{\mathrm{P}}$ equal to 1) can be divided into three main areas: (1) the reservoir is depleted, or in some cases emptied, if insufficient available water cannot guarantee that target water demand is met; (2) the reservoir is filled during conditions in which water availability is higher than target demand; and (3) water is spilled downstream when reservoir volume and target water demand exceed reservoir capacity. However, during drought periods, it may not be possible to reach the volume target because of the inability of standard operational policy of rationing water release for future demand when water is insufficient (Wang et al. 2018, Men et al. 2019). For this reason, hedging rules can be used to create a trade-off between ongoing demands and adequate reservoir volume, minimizing the impact of drought conditions (Shiau 2009, Baes and Bürgisser 2013). In this way, by reducing the water release when reservoir capacity is low (area "a" in Fig. 4), the hedging rule allows more water in the reservoir and reduces shortfalls when the inflow is insufficient during drought periods (You and Cai 2008, Shiau 2011, Zhao et al. 2011). In our study, we used a one-point linear hedging rule where $K_{\mathrm{p}}$ is the hedging release slope (Draper and Lund 2004). Following this operational policy, the water withdrawal for supply purposes $W$ was calculated as a function of reservoir volume and monthly inflow:

$$
W_{t}=\left\{\begin{array}{cc}
\frac{V_{t}+Q_{t}^{I} \Delta t-Q_{t}^{E} \Delta t}{K_{t}^{P} \Delta t} & \text { if } V_{t}+Q_{t}^{I} \Delta t-Q_{t}^{E} \Delta t<K_{t}^{P} D_{t} P_{t} \\
D_{t} P_{t} & \text { Otherwise }
\end{array}\right.
$$

where $V_{\mathrm{t}}$ is the volume of the reservoir, $D$ is the monthly per-capita water demand, $P$ is the total population of the downstream area receiving water from the reservoir system, and $\mathrm{D} t$ is the model time step in seconds. In particular, $K^{\mathrm{P}}$ was calculated as a function of the hedging policy coefficient $\eta$ and the drought awareness of the reservoir operator $A^{\mathrm{DRes}}$ at time step $t$ :

$$
K_{t}^{P}=1+\eta A_{t}^{D R e s}
$$

Because we are modeling a reservoir for water supply and flood control purposes, we divided the reservoir storage in two compartments and used the full supply volume (FSV in Fig. 4) as the maximum volume for water supply. After such a threshold is reached, the reservoir operates as a flood-control structure and the monthly spillway release was calculated using the aforementioned operational policy as:

$$
\begin{aligned}
& Q_{t}^{S}=\left\{\begin{array}{c}
0 \\
\left(V_{t}+Q_{t}^{I} d t-Q_{t}^{E} d t-F S V\right)
\end{array}\right. \frac{1}{\Delta t} \text { if } \\
& V_{t}+Q_{t}^{I} \Delta t-Q_{t}^{E} \Delta t>D_{t} P_{t} \Delta t+F S V
\end{aligned}
$$

If a fighting-floods strategy is adopted during flood conditions, we assumed that the reservoir operator can decide to temporarily reduce the FSV value, based on their flood awareness, to store more water for future flood conditions and mitigate the impacts of flooding downstream of the reservoir. The reduced value of FSV was calculated as:

$$
F S V_{t+1}=F S V_{t}-A_{t}^{F R e s}\left(F S V_{t}-F S V_{m}\right)
$$


Fig. 4. Operational policy used in this study, where FSV is full supply volume, $D$ is the per-capita water demand, $P$ is the population, $V$ is the reservoir volume, $Q^{I}$ is the inflow to the reservoir, $W$ is the water withdrawal, $Q^{S}$ is the monthly spillway released, $Q^{F}$ is the spillway released during flooding, $Q^{E}$ is the environmental flow, and $K^{P}$ is the slope of the hedging release function (adapted from Shih and ReVelle 1994).

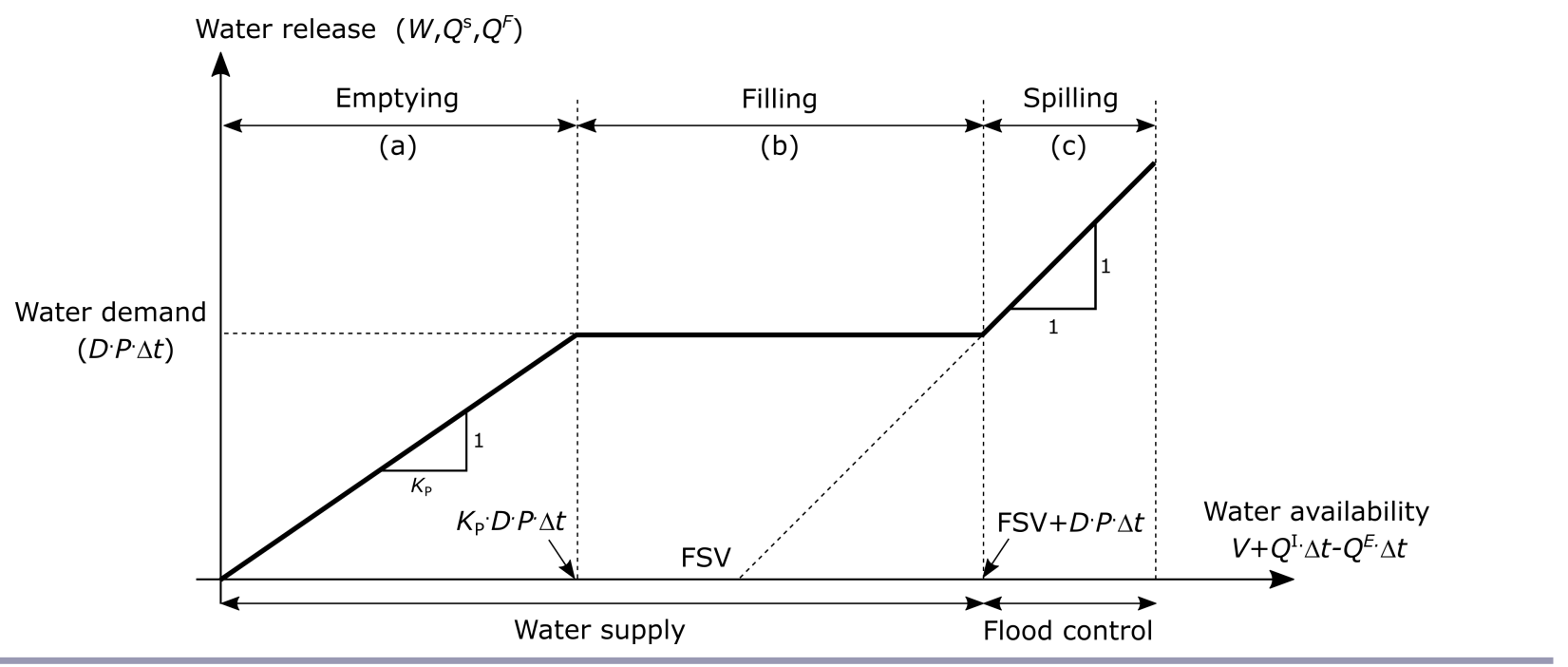

where $A^{\text {FRes }}$ is the flood awareness of the reservoir operator at time step $t$, and $F S V_{\mathrm{m}}$ is the minimum possible value of FSV not to compromise the water-supply compartment for floodmitigation purposes.

On the other hand, if a water-exploitation strategy is adopted, reservoir operators and governments may decide to face water shortages increasing FSV to provide the target water demand in the near future. The value of FSV after the occurrence of a water shortage at time $t$ was calculated as:

$$
F S V_{t+1}=F S V_{t}+\varepsilon_{V}\left(D_{t} P_{t}-W_{t}\right) \Delta t
$$

where $\varepsilon_{\mathrm{V}}$ is the model parameter representing the safety factor for the enlargement of the storage capacity. In case of no-actions and water-conservation strategies, FSV was kept constant in time.

The choice to distinguish between reservoir operators' and broader society's risk awareness is based on the concept that the two often differ (Slovic 1987, Sandman 1989, Knuth et al. 2014, $\mathrm{Su}$ et al. 2015). Experts tend to assess risk based on technical aspects, following an "analytical" system, whereas lay people tend to base their judgment on other hazard characteristics, such as threat to future generations, economic damage, and human losses, following an "experiential" system (Slovic 1987, Slovic et al. 2004). Here, reservoir operators' risk awareness is a function of reservoirs' levels, whereas society's awareness is a function of drought losses. Specifically, the value of the drought awareness of the reservoir operator was estimated following the approach proposed by Di Baldassarre et al. (2017):

$$
A_{t+1}^{D R e s}=A_{t}^{D R e s}+\mu_{D R e s}\left(\left(1-\frac{V_{t}}{F S V}\right)^{\Theta}-A_{t}^{D R e s}\right) \Delta t
$$

where $\mu_{\text {Dres }}$ is the drought-awareness decay of the reservoir operator. The parameter $\Theta$ represents the level of bias caused by the difference between drought (water shortages) and flood memories, as proposed by Di Baldassarre et al. (2017). Other factors influencing $A^{\text {DRes }}$, such as the political appeal of the strategy, were not included in our model. Similarly, the flood awareness of the reservoir operator $\left(A^{\text {FRes }}\right)$ over time was estimated as:

$$
A_{t+1}^{F R e s}=A_{t}^{F R e s}+\mu_{F R e s}\left(\left(\frac{V_{t}}{F S V}\right)^{\Theta}-A_{t}^{F R e s}\right) \Delta t
$$

where $\mu_{\text {FRes }}$ is the flood-awareness decay of the reservoir operator.

Finally, the environmental flow released by the reservoir required to sustain downstream natural ecosystems at each time step was set equal to the product of monthly inflow and the percentage of input flow assigned as environmental flow $E$ :

$$
Q_{t}^{E}=E Q_{t}^{I}
$$

Drought system

The drought system allows for a deeper insight into the urban system's behavior by estimating the consequences of mitigation choices on future drought conditions. Following a prolonged drought, the water supply cannot guarantee the total water demand. Thus, water shortage was calculated as the difference between water withdrawals $W$ and total water demand $D P$. The water shortage induces a shock in the society and a consequent increase in the society's drought awareness $A^{\mathrm{D}}$, calculated following the approach proposed by Di Baldassarre et al. (2015) and Garcia et al. (2016):

$$
A_{t+1}^{D}=A_{t}^{D}+L_{t}^{D}\left(1-A_{t}^{D}\right)-\mu_{D} A_{t}^{D} \Delta t
$$


where $L^{\mathrm{D}}$ indicates the drought losses, and $\mu_{\mathrm{D}}$ is a parameter representing the decay of the society's drought awareness over time. The second term represents the increase in awareness due to the drought losses impact, while the third term is the decay in the drought awareness (Garcia et al. 2016, Gonzales and Ajami 2017). We assumed that when drought awareness is already high, only a large drought can significantly increase society's awareness (represented using 1- $A^{\mathrm{D}}$ ). The drought losses were expressed as the ratio between water shortage and water demand:

$$
L_{t}^{D}=\left(\frac{D_{t} P_{t}-W_{t}}{D_{t} P_{t}}\right)^{2}
$$

When no water shortage is occurring, $L^{\mathrm{D}}$ was set equal to zero. During drought conditions, a water-conservation strategy can be adopted to reduce per-capita water demand and avoid future critical water shortages. Response triggers corresponding to different reservoir volumes were defined in our model. Then, a target per-capita water demand was associated to each response trigger. Therefore, once the reservoir volume at a certain time step drops below a response trigger, the per-capita water demand is adapted to the corresponding target demand to reduce water withdrawals. For example, considering the upper and lower response triggers $V^{\mathrm{U}}$ and $V^{\mathrm{L}}$, with $D^{\mathrm{U}}$ and $D^{\mathrm{L}}$ as their associated suggested target per-capita demands, the corresponding target demand $D^{*}$ for the reservoir volume $V$ at time $t$ was calculated as:

$$
D_{t}^{*}=D^{U}+\frac{D^{U}-D^{L}}{V^{U}-V^{L}}\left(V_{t}-V^{U}\right)
$$

In turn, the suggested target per-capita demand influences society's willingness to reduce water consumption $N^{\mathrm{D}}$, which was calculated as:

$$
N_{t+1}^{D}=\left\{\begin{array}{c}
N_{t}^{D}+\frac{D_{t}-D_{t}^{*}}{D_{t}^{*}}\left(1-N_{t}^{D}\right)-\mu_{N} N_{t}^{D} \Delta t \text { if } D_{t}>D_{t}^{*} \\
N_{t}^{D}-\mu_{N} N_{t}^{D} \Delta t \text { if } D_{t}<D_{t}^{*}
\end{array}\right.
$$

where $\mu_{\mathrm{N}}$ is a parameter representing the decay of the willingness of the society to adopt the suggested per-capita demand over time. If the suggested per-capita demand is higher than the current demand, then the willingness to reduce water consumption decreases following the second term of the equation.

In case a water-conservation strategy is adopted, the per-capita water demand $D$ over time is estimated as:

$$
D_{t+1}=D_{t}-D_{t}\left[\left(N_{t}^{D}+A_{t}^{D}\right) \alpha_{D}\left(1-\frac{D_{\text {min }}}{D_{t}}\right)+\beta_{D}\right] \Delta t
$$

where $D_{\min }$ is the minimum per-capita water demand required for basic health and hygiene, while $\alpha_{D}$ and $\beta_{D}$ are two parameters of a logistic decay function representing the maximum rate and a background decay rate, respectively (Garcia et al. 2016). The same equation was used for the other water-management strategies but with $N^{\mathrm{D}}$ equal to zero because no willingness to reduce per-capita demand was considered.
The second term of equation 14 accounts for the reduction of per-capita demand due to the adoption of more efficient technologies to respond to a drought $\left(A^{\mathrm{D}}>0\right)$ or to new suggested per-capita water demand $\left(N^{\mathrm{D}}>0\right)$. In addition, changes in the water-use behavior (e.g., reduction in length of showers, frequency of dishwasher use, frequency of car washing, etc.) may occur (Campbell et al. 2004, Kenney et al. 2008, Fielding et al. 2012, Giacomoni et al. 2013). In contrast, when no drought occurs or the volume of the reservoir is above a critical threshold, the percapita demand decreases over time, driven by the technological improvement and replacement of the obsolete system. A detailed analysis of the causes of reduction of per-capita water demand over time is reported in Garcia et al. (2016), (2019).

\section{Flood system}

The objective of this system is to represent the human-flood interaction in the downstream area of the reservoir. If river flow generated by the outflow from the reservoir exceeds a certain threshold (e.g., the bankfull depth) the population will experience flooding with consequent flood damages and potential fatalities. In the drought system, water withdrawals, reservoir volume, and outflow were estimated using average monthly flows. However, because the aim of this system is to model downstream flooding due to high water levels, considering the average monthly flow could lead to significant underestimation of the flood levels and consequent flood losses. For this reason, during flood conditions, the maximum spillway release from the reservoir $Q^{\mathrm{F}}$ at time step $t$ was calculated using equation 4 with maximum daily flow as input and neglecting $D \cdot P$ and $Q^{\mathrm{E}}$.

The maximum spillway release was then routed to the location of the downstream area using a three-parameter Muskingum hydrologic model (O'Donnell 1985), which accounts for the distributed lateral inflow along the river reach, to estimate the downstream river flow $Q^{\mathrm{D}}$. The parameters of the threeparameter Muskingum model are the weighting factor $\left(K_{1}\right)$, the storage constant $\left(K_{2}\right)$, and the lateral distributed inflows along the river $\left(K_{3}\right)$. The parameter $K_{2}$ was calculated as the ratio between the length of the river reach and the average flow velocity, which was assumed to be $1 \mathrm{~m} / \mathrm{s}$. Once the downstream flow $Q^{\mathrm{D}}$ is known, the high-water level $W L$ was then estimated using the Manning equation in case of a wide rectangular shape of the river cross-section, or a rating curve when available. The high-water level was then converted in a peak-over threshold, $W D^{*}$, because we assumed that flooding occurs when the water level is higher than a certain threshold, and the relative flood damage $F^{\mathrm{D}}$ was estimated following the equation proposed by Di Baldassarre et al. (2015) and Barendrecht et al. (2019):

$$
F_{t}^{D}=\left\{\begin{array}{cc}
1-\exp \left(-\frac{W D_{t}^{*}+\xi_{H} H_{t}}{\alpha_{H}}\right) & \text { if } W D_{t}^{*}+\xi_{H} H_{t}>H_{t} \\
0 & \text { otherwise }
\end{array}\right.
$$

where $H$ is the flood protection level, $\alpha_{\mathrm{H}}$ indicates a relation of river level to relative damage (Penning-Rowsell et al. 2006), and $\xi_{H}$ is the proportion of flood-level enhancement. If the society adopts a fighting-floods strategy, the amount of levee heightening after the occurrence of a flood was calculated as: 
Table 1. Summary of the different water-management strategies (WMS) used to test the capability of the proposed socio-hydrological model to capture the main human-water dynamics. Note: FSV = full supply volume.

\begin{tabular}{|c|c|c|c|}
\hline WMS & Description & System & Equation \\
\hline No actions & No actions are adopted & - & - \\
\hline Fighting floods & Levee reinforcement and temporarily reduction of FSV & $\begin{array}{l}\text { Reservoir } \\
\text { Flood }\end{array}$ & 5,16 \\
\hline Water conservation & Reduction of the per-capita demand & Drought & $12,13,14$ \\
\hline Water exploitation & Increase of FSV after a water shortage period & Reservoir & 6 \\
\hline
\end{tabular}

where $\varepsilon_{\mathrm{H}}$ is the model parameter representing the safety factor for the levee heightening. The value of society's flood-risk awareness was calculated as proposed by Barendrecht et al. (2019):

$$
A_{t+1}^{F}=A_{t}^{F}+L_{t}^{F}\left(1-A_{t}^{F}\right)-\mu_{F} A_{t}^{F} \Delta t
$$

where $\mu_{\mathrm{F}}$ is the flood-awareness decay of the society. The second term of the equation accounts for the shock (losses) induced by the flooding, following the same idea that if the flood awareness is already high, only a large flood can significantly increase the society's awareness. The flood losses were expressed as an abrupt reduction of the proportion of population living in the floodplains $G$ because we assumed that flooding only affects humans living in those areas:

$$
L_{t}^{F}=F_{t}^{D} G
$$

\section{Population system}

The population system is designed to model the demographic dynamics of the society living in the downstream area. The total population was modeled using an exponential growth to capture the effect of the open system:

$$
P_{t+1}=\left\{\begin{array}{c}
P_{t}+P_{t} \delta_{P} \Delta t \\
P_{t}+P_{t} \delta_{P}\left(1-A_{t}^{D}\right) \Delta t \text { for } A_{t}^{S}>\tau_{P}
\end{array}\right.
$$

where $\delta_{\mathrm{P}}$ is the growth rate of the society living in the downstream area, both in and out the floodplains, and $\tau_{\mathrm{p}}$ is a threshold. The change in population was assumed to be a function of the drought awareness only, and not of the willingness to reduce per-capita demand.

The proportion of population living in the floodplains was assessed as described by Di Baldassarre et al. (2015):

$$
G_{t+1}=G_{t}+\delta_{P}\left(1-G\left(1+A_{t}^{F} \alpha_{G}\right)\right) \Delta t-L_{t}^{F}
$$

where $\alpha_{\mathrm{G}}$ is a parameter accounting for the risk-taking attitude of the community. We assumed that the proportion of a population living in the floodplains is only influenced by the occurrence of floods and not by water shortages. The reduction of the population in the floodplain can occur either because of an abrupt change, e.g., human displacement right after the flood (second term of equation 20) as well as by the long-term effect of society's flood awareness (Pande et al. 2014, Fanta et al. 2019). It is worth mentioning that many other factors that can affect population growth (e.g., economic changes, immigration and emigration processes, etc.) were not considered in our sociohydrological model to reduce the complexity of the system and to focus only on the effects of extreme events and human interventions. Population affected by drought $P^{\mathrm{D}}$ was calculated as a product between drought losses $L^{\mathrm{D}}$ and total population $P$, while population affected by flooding $P^{\mathrm{F}}$ was estimated as a product between the proportion of population in the floodplain $G$, total population $P$, and flood losses $L^{\mathrm{F}}$. A summary of the different water-management strategies with respect to system implementation is reported in Table 1.

\section{APPLICATION}

We applied our model to a case study to qualitatively compare model results to observations. This also allows for testing the model's potential and limitations in explaining multiple phenomena (Fig. 1) when different water-management strategies are implemented. The selected case study is the city of Brisbane, established in 1880 within the floodplain of the Brisbane River, South East Queensland (SEQ), Australia. The SEQ region is one of the fastest-growing areas of Australia, with major demands for water, energy, transport, housing, and construction services (Seqwater 2017). With a rapidly growing urban population of more than three million residents, water consumption in SEQ is largely urban $(70 \%$; Seqwater 2017$)$.

Since its establishment, Brisbane has been hit by severe flooding events in 1841, 1893, and 1974 (Micevski et al. 2006, Smith and McAlpine 2014). As a consequence, the flooding of 1974 led to the construction of the Wivenhoe Dam, which was completed in 1984. It is located about 80 kilometers upstream of the City of Brisbane, with the aim of protecting Brisbane from future floods. Similar to the model schematization in Figure 2, the Wivenhoe Dam constitutes the main water-supply source (compartment capacity of about $1.2 \mathrm{~km}^{3}$ ) and flood control (compartment capacity of about $2 \mathrm{~km}^{3}$ ) for Brisbane and nearby cities (Seqwater 2017). With the presence of the Wivenhoe Dam, many Brisbane residents believed that flood risk was eliminated, and that the city was "flood-proofed," leading to rapid urbanization and development of flood-prone areas (Bohensky and Leitch 2014, Cook 2017, McKinnon 2019). Between 1998 and 2010, Brisbane experienced prolonged low-flow conditions known as the Millennium Drought (Heberger 2012). During this drought period, the level of the Wivenhoe Dam dropped to below $20 \%$ of 
its maximum capacity (Seqwater 2019). To counteract such dramatic water shortage, the Gold Coast Desalination Plant purified recycled water treatment plants were constructed. Moreover, strategies for reduction in the per-capita water demand were implemented (Seqwater 2017), which correspond to the water-conservation strategy implemented in our system dynamic model.

After more than 10 years of severe drought conditions, in 2011 Brisbane experienced an intense flood event that affected $\sim 200,000$ people and caused about 3.3 billion in economic damage (Van den Honert and McAneney 2011). On the one hand, the 2011 flooding was attributed to the excessive rainfall over December and the first half of January. On the other hand, hydrologists appointed by the Insurance Council of Australia considered the flooding as a "dam release flood" due to the excessive flow released from the Wivenhoe Dam (Van den Honert and McAneney 2011). In fact, one of the reasons for the high damage caused by the 2011 flood was the change in reservoir operation rules that were adopted to cope with the drought. More specifically, although the reservoir was originally designed to cope with flooding, it started as a buffer to cope with low flow conditions during the Millennium Drought. As a result, when the flood occurred, the reservoir did not have enough capacity for flood attenuation and the negative consequences downstream were dramatic (van Dijk et al. 2013). This is a clear example of how water-management strategies can exacerbate the effect of consecutive severe hydrological hazards. In the following section, different experiments are designed and implemented to test our model using both observational and synthetic data from Brisbane to investigate the human-water dynamics of increasing flood and drought conditions.

\section{Historical analysis}

We used historical recorded data from 1962 to 2019. The Gregors Creek station (Station number 143009A) on the Brisbane River was selected as the the only model input to the reservoir due to the lack of data for the simulation period. Mean monthly and maximum daily data were retrieved from the Australian Government Bureau of Meteorology (2020). To compensate for the lack of data from the other tributaries to the Wivenhoe Dam (e.g., the outflow from the Somerset Dam), we multiplied the mean and maximum flows by a correction coefficient equal to 1.5 to have a similar maximum mean flow as the one observed in January 2011, equal to $11,500 \mathrm{~m}^{3} / \mathrm{s}$ (Seqwater 2011, Van den Honert and McAneney 2011). The resulting mean monthly and maximum daily flows are reported in Appendix 1.

Because this analysis starts in 1962, the model is run only as a flood system to simulate downstream flooding without reservoir up to 1986, the year in which the first volume observations are available for the Wivenhoe Dam. After 1986, we coupled both flood and drought systems. For the Wivenhoe Dam, we considered an FSV of $1.2 \mathrm{~km}^{3}$. The initial value of the reservoir volume was set to $0.9 \mathrm{~km}^{3}$ to avoid any initial reduction of percapita demand due to low reservoir volume. Observed reservoir volume from 1986 to 2019 was then used to test the model. An initial per-capita demand equal to $300 \mathrm{~L} / \mathrm{d}$ per person was assumed, based on Beal et al. (2011). Observed per-capita water demands from 2005 to 2010, reported in Beal et al. (2011), were used to test our model. The response triggers corresponding to the water-conservation strategies for the Wivenhoe Dam used in this study are reported in Table 2 .

Table 2. Drought response triggers for the Wivenhoe Dam (Seqwater 2017). Note: FSV = full supply volume.

\begin{tabular}{lc}
\hline \hline Reservoir volume & Target per-capita demand \\
\hline $0.6 \cdot \mathrm{FSV}$ & $150 \mathrm{~L} / \mathrm{p} /$ day \\
$0.5 \cdot \mathrm{FSV}$ & $140 \mathrm{~L} / \mathrm{p} /$ day \\
$0.25 \mathrm{FSV}$ & $120 \mathrm{~L} / \mathrm{p} /$ day \\
$0.10 \mathrm{FSV}$ & $100 \mathrm{~L} / \mathrm{p} /$ day \\
\hline
\end{tabular}

The rating curve provided by Smyth and Toombes (2015) was used to convert the downstream flow in the Brisbane River at the Brisbane station into water level values. The estimation of the peak-over a threshold water level was performed assuming the threshold indicating moderate flood level $(2.6 \mathrm{~m})$ of the Brisbane River at the Brisbane center gage as flooding threshold. In this study, we assumed that society's awareness decay for drought conditions was faster than flood-awareness decay because it is a continuous process lasting longer than floods and the impacts are not immediately discernible as those of floods. Beal et al. (2014) and Gonzales and Ajami (2017) showed an increased water consumption following a period of sustained low demand during a drought period as possible reduced awareness and other behavioral factors. Data of affected population during the 1974 and 2011 floods are retrieved from Van den Honert and McAneney (2011). State variable, fluxes, and parameters of the socio-hydrological model are summarized in Table 3 and Table 4.

\section{Synthetic experiments}

The synthetic experiments aim at unravelling the complex dynamics between human, floods, and droughts in view of increasing future hydrological extremes and different watermanagement strategies. For this reason, we generated a synthetic time series of 80 years of mean monthly and maximum daily flow based on the observed data at the Gregors Creek station from 1962 to 2019. The synthetic inflow values are specifically generated to represent a series of alternating periods with increasing intensity of both droughts and floods, as supported by Smith and McAlpine (2014). This is a crucial aspect in our study because the occurrence and severity of different hydrological extreme events may trigger different human responses, which may affect the system when following events occur. In particular, we assumed that drought frequency and flood magnitude are increasing over the years (see Appendix 1).

We conceived two different settings of the case study. In the first setting, we assumed that the Wivenhoe Dam was not constructed and only downstream human-flood interactions with no-actions and fighting-floods strategies were considered. The time series of maximum daily flow was used to directly calculate river water level, and the drought system (Fig. 3) was not implemented. In the second setting, we represented both the construction of the Wivenhoe Dam in 1986 and human-flood interactions. Noactions, fighting-floods, water-conservation, and waterexploitation strategies were implemented in this setting. State variable and parameters of the socio-hydrological model were the same as those used in the historical analysis and are summarized in Tables 2 and 3. 
Table 3. Summary of the state variables and fluxes of the proposed socio-hydrological model.

\begin{tabular}{|c|c|c|c|c|c|c|}
\hline Name & Description & Initial value & Units & System & Equation & Type \\
\hline$V$ & Reservoir volume & $0.9 \cdot 10^{9}$ & $\mathrm{~m}^{3}$ & Reservoir & 1 & State \\
\hline$W$ & Water withdrawals & 0 & $\mathrm{~m}^{3} / \mathrm{s}$ & Reservoir & 2 & Flux \\
\hline$K^{\mathrm{P}}$ & Hedging release slope & 5 & - & Reservoir & 3 & Flux \\
\hline$Q^{\mathrm{S}}$ & Monthly spillway flow & 0 & $\mathrm{~m}^{3} / \mathrm{s}$ & Reservoir & 4 & Flux \\
\hline$Q^{I}$ & Inflow to the reservoir & 0 & $\mathrm{~m}^{3} / \mathrm{s}$ & Reservoir & 1 & Flux \\
\hline$F S V$ & $\begin{array}{l}\text { Full supply volume of the water supply } \\
\text { compartment }\end{array}$ & 1.2 & $\mathrm{~m}^{3}$ & Reservoir & $5-6$ & State \\
\hline$A^{\mathrm{DRES}}$ & $\begin{array}{l}\text { Drought awareness of the } \\
\text { reservoir operator }\end{array}$ & 0 & - & Reservoir & 7 & State \\
\hline$A^{\mathrm{FRES}}$ & $\begin{array}{l}\text { Flood awareness of the } \\
\text { reservoir operator }\end{array}$ & 0 & - & Reservoir & 8 & State \\
\hline$Q^{\mathrm{E}}$ & Environmental flow & 0 & $\mathrm{~m}^{3} / \mathrm{s}$ & Reservoir & 9 & Flux \\
\hline$A^{\mathrm{D}}$ & Society's drought awareness & 0 & - & Drought & 10 & State \\
\hline$L^{\mathrm{D}}$ & Drought losses & 0 & - & Drought & 11 & Flux \\
\hline$D^{*}$ & Target per-capita demand & 250 & $\mathrm{~L} / \mathrm{d} / \mathrm{p}$ & Drought & 12 & Flux \\
\hline$N^{\mathrm{D}}$ & $\begin{array}{l}\text { Willingness of the society to reducing per-capita } \\
\text { demand }\end{array}$ & 0 & - & Drought & 13 & State \\
\hline$D$ & Per-capita water demand & 300 & $\mathrm{~L} / \mathrm{d} / \mathrm{p}$ & Drought & 14 & State \\
\hline$Q^{F}$ & Maximum spillway flow & 0 & $\mathrm{~m}^{3} / \mathrm{s}$ & Flood & - & Flux \\
\hline$Q^{D}$ & Downstream river flow & 0 & $\mathrm{~m}^{3} / \mathrm{s}$ & Flood & - & Flux \\
\hline$W L$ & High-water level & 0 & $\mathrm{~m}$ & Flood & - & Flux \\
\hline$W D^{*}$ & Peak-over threshold water depth & 0 & $\mathrm{~m}$ & Flood & - & Flux \\
\hline$F^{\mathrm{D}}$ & Relative flood damage & 0 & - & Flood & 15 & Flux \\
\hline$H$ & Flood protection level & 0 & $\mathrm{~m}$ & Flood & 16 & State \\
\hline$A^{\mathrm{F}}$ & Society's flood awareness & 0 & - & Flood & 17 & State \\
\hline$L^{\mathrm{F}}$ & Flood losses & 0 & - & Flood & 18 & Flux \\
\hline$P$ & Total population & $6 \cdot 10^{5}$ & $\mathrm{p}$ & Population & 19 & State \\
\hline$G$ & Proportion of population living in the floodplain & 0.05 & - & Population & 20 & State \\
\hline$P^{\mathrm{D}}$ & Population affected by shortage & 0 & $\mathrm{p}$ & Population & - & Flux \\
\hline$P^{\mathrm{F}}$ & Population affected by flooding & 0 & $\mathrm{p}$ & Population & - & Flux \\
\hline
\end{tabular}

\section{Sensitivity analysis}

We performed a sensitivity analysis on the model parameters to investigate their effect on eight model variables: reservoir volume $(V)$, river water level $(W L)$, total water demand $(D P)$, proportion of population living in the floodplains $(G)$, society's drought awareness $\left(A^{\mathrm{D}}\right)$, society's flood awareness $\left(A^{\mathrm{F}}\right)$, drought losses $\left(L^{\mathrm{S}}\right)$, and flood losses $\left(L^{\mathrm{F}}\right)$. The analysis was conducted on the synthetic experiment, with the presence of a dam. We implemented a one-factor-at-a-time method to assess the parameter sensitivity based on the variance of six model variables (van Emmerik et al. 2014, Pianosi et al. 2016). In particular, an ensemble of 5000 model runs was generated by perturbing only one parameter at a time within its range of variation while the other parameters were kept unchanged. The variance of the cumulated value of the time series of each ensemble member was calculated for each model parameter. The sensitivity index $S$ of a given parameter $j$ for a specific model state was calculated as:

$$
S_{j}=\frac{\sigma_{j}^{2}}{\sum_{j=1}^{J} \sigma_{j}^{2}}
$$

where $J$ is the total number of tested parameters, $\sigma^{2}$ is the variance, and the denominator is the sum of variances over all parameters. In our analysis, we did not include the population growth rate because a small perturbation of this parameter can highly affect model results and the sensitivity analysis would be biased toward that parameter.

\section{RESULTS AND DISCUSSION}

Historical analysis

We evaluated both potentials and limitations of the model to qualitatively capture the human-water dynamics emerging from different water-management strategies against consecutive extreme hydrological events for the Brisbane case study. We simulated model behavior with the aforementioned prototypes of water-management strategies: no-actions, fighting-flood, waterconservation, and water-exploitation strategies. It is worth noting that the water-conservation strategy corresponds to the historical management strategy implemented in Brisbane during the Millennium Drought.

The results of this analysis are summarized in Figure 5. As can be observed, the simulated reservoir volume closely follows the observed values. No-actions, fighting-floods, and waterexploitation strategies show a drop in the reservoir volume from 
Table 4. Summary of the model parameters. Note: FSV = full supply volume.

\begin{tabular}{|c|c|c|c|c|c|c|c|}
\hline $\begin{array}{l}\text { Param- } \\
\text { eter }\end{array}$ & Description & Value & Min* & $\operatorname{Max}^{*}$ & Units & Eq. & Source \\
\hline$\eta$ & Hedging policy coefficient & 3 & 1 & 10 & - & 3 & Garcia et al. 2016 \\
\hline$F S V_{\mathrm{m}}$ & $\begin{array}{l}\text { Minimum value of the full supply } \\
\text { volume }\end{array}$ & $1 \cdot 10^{9}$ & $0.6 \cdot 10^{9}$ & $1.1 \cdot 10^{9}$ & $\mathrm{~m}^{3}$ & 5 & - \\
\hline$\varepsilon_{\mathrm{v}}$ & $\begin{array}{l}\text { Safety factor for the enlargement of } \\
\text { the full supply level }\end{array}$ & 0.7 & 0 & 2 & - & 6 & - \\
\hline$\theta$ & $\begin{array}{l}\text { Bias due to the difference between } \\
\text { drought and flood memories }\end{array}$ & 3 & 0 & 30 & - & $7-8$ & $\begin{array}{l}\text { Di Baldassarre et } \\
\text { al. } 2017\end{array}$ \\
\hline$\mu_{\text {DRES }}$ & $\begin{array}{l}\text { Drought awareness decay of the } \\
\text { reservoir operator (half-life) }\end{array}$ & $\begin{array}{c}0.005 \\
(11.55)\end{array}$ & $\begin{array}{c}0 \\
(\infty)\end{array}$ & $\begin{array}{l}0.058 \\
(1)\end{array}$ & $\begin{array}{l}1 / \mathrm{mo} \\
\text { (years) }\end{array}$ & 7 & $\begin{array}{l}\text { Di Baldassarre et } \\
\text { al. } 2017\end{array}$ \\
\hline$\mu_{\mathrm{FRES}}$ & $\begin{array}{l}\text { Flood awareness decay of the } \\
\text { reservoir operator (half-life) }\end{array}$ & $\begin{array}{c}0.005 \\
(11.55)\end{array}$ & $\begin{array}{c}0 \\
(\infty)\end{array}$ & $\begin{array}{l}0.058 \\
(1)\end{array}$ & $\begin{array}{l}1 / \mathrm{mo} \\
\text { (years) }\end{array}$ & 8 & $\begin{array}{l}\text { Di Baldassarre et } \\
\text { al. } 2017\end{array}$ \\
\hline$E$ & $\begin{array}{l}\text { Percentage of input flow assigned as } \\
\text { environmental flow }\end{array}$ & 0.25 & 0 & 0.4 & - & 9 & Garcia et al. 2016 \\
\hline$\mu_{\mathrm{D}}$ & $\begin{array}{l}\text { Drought awareness decay of the } \\
\text { society (half-life) }\end{array}$ & $\begin{array}{l}0.029 \\
(2)\end{array}$ & $\begin{array}{c}0 \\
(\infty)\end{array}$ & $\begin{array}{l}0.12 \\
(0.5)\end{array}$ & $1 / \mathrm{mo}$ & 10 & Beal et al. 2014 \\
\hline$\mu_{\mathrm{N}}$ & $\begin{array}{l}\text { Willingness decay of the society } \\
\text { (half-life) }\end{array}$ & $\begin{array}{l}0.029 \\
(2)\end{array}$ & $\begin{array}{c}0 \\
(\infty)\end{array}$ & $\begin{array}{l}0.12 \\
(0.5)\end{array}$ & $1 / \mathrm{mo}$ & 13 & Beal et al. 2014 \\
\hline$D_{\min }$ & Minimum per-capita water demand & 100 & 50 & 150 & $\mathrm{~L} / \mathrm{d} / \mathrm{p}$ & 14 & Seqwater 2017 \\
\hline$\alpha_{D}$ & Fractional efficiency adoption rate & 0.013 & 0 & 0.083 & $1 / \mathrm{mo}$ & 14 & Garcia et al. 2016 \\
\hline$\beta_{D}$ & Background decay rate & $8.3 \cdot 10^{-5}$ & $3 \cdot 10^{-5}$ & $8.3 \cdot 10^{-4}$ & $1 / \mathrm{mo}$ & 14 & Garcia et al. 2016 \\
\hline$K_{1}$ & $\begin{array}{l}\text { Weighting factor of the Muskingum } \\
\text { model }\end{array}$ & 0.4 & 0.01 & 0.48 & - & - & - \\
\hline$K_{3}$ & $\begin{array}{l}\text { Lateral distributed contribute along } \\
\text { the river }\end{array}$ & 1.2 & 0 & 3 & - & - & - \\
\hline$\xi_{\mathrm{H}}$ & $\begin{array}{l}\text { Proportion of flood level } \\
\text { enhancement }\end{array}$ & 0.2 & 0.1 & 5 & - & $15-16$ & $\begin{array}{l}\text { Heine and Pinter } \\
2012\end{array}$ \\
\hline$\alpha_{H}$ & $\begin{array}{l}\text { Parameter representing the relation } \\
\text { between flood levels and relative } \\
\text { damage }\end{array}$ & 3 & 1 & 50 & $\mathrm{~m}$ & 15 & $\begin{array}{l}\text { Penning-Rowsell et } \\
\text { al. } 2006\end{array}$ \\
\hline$\varepsilon_{\mathrm{H}}$ & $\begin{array}{l}\text { Safety factor for the enlargement of } \\
\text { the levee }\end{array}$ & 1.1 & 0 & 2 & - & 16 & $\begin{array}{l}\text { Da Deppo et al. } \\
2004\end{array}$ \\
\hline$\mu_{\mathrm{F}}$ & $\begin{array}{l}\text { Flood awareness decay of the society } \\
\text { (half-life) }\end{array}$ & $\begin{array}{c}0.005 \\
(11.55)\end{array}$ & $\begin{array}{c}0 \\
(\infty)\end{array}$ & $\begin{array}{l}0.023 \\
(2.5)\end{array}$ & $1 / \mathrm{mo}$ & 17 & $\begin{array}{l}\text { Baldassarre et al. } \\
2015\end{array}$ \\
\hline$\tau_{\mathrm{P}}$ & Population threshold & 0.4 & - & - & - & 19 & Garcia et al. 2016 \\
\hline$\alpha_{G}$ & Ratio preparedness/awareness & 5 & 1 & 20 & - & 20 & Scolobig et al. 2012 \\
\hline$\delta_{\mathrm{P}}$ & Population growth rate & 0.002 & - & - & $1 / \mathrm{mo}$ & 20 & $\begin{array}{l}\text { Australian Bureau } \\
\text { of Statistics } 2020\end{array}$ \\
\hline
\end{tabular}

2006 because no conservation strategies are taken into consideration to reduce water use. The higher observed volume could be due to the restrictive measures undertaken by the government for an efficient use of water and diverse sources of supply (Seqwater 2017). On the other hand, the waterconservation strategy provides a higher reservoir volume due to the lower per-capita water demand (Fig. 5D). Simulated percapita demand values obtained in 2006 and 2010 are similar to the recorded ones.

The coupled-modeling approach captured the emergence of the "sequence effect" when adopting the water-conservation strategy, in agreement with the historical management. Indeed, the reduced per-capita demand generates low withdrawals from the reservoir during drought periods (Figs. 5B, 5D). During the flood periods, as witnessed in 2011, the dam is unable to handle the floods due to its low capacity (Fig. 5B between the years 2009 and 2010). Therefore, high flood releases are necessary to keep the reservoir volume below the maximum during the extreme rainfall events that occurred in 2011. Because of this, river water level and flood losses downstream are significantly higher compared to other strategies. This indicates that interventions aimed at avoiding unintended consequences of shortage periods might exacerbate future flood losses, as happened during the 2011 flood event (Van den Honert and McAneney 2011). This result confirms how a coupled-modeling approach, such as the one presented here, allows for capturing the emergence of those socio-hydrological phenomena that would otherwise go unnoticed.

Simulated flood awareness shows high values during the events of 1974 and 1983 for all the water-management strategies (Fig. $5 \mathrm{G})$. The construction of Wivenhoe Dam for Brisbane "flood- 
Fig. 5. Historical analysis on the Brisbane case study considering the three management strategies. (A) water level (WL), (B) reservoir volume (V), (C) levee height (H), (D) per-capita demand (D), (E) population (P), (F) drought awareness of reservoir operator $\left(A^{\text {DRes }}\right),(G)$ flood awareness $\left(A^{F}\right),(H)$ drought awareness $\left(A^{D}\right),(I)$ population affected by floods $\left(\mathrm{P}^{\mathrm{F}}\right)$, and $(\mathrm{L})$ population affected by droughts $\left(\mathrm{P}^{\mathrm{D}}\right)$. The gray dashed lines indicate the construction of the Wivenhoe Dam.
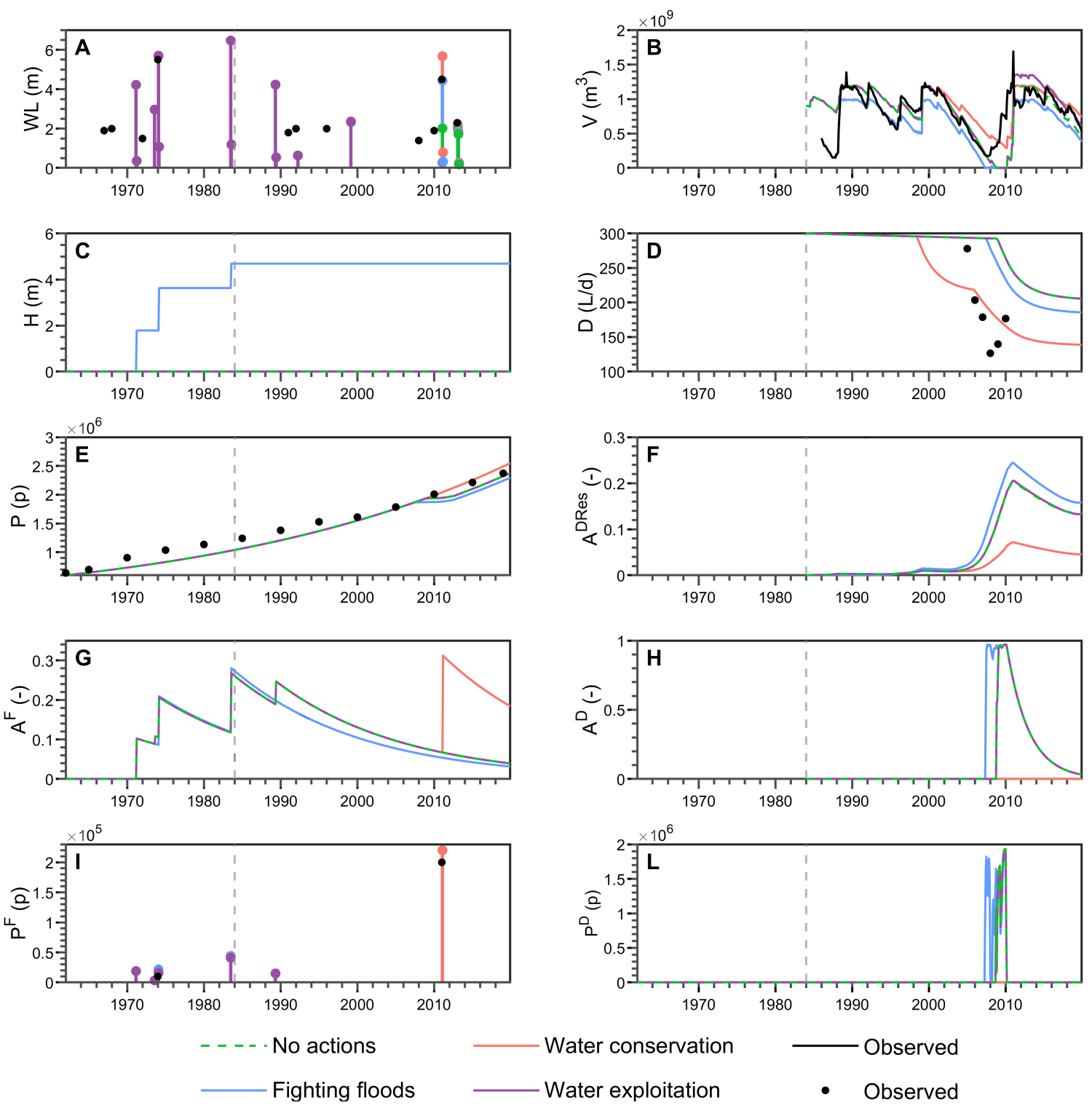

proofing" resulted from the high flood awareness after the 1974 event (Head 2014). After the construction of the Wivenhoe Dam, the simulated flood awareness decreased. This agrees with the findings of Head (2014) because no flooding events were experienced in the downstream urban area. This is mainly because of the low values of monthly flow and the reservoir volume achieved with the different water-management strategies, which allow for additional water retention space. On the other hand, the construction of the levee system with the fighting-floods strategy after the 1974 and 1983 events protected the downstream area from flooding (Fig. 5C). Following the catastrophic flood event of 2011, concerns were raised about the adequacy of flood- mitigation planning and market-driven urban growth (Head 2014). Our model reported similar results under the waterconservation strategy in which higher simulated flood losses and flood-awareness values were obtained in 2011 (Figs. 5G, 5I). A good agreement is found between simulated and observed affected populations during the 2011 flood event (Fig. 5I)).

Because of the Wivenhoe Dam construction, there is no simulated drought awareness up to 2007 (Fig. 5H). As reported by Head (2014), drought awareness in the 80 s and 90 s was low due to the construction of the Wivenhoe Dam but also due to the absence of significant drought events. However, following the Millennium 
Table 5. Average values of different model variables obtained for the different experiments with the four water-management strategies (NA: no actions; FF: fighting floods; WC: water conservation; and WE: water exploitation). Note: WL = high-water level; V = reservoir volume; $D=$ per-capita water demand; $G=$ proportion of population living in the floodplain; $H=$ flood protection level; $A^{F}=$ society's flood awareness; $\mathrm{A}^{\mathrm{D}}=$ society's drought awareness; $\mathrm{L}^{\mathrm{F}}=$ flood losses; $\mathrm{L}^{\mathrm{D}}=$ drought losses; and $\mathrm{P}^{\mathrm{F}}=$ population affected by flooding.

\begin{tabular}{|c|c|c|c|c|c|c|c|c|c|c|}
\hline \multirow{2}{*}{$\begin{array}{l}\text { Mo- } \\
\text { del } \\
\text { vari- } \\
\text { able }\end{array}$} & \multicolumn{4}{|c|}{ Historical analysis } & \multicolumn{2}{|c|}{$\begin{array}{l}\text { Synthetic experiment, no dam } \\
\text { constructed }\end{array}$} & \multicolumn{4}{|c|}{$\begin{array}{c}\text { Synthetic } \\
\text { experiment, dam constructed }\end{array}$} \\
\hline & NA & FF & WC & WE & NA & FF & NA & FF & WC & WE \\
\hline$W L$ & 2.38 & 2.42 & 2.54 & 2.26 & 3.10 & 3.10 & 2.21 & 2.27 & 2.31 & 2.38 \\
\hline$V$ & $8.4 \cdot 10^{8}$ & $7.0 \cdot 10^{8}$ & $9.3 \cdot 10^{8}$ & $8.8 \cdot 10^{8}$ & - & - & $6.5 \cdot 10^{8}$ & $5.6 \cdot 10^{8}$ & $7.5 \cdot 10^{8}$ & $8.3 \cdot 10^{8}$ \\
\hline$D$ & 274.5 & 266.5 & 231.4 & 274.5 & - & - & 189.4 & 180.1 & 151.8 & 191.3 \\
\hline$G$ & 0.24 & 0.26 & 0.20 & 0.24 & 0.17 & 0.29 & 0.37 & 0.57 & 0.33 & 0.42 \\
\hline$H$ & 0.001 & 3.62 & 0.00 & 0.00 & 0.00 & 6.04 & 0.00 & 4.24 & 0.00 & 0.00 \\
\hline$A^{\mathrm{F}}$ & 0.11 & 0.10 & 0.14 & 0.11 & 0.20 & 0.16 & 0.11 & 0.05 & 0.12 & 0.09 \\
\hline$A^{\mathrm{D}}$ & 0.11 & 0.15 & 0.00 & 0.11 & - & - & 0.25 & 0.27 & 0.20 & 0.21 \\
\hline$L^{\mathrm{F}}$ & 0.10 & 0.14 & 0.12 & 0.10 & 0.13 & 0.26 & 0.11 & 0.14 & 0.11 & 0.12 \\
\hline$L^{\mathrm{D}}$ & 0.71 & 0.67 & 0.00 & 0.72 & - & - & 0.82 & 0.81 & 0.84 & 0.80 \\
\hline$P^{\mathrm{F}}$ & $1.9 \cdot 10^{4}$ & $2.8 \cdot 10^{4}$ & $5.2 \cdot 10^{4}$ & $1.9 \cdot 10^{4}$ & $1.8 \cdot 10^{5}$ & $6.9 \cdot 10^{5}$ & $1.3 \cdot 10^{5}$ & $2.8 \cdot 10^{4}$ & $1.1 \cdot 10^{5}$ & $8.0 \cdot 10^{4}$ \\
\hline
\end{tabular}

Drought period between 2000 and 2006, drought awareness was high among the water-policy experts but still low within the population (Head 2014). The water shortage between 2000 and 2006 was perceived as a supply-side crisis by the government, and the people were not held accountable for it. A slight increase in awareness in 2000-2006 was detected by the model when considering reservoir operators' drought awareness (Fig. 5F) with no-actions, fighting-floods, and water-exploitation strategies. In 2006, the deterioration of the water supply became significant, and local and state authorities became alarmed as volumes of major dams dropped below $20 \%$ of the full supply capacity. This situation resulted in an increased drought awareness, as captured by the model (Figs. 5F, 5H). To solve the water shortage issue, the SEQ government undertook engineering solutions to increase water supply. After two years of devoted intensive upgrading of water infrastructures, increase in rainfall was observed in 2009 , making the government consider relaxing the water restrictions (Head 2014). Assuming that drought awareness started declining after 2009, our model reproduces this reduction in 2011 when maximum inflow increased and filled the Wivenhoe Dam. No drought awareness is observed with the water-conservation strategy because of the low per-capita demand.

In addition to the previous trend analysis, we also performed behavioral tests to evaluate whether the model is capable of producing the observed variables (Barlas 1989, Mai and Smith 2018). Thus, percent error in the variation and the discrepancy coefficients (Barlas 1989) were calculated to compare the observed and simulated values of water level, reservoir volume, and population (see Appendix 1). The results show low values of the discrepancy coefficients when simulating reservoir volume and population, which indicates a good performance (Barlas 1989). In particular, lower values are obtained when the waterconservation strategy is adopted, i.e., the historical water management in Brisbane during the Millennium Drought.

\section{Synthetic experiments}

Absence of dam

In this analysis, we assumed the absence of the Wivenhoe Dam and that the downstream area was only affected by river flooding. The maximum daily flow values are directly used to calculate the overbank flow considering no reservoir upstream.

Flood adaptation can be observed when no actions are adopted (Fig. 6). Frequent flood events generate frequent losses, which lead to an increased flood awareness in society over the years (higher average values as reported in Table 5). Such awareness influenced population growth in the floodplains, which is significantly lower than the awareness simulated with the fightingfloods strategy between months 450 and 1285 .

The levee paradox is evident with the fighting-floods strategy following increased flood losses after previously raising the levee height (Fig. 6). Increasing levee heights with the fighting flood strategy ensured minimized losses compared to the no-actions strategy. However, when the levee is overtopped, the fightingfloods strategy would lead to higher damages. Increased population is observed in the floodplains (Fig. 6B) after levee reinforcement at time step 590 due to a lowered flood awareness (Fig. 6D). This is observed to likely generate flood losses (Fig. $6 \mathrm{E})$ at month 1285 almost three times higher than the one at month 590 even if water-level values (Fig. 6A) are comparable at those moments. On average, higher losses $L^{F}$ and proportion of floodplain population $G$ are obtained with the fighting-floods strategy, compared to no actions (Table 5). Similar dynamics were reported in other studies that have focused on human-flood dynamics (e.g., Di Baldassarre et al. 2013, 2015, Ciullo et al. 2017).

\section{Presence of dam}

Here, we describe the results of the proposed integrated framework in which the Wivenhoe Dam is constructed. In addition to the no-actions and fighting-floods strategies, waterconservation and water-exploitation strategies can also be 
Fig. 6. Numerical experiments considering only human-flood interaction and no dam construction with the baseline and fighting-floods strategies. (A) Water level (WL), (B) proportion of population in floodplain $(\mathrm{G}),(\mathrm{C})$ levee height $(\mathrm{H}),(\mathrm{D})$ flood awareness $\left(\mathrm{A}^{\mathrm{F}}\right)$, and $(\mathrm{E})$ flood losses $\left(\mathrm{L}^{\mathrm{F}}\right)$.
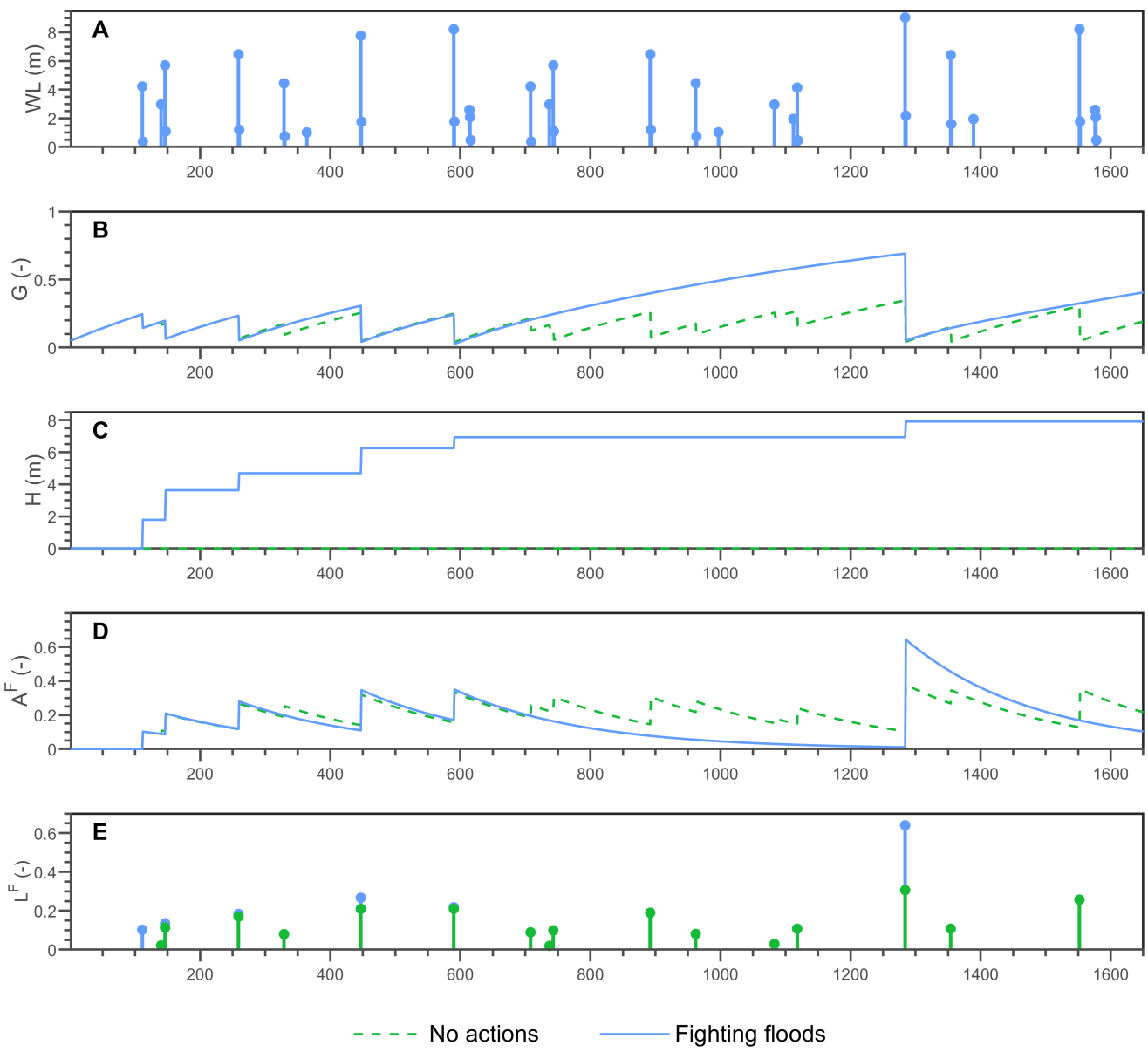

undertaken to reduce the per-capita water demand and increase the water-supply capacity of the Wivenhoe Dam.

The supply-demand cycle can be observed with the waterexploitation strategy because it tends to increase the reservoir FSV and more water is stored during normal and high flow periods in response to water shortages that occurred during the drought periods between months 560-590, 1050-1080, 1240-1255, and 1460-1540 (Fig. 7A). This leads to more water availability and a higher total demand compared to the other water-management strategies (Fig. 7B). These results demonstrate that the supplydemand cycle produces positive feedbacks, and the occurrence of a drought condition may lead to a further expansion of reservoir volume (Di Baldassarre et al. 2018). The reduction of total demand during drought periods is linked to the decrease in population due to increase of drought awareness (Fig. 7D) as the reservoir volume drops to zero and the water supply is not guaranteed.

The reservoir effect can be observed in the water-exploitation strategy as a consequence of the increased FSV and reservoir volume after the drought event between months 560 and 580 (Fig. 7A). The increased water availability helps avoid the probable water shortage in months $870-890$, experienced with the noactions strategy. This leads to increased population and water demand (as previously described in the supply-demand cycle) during almost 40 years without shortages. As a consequence, during the droughts in months 1240 and 1460, the waterexploitation strategy shows a higher population affected by drought than the no-actions and fighting-floods strategies.

Under the water-conservation strategy, a low per-capita demand led to no water shortages as well as low drought awareness (Fig. 7D), and consequent higher population growth until month 1065 . However, when a drought occurs in month 1065, a greater population is expected to be affected by the shortage. The waterconservation strategy results in high average drought losses and affected population (Table 5). These results demonstrate that reducing water consumption to cope with future drought can prevent shortages but generate high losses due to increased population when extreme events occur.

When analyzing the results of the flood-related output (Fig. 8), the presence of the reservoir led to lower flood awareness, lower flood losses, lower levee height, and consequently higher proportion of the floodplains population with the no-actions and 
Fig. 7. Water shortage-based variables of the synthetic numerical experiments considering dam construction and human-flood interactions with the four water-management strategies introduced in this study. (A) reservoir volume (V), (B) total water demand (DP), (C) willingness adopt the new per-capita demand $\left(\mathrm{N}^{\mathrm{D}}\right)$, (D) drought awareness $\left(\mathrm{A}^{\mathrm{D}}\right)$, and $(\mathrm{E})$ population affected by droughts $\left(\mathrm{P}^{\mathrm{D}}\right)$. The gray dashed line indicates the construction of the Wivenhoe Dam.
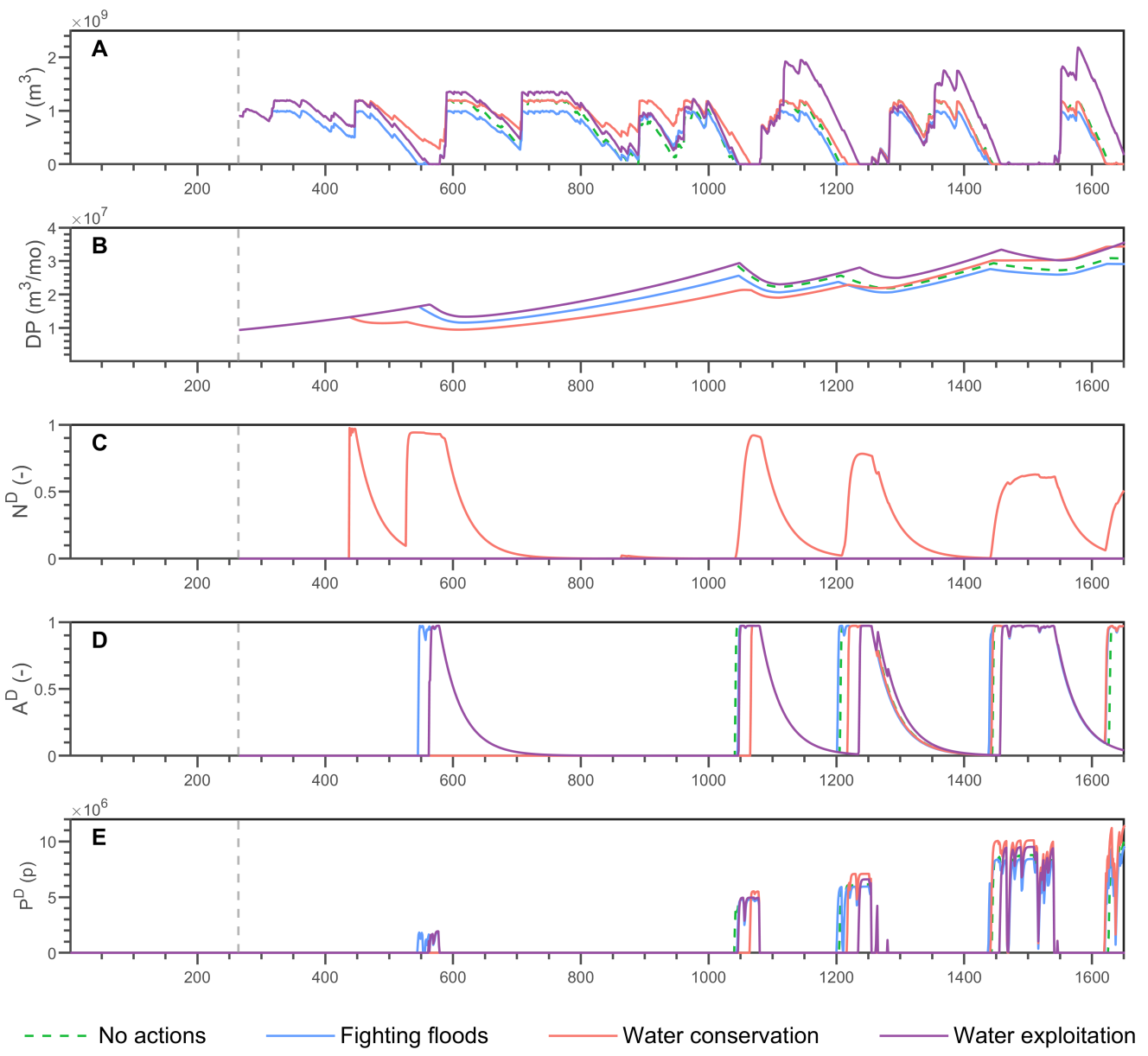

fighting-floods strategies compared to the synthetic experiment without dam (see Figs. 6, 8 and Table 5). A less pronounced levee and adaptation effect (see Figs. 8D, 8E) are observed because the population dynamics in the floodplain are now also influenced by the presence of the Wivenhoe Dam and not only by the flooding. For example, the high reservoir volume in month 740 with the water-exploitation strategy generates the high downstream water-level value and a consequent abrupt change in the proportion of floodplain population. A smaller change is obtained with water-conservation strategies in month 1120 . Moreover, from Figure 7 it can also be observed that watermanagement strategies aimed at alleviating floods can in turn shape reservoir volume, drought awareness, and affected population during drought periods. In a similar way, Figure 8 shows that drought-management strategies can differently affect flood awareness and consequent losses. Similar dynamics are also found when considering different synthetic scenarios of river flow characterized by a different occurrence of droughts and floods, as reported in Appendix 1. These dynamics confirm that water- management strategies aimed at specific hydrological extremes can in turn shape the severity of opposite natural hazards, highlighting the importance of coupling drought and flood systems in socio-hydrological modeling applications.

\section{Model sensitivity}

The results of the sensitivity analysis (Fig. 9) show that not all parameters have a significant influence on the model performances. Although reservoir volume, total water demand, drought awareness, and losses are mainly influenced by model parameters related to water demand (e.g., $\mu_{\mathrm{D}}, D_{\min }$, and $\alpha_{\mathrm{D}}$ ), water level, floodplain population, flood awareness, and flood losses are sensitive to the flood-system parameters and partially to those of the drought system (e.g., $\alpha_{\mathrm{D}}$ ). This is indicative that strategies aimed at reducing the consequences of droughts and the resulting change in society's drought awareness can both influence the impact of floods.

As expected, the flood and drought-awareness decay parameters $\mu_{\mathrm{F}}$ and $\mu_{\mathrm{D}}$ have a significant influence on flood and drought 
Fig. 8. Flooding-based variables of the synthetic numerical experiments considering dam construction and human-flood interactions with the four water-management strategies introduced in this study. (A) Water level (WL), (B) proportion of population in floodplain $(G),(C)$ levee height $(\mathrm{H}),(\mathrm{D})$ flood awareness $\left(\mathrm{A}^{\mathrm{F}}\right)$, and $(\mathrm{E})$ flood losses $\left(\mathrm{L}^{\mathrm{F}}\right)$. The gray dashed line indicates the construction of the Wivenhoe Dam.
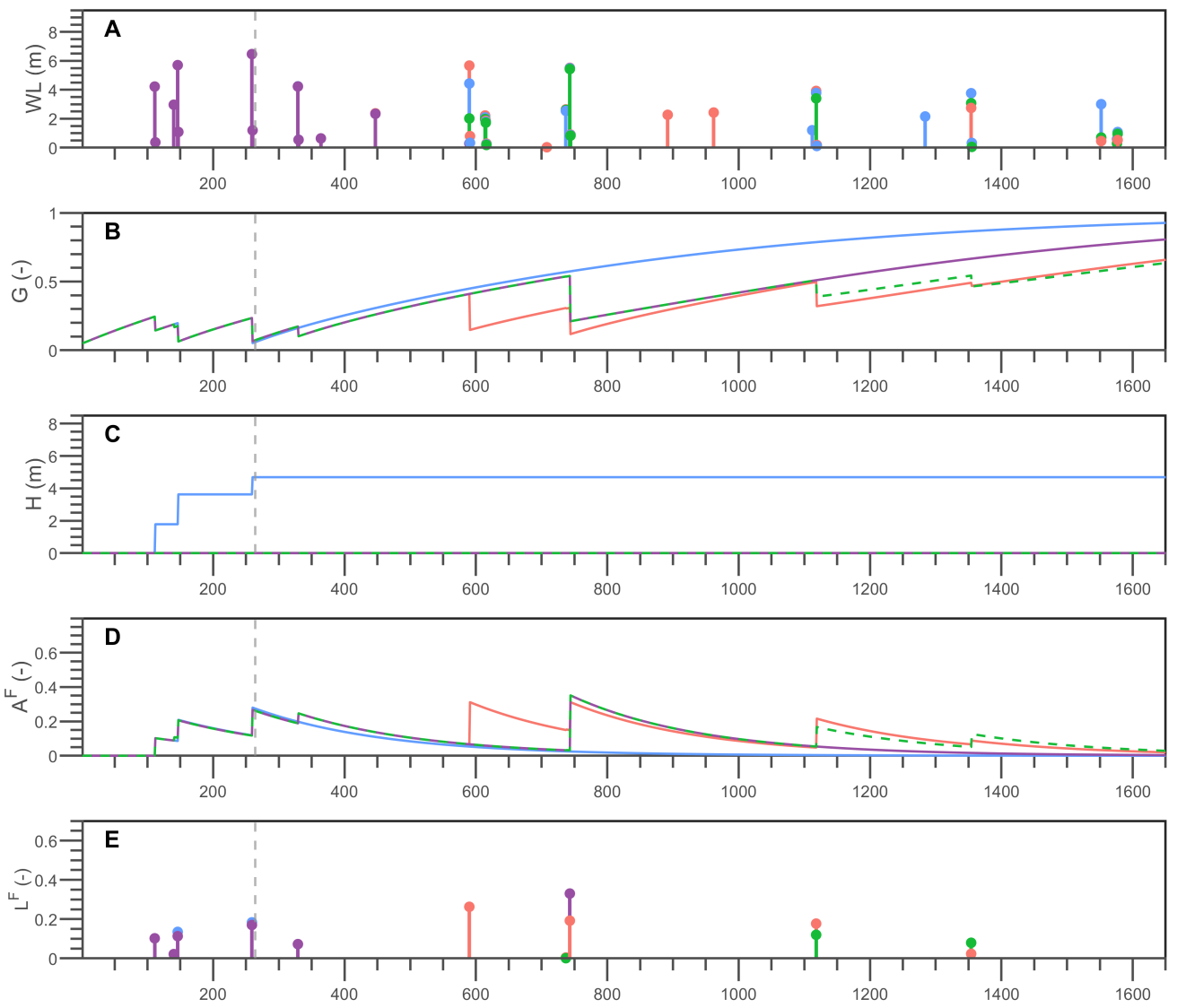

- - - No actions

Fighting floods

Water conservation

Water exploitation

awareness with all the water-management strategies. Floodplain population and flood losses are more sensitive to the parameters of the Muskingum model $K_{1}$, and $K_{3}$, and to the proportion of flood-level enhancement $\xi_{\mathrm{H}}$ when the fighting-floods strategy is implemented. Furthermore, drought-awareness decay $\mu_{\mathrm{D}}$, environmental flow coefficient $E$, and fractional efficiency adoption rate $\alpha_{D}$ also influence the downstream water level, the floodplain population, and flood losses.

Regarding drought-related model output (left column of Fig. 9), drought-awareness decay $\mu_{\mathrm{D}}$ and fractional efficiency adoption rate $\alpha_{D}$ play a key role in the sensitivity of model outcomes with all the implemented water-management strategies. However, the minimum value of per-capita demand $D_{\min }$ is significantly influencing drought losses and total water demand with waterconservation strategies. Drought losses with water-exploitation strategies are strongly influenced not only by $D_{\min }$ but also by the environmental flow released by the Wivenhoe Dam. Finally, the decay of society's willingness to adopt a lower per-capita demand does not significantly influence model outcomes.

Although the unusually high number of model parameters is known to increase model complexity, our sensitivity analysis shows that model results are most sensitive to only 9 of the 19 parameters. In particular, two of the parameters associated with awareness variables, $\mu_{\mathrm{D}}$ (drought-awareness decay), and $\mu_{\mathrm{F}}$ (floodawareness decay) would require empirical longitudinal data, hence the uncertainty. Socio-hydrological models do not aim to reproduce reality in a quantitative way, but rather they enable a qualitative exploration of system dynamics, including the identification of knowledge gaps. In this instance, the model sheds light on which types of data play critical roles in shaping the coevolution of human-water interactions, i.e., data on society's awareness (in terms of droughts and floods). Thus, the model suggests the need for new types of observations to monitor the dynamics of human-water systems.

\section{CONCLUSIONS}

We developed a system-dynamics model that considers mutual interactions between reservoir, drought, flood, and population systems under different water-management strategies. Our fundamental hypothesis is that multiple phenomena, which were identified by numerous scholars from various disciplines in different places around the world (Fig. 1), are generated by the accumulation and the decay of flood and drought awareness. The 
Fig. 9. Sensitivity index of the selected model parameters showing the sensitivity of the (A) reservoir volume (V), (B) water level (WL), (C) total water demand (DP), (D) population living in floodplain areas $(\mathrm{G}),(\mathrm{E})$ drought awareness $\left(\mathrm{A}^{\mathrm{D}}\right),(\mathrm{F})$ flood awareness $\left(\mathrm{A}^{\mathrm{F}}\right),(\mathrm{G})$ drought losses $\left(\mathrm{L}^{\mathrm{D}}\right)$, and $(\mathrm{H})$ flood losses $\left(\mathrm{L}^{\mathrm{F}}\right)$ with respect to the implemented water-management strategies.
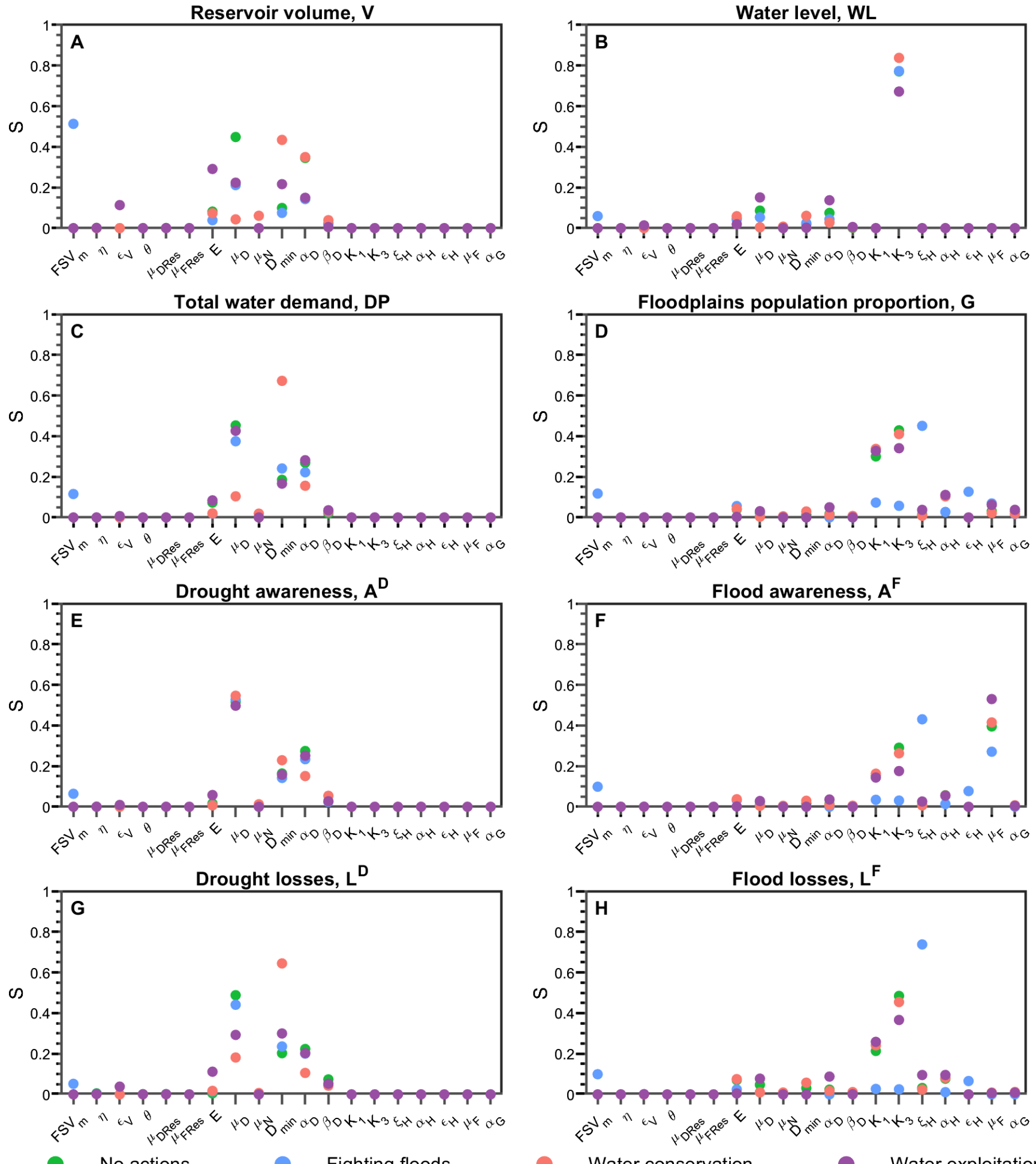

No actions

Fighting floods

Water conservation

Water exploitation 
model was applied to the Brisbane case study to test our assumption and explore the model's capability in representing human-water dynamics when adopting four different watermanagement strategies: no actions, fighting floods, water conservation, and water exploitation. Historical and synthetic scenarios of cascading drought to flood events with increasing frequency and magnitude were also implemented. Because our model is not intended to be predictive, its parameters were not calibrated by fitting observations, but derived from the literature and empirical studies.

The application to the Brisbane case study indicates that our model captures macroscopic trends in observed reservoir volume, population, per-capita water demand, and populations affected by floods. Dynamics of flood and drought awareness agree with the qualitative assessment reported in the literature. In particular, the proposed coupling of the flood and drought systems allowed for the capture of the emergence of the sequence effect when adopting the water-conservation strategy. Water-conservation strategy led to a higher reservoir volume during the Millennium Drought, such that during a flood event, the retention capacity of the dam was reduced. As a consequence, the flood control function of the Wivenhoe Dam was compromised. This dynamic can exacerbate the flooding impact downstream (if no prior reservoir releases are performed) and increase flood losses as a consequence of drought-mitigation strategies during a cascade of opposite extreme hydrological events. This result stresses the importance of the proposed coupled-modeling approach in capturing the emergence of those socio-hydrological phenomena that would otherwise go unnoticed when using socio-hydrological models focused only on a specific hydrological extreme.

The results of the synthetic experiments also confirmed the importance of coupling the flood and drought systems in the modeling framework. Although levee and adaptation effects are also found in the absence of the Wivenhoe Dam under fightfloods and no-actions strategies, less pronounced effects are observed because of the influence of the reservoir on downstream flood losses, leading to different flood-awareness levels and consequent different proportion of floodplain population. Although water-management strategies aimed at mitigating floods can alter reservoir volume, drought awareness, and affected population during drought periods, drought-management strategies can differently affect flood awareness and consequent losses. These results confirm how drought water-management strategies can in turn shape the severity of flooding and consequent losses. As reported in previous research in the field, we found that supply-demand cycle and reservoir effect can emerge when increasing the maximum value of reservoir capacity. The water-exploitation strategy shows an increment in the water demand as a response to an increased value of the full supply volume (and consequent storage capacity) for water supply after a prolonged drought. Because of the trust in the water-supply system and low drought awareness, an increase in affected population is found with exploitation strategy after a severe drought period, indicating the emergence of a reservoir effect.

The sensitivity analysis shows the influence of flood-awareness decay on the model output. River water level, flood awareness, and flood losses are sensitive not only to the parameters of the flood system but also to the parameters of both the reservoir and the drought systems. This is indicative that strategies aimed at reducing the consequences of droughts and the resulting change in society's drought awareness can influence the impact of floods. The proper estimation of the hydraulic model parameters is crucial for the assessment of floodplain population and flood losses. The choice of the minimum value of per-capita water demand is crucial for the model outcomes with the waterconservation strategy. Moreover, drought losses under the waterexploitation strategy are influenced by the released environmental flow.

Our study is inevitably subject to a number of caveats. First, the model does not consider different social groups because spatially distributed characteristics of heterogeneous human societies are not included. Agent-based models, which aim to simulate the role of individual and collective behavior (Wens et al. 2019, Alonso Vicario et al. 2020, Michaelis et al. 2020) in relation to floods and droughts, can be used in future studies to capture social heterogeneity. In our model, water-management strategies are considered as an external model control constant in time because they are aimed at unravelling and quantifying the human-water phenomena under specific adaptation actions. Another possible approach could be to consider time-varying water-management strategies as an internal model state driven by the different awareness levels of both society and the reservoir operator. In flood-risk management, water managers will often mitigate flood losses by releasing water in advance based on flood forecasting. We do not include this component in our modeling framework. In addition, our model does not capture the complex link between awareness and preparedness, which is related to many factors, such as the residents' threat and coping appraisal, which include the perceived efficacy and cost of the protection measure, in addition to the flood-risk awareness itself (Grothmann and Reusswig 2006, Miceli et al. 2008, Scolobig et al. 2012, Mondino et al. 2020). Risk-communication strategies, economics, political processes, power relationships, and impacts of the role of institutional structure on reservoir rules change (Novo and Garrido 2014, Garcia et al. 2019) are not included in the proposed model. Future modeling efforts on the interplay of flood and drought risk management would benefit from the inclusion of such factors.

Because of its middle-ground nature, our modeling approach can be used for: (1) testing new hypotheses about the way in which phenomena and/or risks are generated by the interaction between consecutive hydrological extremes and adaptation actions; (2) integrating qualitative and quantitative observations; and (3) suggesting new types of observations to monitor the dynamics of human-water systems, such us societal awareness. Our modeling approach can be applied to other case studies to investigate whether similar feedback mechanisms can be observed, allowing for advancing the general understanding about the sociohydrology of human-water systems. Moreover, our model can also be used as a simplified tool to support policymakers by allowing the exploration of trajectories and trade-offs in the study of human-water systems at a strategic/macroscopic level.

The relationships between the human and the water system are more complex than the ones conceptualized in our model. As such, socio-hydrological models like the one we proposed are useful for stakeholders and decision makers to better understand 
the complex human-water system under global anthropogenic and climatic changes, but they are not sufficient. They should always be complemented by empirical research and instrumental case studies to advance theory and better understand how the interactions and feedback mechanisms between physical and social processes influence the dynamics of hydrological risk.

Responses to this article can be read online at: https://www.ecologyandsociety.org/issues/responses. $\mathrm{php} / 12643$

\section{Acknowledgments:}

This research was partly supported by the European Research Council (ERC) within the project "HydroSocialExtremes: Uncovering the Mutual Shaping of Hydrological Extremes and Society", ERC Consolidator Grant no. 761678, H2020 Excellent Science. Part of this research was also supported by the Swedish Research Council FORMAS and the Centre of Natural Hazards and Disaster Science, CNDS, in Sweden. Monthly river flow data for the Brisbane case study are provided by the Australian Government Bureau of Meteorology and can be found at http:// www.bom.gov.au/waterdata

\section{Data Availability:}

The data and codes that support the findings of this study are openly available on Zenodo at https://doi.org/10.5281/zenodo.4705084

\section{LITERATURE CITED}

AghaKouchak, A., D. Feldman, M. Hoerling, T. Huxman, and J. Lund. 2015. Water and climate: recognize anthropogenic drought. Nature 524(7566):409-411. https://doi.org/10.1038/524409a

Aimers, J., and D. Hodell. 2011. Societal collapse: drought and the Maya. Nature 479(7371):44-45. https://doi.org/10.1038/479044a

Albertini, C., M. Mazzoleni, V. Totaro, V. Iacobellis, and G. Di Baldassarre. 2020. Socio-hydrological modelling: the influence of reservoir management and societal responses on flood impacts. Water 12(5):1384. https://doi.org/10.5194/egusphere-egu2020-673

Alonso Vicario, S., M. Mazzoleni, S. Bhamidipati, M. Gharesifard, E. Ridolfi, C. Pandolfo, and L. Alfonso. 2020. Unravelling the influence of human behaviour on reducing casualties during flood evacuation. Hydrological Sciences Journal 65(14):2359-2375. https://doi.org/10.1080/02626667.2020.1810254

Australian Bureau of Statistics. 2020. Historical population. Australian Bureau of Statistics, Canberra, Australia. [online] URL: https://www.abs.gov.au/statistics/people/population/historicalpopulation/latest-release

Baes, M., and M. Bürgisser. 2013. Hedge algorithm and dual averaging schemes. Mathematical Methods of Operations Research 77(3):279-289. https://doi.org/10.1007/s00186-012-0418-1
Bakarji, J., D. O'Malley, and V. V. Vesselinov. 2017. Agent-based socio-hydrological hybrid modeling for water resource management. Water Resources Management 31(12):3881-3898. https://doi.org/10.1007/s11269-017-1713-7

Barendrecht, M. H., A. Viglione, H. Kreibich, B. Merz, S. Vorogushyn, and G. Blöschl. 2019. The value of empirical data for estimating the parameters of a sociohydrological flood risk model. Water Resources Research 55(2):1312-1336. https://doi. org/10.1029/2018wr024128

Barlas, Y. 1989. Multiple tests for validation of system dynamics type of simulation models. European Journal of Operational Research 42(1):59-87. https://doi.org/10.1016/0377-2217(89) 90059-3

Beal, C. D., A. Makki, and R. A. Stewart. 2014. What does rebounding water use look like? An examination of post-drought and post-flood water end-use demand in Queensland, Australia. Water Supply 14(4):561-568. https://doi.org/10.2166/ws.2014.008

Beal, C. D., and R. A. Stewart. 2011. South East Queensland residential end use study: final report. Urban Water Security Research Alliance Technical Report No. 47. Urban Water Security Research Alliance, City East, Queensland, Australia. [online] URL: http://www.urbanwateralliance.org.au/publications/ UWSRA-tr47.pdf

Blair, P., and W. Buytaert. 2016. Socio-hydrological modelling: a review asking "why, what and how?"Hydrology and Earth System Sciences 20(1):443-478. https://doi.org/10.5194/hess-20-443-2016

Blöschl, G., T. Nester, J. Komma, J. Parajka, and R. A. Perdigão. 2013. The June 2013 flood in the Upper Danube basin, and comparisons with the 2002, 1954 and 1899 floods. Hydrology and Earth System Sciences Discussions 10(7):9533-9573. https://doi. org/10.5194/hessd-10-9533-2013

Bohensky, E. L., and A. M. Leitch. 2014. Framing the flood: a media analysis of themes of resilience in the 2011 Brisbane flood. Regional Environmental Change 14(2):475-488. https://doi. org/10.1007/s10113-013-0438-2

Brelsford, C., M. Dumas, E. Schlager, B. J. Dermody, M. Aiuvalasit, M. R. Allen-Dumas, J. Beecher, U. Bhatia, P. D’Odorico, M. Garcia, P. Gober, D. Groenfeldt, S. Lansing, K. Madani, L. E. Méndez-Barrientos, E. Mondino, M. F. Müller, F. C. O'Donnell, P. M. Owuor, J. Rising, M. R. Sanderson, F. A. A. Souza, and S. C. Zipper. 2020. Developing a sustainability science approach for water systems. Ecology and Society 25(2):23. https:// doi.org/10.5751/es-11515-250223

Campbell, H. E., R. M. Johnson, and E. H. Larson. 2004. Prices, devices, people, or rules: the relative effectiveness of policy instruments in water conservation. Review of Policy Research 21 (5):637-662. https://doi.org/10.1111/j.1541-1338.2004.00099.x

Ciullo, A., A. Viglione, A. Castellarin, M. Crisci, and G. Di Baldassarre. 2017. Socio-hydrological modelling of flood-risk dynamics: comparing the resilience of green and technological systems. Hydrological Sciences Journal 62(6):880-891. https:// doi.org/10.1080/02626667.2016.1273527

Cook, M. 2017. Vacating the floodplain: urban property, engineering, and floods in Brisbane (1974-2011). Conservation and Society 15(3):344. 
Coumou, D., and S. Rahmstorf. 2012. A decade of weather extremes. Nature Climate Change 2(7):491-496. https://doi. org/10.1038/nclimate1452

Da Deppo, L., C. Datei, and P. Salandin. 2004. Sistemazione dei Corsi D'acqua [in Italian]. Libreria Int. Cortina Padova, Padova, Italy.

Dadson, S., J. W. Hall, D. Garrick, C. Sadoff, D. Grey, and D. Whittington. 2017. Water security, risk, and economic growth: insights from a dynamical systems model. Water Resources Research 53(8):6425-6438. https://doi.org/10.1002/2017WR020640

de Graaf, I. E. M., T. Gleeson, L. P. H. van Beek, E. H. Sutanudjaja, and M. F. P. Bierkens. 2019. Environmental flow limits to global groundwater pumping. Nature 574(7776):90-94. https://doi.org/10.1038/s41586-019-1594-4

Destouni, G., F. Jaramillo, and C. Prieto. 2013. Hydroclimatic shifts driven by human water use for food and energy production. Nature Climate Change 3(3):213-217. https://doi.org/10.1038/ $\underline{\text { nclimate } 1719}$

Di Baldassarre, G., F. Martinez, Z. Kalantari, and A. Viglione. 2017. Drought and flood in the Anthropocene: feedback mechanisms in reservoir operation. Earth System Dynamics 8 (1):225-233. https://doi.org/10.5194/esd-8-225-2017

Di Baldassarre, G., A. Viglione, G. Carr, L. Kuil, J. L. Salinas, and G. Blöschl. 2013. Socio-hydrology: conceptualising humanflood interactions. Hydrology and Earth System Sciences 17 (8):3295-3303. https://doi.org/10.5194/hess-17-3295-2013

Di Baldassarre, G., A. Viglione, G. Carr, L. Kuil, K. Yan, L. Brandimarte, and G. Blöschl. 2015. Debates-Perspectives on socio-hydrology: capturing feedbacks between physical and social processes. Water Resources Research 51(6):4770-4781. https:// doi.org/10.1002/2014wr016416

Di Baldassarre, G., N. Wanders, A. AghaKouchak, L. Kuil, S. Rangecroft, T. I. E. Veldkamp, M. Garcia, P. R. van Oel, K. Breinl, and A. F. Van Loon. 2018. Water shortages worsened by reservoir effects. Nature Sustainability 1(11):617-622. https://doi. org/10.1038/s41893-018-0159-0

Draper, A. J., and J. R. Lund. 2004. Optimal hedging and carryover storage value. Journal of Water Resources Planning and Management 130(1):83-87. https://doi.org/10.1061/(ASCE)0733-9496 (2004)130:1(83)

Dubbelboer, J., I. Nikolic, K. Jenkins, and J. Hall. 2017. An Agentbased model of flood risk and insurance. Journal of Artificial Societies and Social Simulation 20(1):6. https://doi.org/10.18564/ jasss. 3135

Dumont, A., B. Mayor, and E. López-Gunn. 2013. Is the rebound effect or Jevons paradox a useful concept for better management of water resources? Insights from the irrigation modernisation process in Spain. Aquatic Procedia 1:64-76. https://doi. org/10.1016/j.aqpro.2013.07.006

Elshafei, Y., M. Sivapalan, M. Tonts, and M. R. Hipsey. 2014. A prototype framework for models of socio-hydrology: identification of key feedback loops with application to two Australian case-studies. Hydrology and Earth System Sciences Discussions 11:629-689. https://doi.org/10.5194/hessd-11-629-2014
Falkenmark, M., and J. Rockström. 2008. Building resilience to drought in desertification-prone savannas in Sub-Saharan Africa: the water perspective. Natural Resources Forum 32:93-102. https://doi.org//10.1111/j.1477-8947.2008.00177.x

Fanta, V., M. Šálek, and P. Sklenicka. 2019. How long do floods throughout the millennium remain in the collective memory? Nature communications 10(1):1105. https://doi.org/10.1038/ s41467-019-09102-3

Fielding, K. S., S. Russell, A. Spinks, and A. Mankad. 2012. Determinants of household water conservation: the role of demographic, infrastructure, behavior, and psychosocial variables. Water Resources Research 48(10). https://doi. org/10.1029/2012WR012398

Filatova, T. 2015. Empirical agent-based land market: integrating adaptive economic behavior in urban land-use models. Computers, Environment and Urban Systems 54:397-413. https:// doi.org/10.1016/j.compenvurbsys.2014.06.007

Freire-González, J. 2019. Does water efficiency reduce water consumption? The economy-wide water rebound effect. Water Resources Management 33(6):2191-2202. https://doi.org/10.1007/ s11269-019-02249-0

Garcia, M., E. Koebele, A. Deslatte, K. Ernst, K. F. Manago, and G. Treuer. 2019. Towards urban water sustainability: Analyzing management transitions in Miami, Las Vegas, and Los Angeles. Global Environmental Change 58:101967. https://doi.org/10.1016/ j.gloenvcha.2019.101967

Garcia, M., K. Portney, and S. Islam. 2016. A question driven socio-hydrological modeling process. Hydrology and Earth System Sciences 20(1):73-92. https://doi.org/10.5194/hess-20-73-2016

Giacomoni, M. H., L. Kanta, and E. M. Zechman. 2013. Complex adaptive systems approach to simulate the sustainability of water resources and urbanization. Journal of Water Resources Planning and Management 139(5):554-564. https://doi.org/10.1061/(ASCE) WR.1943-5452.0000302

Gohari, A., S. Eslamian, A. Mirchi, J. Abedi-Koupaei, A. Massah Bavani, and K. Madani. 2013. Water transfer as a solution to water shortage: a fix that can Backfire. Journal of Hydrology 491:23-39. https://doi.org/10.1016/j.jhydrol.2013.03.021

Gohari, A., A. Mirchi, and K. Madani. 2017. System Dynamics Evaluation of Climate Change Adaptation Strategies for Water Resources Management in Central Iran. Water Resources Management 31(5):1413-1434. https://doi.org/10.1007/s11269-017-1575$\underline{z}$

Gonzales, P., and N. Ajami. 2017. Social and structural patterns of drought-related water conservation and rebound. Water Resources Research 53(12):10619-10634. https://doi. org/10.1002/2017WR021852

Gralepois, M., C. Larrue, M. Wiering, A. Crabbé, S. Tapsell, H. Mees, K. Ek, and M. Szwed. 2016. Is flood defense changing in nature? Shifts in the flood defense strategy in six European countries. Ecology and Society 21(4):37. https://doi.org/10.5751/ ES-08907-210437

Grames, J., A. Prskawetz, D. Grass, A. Viglione, and G. Blöschl. 2016. Modeling the interaction between flooding events and 
economic growth. Ecological Economics 129:193-209. https:// doi.org/10.1016/j.ecolecon.2016.06.014

Grothmann, T., and F. Reusswig. 2006. People at risk of flooding: why some residents take precautionary action while others do not. Natural Hazards 38(1):101-120. https://doi.org/10.1007/s11069-005-8604-6

Haer, T., W. J. W. Botzen, and J. C. J. H. Aerts. 2019. Advancing disaster policies by integrating dynamic adaptive behaviour in risk assessments using an agent-based modelling approach. Environmental Research Letters 14(4):044022. https://doi. org/10.1088/1748-9326/ab0770

Haer, T., W. J. W. Botzen, H. de Moel, and J. C. J. H. Aerts. 2017. Integrating household risk mitigation behavior in flood risk analysis: an agent-based model approach. Risk Analysis 37 (10):1977-1992. https://doi.org/10.1111/risa.12740

Hall, J. W. 2019. Socio-hydrology in perspective - circa 2018. Water Resources Research 55(3):1776-1777. https://doi. org/10.1029/2019wr024870

Happe, K., K. Kellermann, and A. Balmann. 2006. Agent-based analysis of agricultural policies: an illustration of the agricultural policy simulator AgriPoliS, its adaptation and behavior. Ecology and Society 11(1):49. https://doi.org/10.5751/ES-01741-110149

Head, B. W. 2014. Managing urban water crises: adaptive policy responses to drought and flood in Southeast Queensland, Australia. Ecology and Society 19(2):33. https://doi.org/10.5751/ ES-06414-190233

Heberger, M. 2012. Australia's millennium drought: impacts and responses. Pages 97-125 in P. H. Gleick, editor. The world's water. Island, Washington, D.C., USA. https://doi.org/10.5822/978-1-59726-228-6 5

Heine, R. A., and N. Pinter. 2012. Levee effects upon flood levels: an empirical assessment. Hydrological Processes 26(21):3225-3240. https://doi.org/10.1002/hyp.8261

International Panel on Climate Change (IPCC). 2012. Managing the risks of extreme events and disasters to advance climate change adaptation. Cambridge University Press, Cambridge, UK. [online] URL: https://www.ipcc.ch/report/managing-therisks-of-extreme-events-and-disasters-to-advance-climate-changeadaptation/

Janssen, M. A., and E. Ostrom. 2006. Empirically based, agentbased models. Ecology and Society 11(2):37. https://doi. org/10.5751/ES-01861-110237

Jongman, B., E. E. Koks, T. G. Husby, and P. J. Ward. 2014. Increasing flood exposure in the Netherlands: implications for risk financing. Natural Hazards and Earth System Sciences 14 (5):1245-1255. https://doi.org/10.5194/nhess-14-1245-2014

Juhola, S., E. Glaas, B.-O. Linnér, and T.-S. Neset. 2016. Redefining maladaptation. Environmental Science and Policy 55:135-140. https://doi.org/10.1016/j.envsci.2015.09.014

Kallis, G. 2010. Coevolution in water resource development: the vicious cycle of water supply and demand in Athens, Greece. Ecological Economics 69(4):796-809. https://doi.org/10.1016/j. ecolecon.2008.07.025
Kates, R. W., C. E. Colten, S. Laska, and S. P. Leatherman. 2006. Reconstruction of New Orleans after Hurricane Katrina: a research perspective. Proceedings of the National Academy of Sciences 103(40):14653-14660. https://doi.org/10.1073/pnas.0605726103

Kenney, D. S., C. Goemans, R. Klein, J. Lowrey, and K. Reidy. 2008. Residential water demand management: lessons from Aurora, Colorado1. JAWRA Journal of the American Water Resources Association 44(1):192-207. https://doi.org/10.1111/ j.1752-1688.2007.00147.x

Knuth, D., D. Kehl, L. Hulse, and S. Schmidt. 2014. Risk perception, experience, and objective risk: a cross-national study with European emergency survivors. Risk Analysis 34 (7):1286-1298. https://doi.org/10.1111/risa.12157

Konar, M., M. Garcia, M. R. Sanderson, D. J. Yu, and M. Sivapalan. 2019. Expanding the scope and foundation of sociohydrology as the science of coupled human-water systems. Water Resources Research 55(2):874-887. https://doi. org/10.1029/2018WR024088

Kreibich, H., V. Blauhut, J. C. J. H. Aerts, L. M. Bouwer, H. A. J. Van Lanen, A. Mejia, M. Mens, and A. F. Van Loon. 2019. How to improve attribution of changes in drought and flood impacts. Hydrological Sciences Journal 64(1):1-18. https://doi. org/10.1080/02626667.2018.1558367

Kreibich, H., G. Di Baldassarre, S. Vorogushyn, J. C. J. H. Aerts, H. Apel, G. T. Aronica, K. Arnbjerg-Nielsen, L. M. Bouwer, P. Bubeck, T. Caloiero, D. T. Chinh, M. Cortès, A. K. Gain, V. Giampá, C. Kuhlicke, Z. W. Kundzewicz, M. C. Llasat, J. Mård, P. Matczak, M. Mazzoleni, D. Molinari, N. V. Dung, O. Petrucci, K. Schröter, K. Slager, A. H. Thieken, P. J. Ward, and B. Merz. 2017. Adaptation to flood risk: results of international paired flood event studies. Earth's Future 10:953-965. https://doi. org/10.1002/2017EF000606

Krysanova, V., H. Buiteveld, D. Haase, F. Hattermann, K. van Niekerk, K. Roest, P. Martínez-Santos, and M. Schlüter. 2008. Practices and lessons learned in coping with climatic hazards at the river-basin scale: floods and droughts. Ecology and Society 13(2):32. https://doi.org/10.5751/ES-02345-130232

Kuil, L., G. Carr, A. Viglione, A. Prskawetz, and G. Blöschl. 2016. Conceptualizing socio-hydrological drought processes: the case of the Maya collapse. Water Resources Research 52(8):6222-6242. https://doi.org/10.1002/2015WR018298

Li, B., M. Sivapalan, and X. Xu. 2019. An urban sociohydrologic model for exploration of Beijing's water sustainability challenges and solution spaces. Water Resources Research 55(7):5918-5940. https://doi.org/10.1029/2018wr023816

Liu, Y., F. Tian, H. Hu, and M. Sivapalan. 2014. Socio-hydrologic perspectives of the co-evolution of humans and water in the Tarim River basin, Western China: the Taiji-Tire model. Hydrology and Earth System Sciences 18(4):1289-1303. https://doi.org/10.5194/ hess-18-1289-2014

Lu, Z., Y. Wei, Q. Feng, A. W. Western, and S. Zhou. 2018. A framework for incorporating social processes in hydrological models. Current Opinion in Environmental Sustainability 33:42-50. https://doi.org/10.1016/j.cosust.2018.04.011 
Ludy, J., and G. M. Kondolf. 2012. Flood risk perception in lands "protected" by 100-year levees. Natural Hazards 61(2):829-842. https://doi.org/10.1007/s11069-011-0072-6

Mai, T., and C. Smith. 2018. Scenario-based planning for tourism development using system dynamic modelling: a case study of Cat Ba Island, Vietnam. Tourism Management 68:336-354. https://doi.org/10.1016/j.tourman.2018.04.005

Mård, J., G. D. Baldassarre, and M. Mazzoleni. 2018. Nighttime light data reveal how flood protection shapes human proximity to rivers. Science Advances 4(8):eaar5779. https://doi. org/10.1126/sciadv.aar5779

Mashhadi Ali, A., M. E. Shafiee, and E. Z. Berglund. 2017. Agentbased modeling to simulate the dynamics of urban water supply: climate, population growth, and water shortages. Sustainable Cities and Society 28:420-434. https://doi.org/10.1016/j. $\underline{\text { scs.2016.10.001 }}$

Marzocchi, W., A. Garcia-Aristizabal, P. Gasparini, M. L. Mastellone, and A. Di Ruocco. 2012. Basic principles of multirisk assessment: a case study in Italy. Natural Hazards 62 (2):551-573. https://doi.org/10.1007/s11069-012-0092-X

Mateo, C. M., N. Hanasaki, D. Komori, K. Tanaka, M. Kiguchi, A. Champathong, T. Sukhapunnaphan, D. Yamazaki, and T. Oki. 2014. Assessing the impacts of reservoir operation to floodplain inundation by combining hydrological, reservoir management, and hydrodynamic models. Water Resources Research 50 (9):7245-7266. https://doi.org/10.1002/2013WR014845

McKinnon, S. 2019. Remembering and forgetting 1974: the 2011 Brisbane floods and memories of an earlier disaster. Geographical Research 57(2):204-214. https://doi. org/10.1111/1745-5871.12335

Mechler, R., and L. M. Bouwer. 2014. Understanding trends and projections of disaster losses and climate change: is vulnerability the missing link? Climatic Change 133:23-35. https://doi. org/10.1007/s10584-014-1141-0

Men, B., Z. Wu, Y. Li, and H. Liu. 2019. Reservoir operation policy based on joint hedging rules. Water 11(3):419. https://doi. org/10.3390/w11030419

Miceli, R., I. Sotgiu, and M. Settanni. 2008. Disaster preparedness and perception of flood risk: a study in an alpine valley in Italy. Journal of Environmental Psychology 28 (2):164-173. https://doi.org/10.1016/j.jenvp.2007.10.006

Micevski, T., S. W. Franks, and G. Kuczera. 2006. Multidecadal variability in coastal eastern Australian flood data. Journal of Hydrology 327(1):219-225. https://doi.org/10.1016/j.jhydrol.2005.11.017

Michaelis, T., L. Brandimarte, and M. Mazzoleni. 2020. Capturing flood-risk dynamics with a coupled agent-based and hydraulic modelling framework. Hydrological Sciences Journal 9:1458-1473. https://doi.org/10.1080/02626667.2020.1750617

Mondino, E., A. Scolobig, M. Borga, F. Albrecht, J. Mård, P. Weyrich, and G. Di Baldassarre. 2020. Exploring changes in hydrogeological risk awareness and preparedness over time: a case study in northeastern Italy. Hydrological Sciences Journal 65 (7):1049-1059. https://doi.org/10.1080/02626667.2020.1729361
Montz, B. E., and G. A. Tobin. 2008. Livin' large with levees: lessons learned and lost. Natural Hazards Review 9(3):150-157. https://doi.org/10.1061/(asce)1527-6988(2008)9:3(150)

Novo, P., and A. Garrido. 2014. From policy design to implementation: an institutional analysis of the new Nicaraguan Water Law. Water Policy 16(6):1009-1030. https://doi. org/10.2166/wp.2014.188

O’Donnell, T. 1985. A direct three-parameter Muskingum procedure incorporating lateral inflow. Hydrological Sciences Journal 30(4):479-496. https://doi.org/10.1080/02626668509491013

Pande, S., and M. Ertsen. 2014. Endogenous change: on cooperation and water availability in two ancient societies. Hydrology and Earth System Sciences 18(5):1745-1760. https:// doi.org/10.5194/hess-18-1745-2014

Pande, S., M. Ertsen, and M. Sivapalan. 2014. Endogenous technological and population change under increasing water scarcity. Hydrology and Earth System Sciences 18(8):3239-3258. https://doi.org/10.5194/hess-18-3239-2014

Pande, S., and M. Sivapalan. 2017. Progress in socio-hydrology: a meta-analysis of challenges and opportunities. WIREs Water 4 (4):e1193. https://doi.org/10.1002/wat2.1193

Penning-Rowsell, E. C. 1996. Flood-hazard response in Argentina. Geographical Review 86:72-90. https://doi. org/10.2307/215142

Penning-Rowsell, E., C. Johnson, and S. Tunstall. 2006. 'Signals' from pre-crisis discourse: lessons from UK flooding for global environmental policy change? Global Environmental Change 16 (4):323-339. https://doi.org/10.1016/j.gloenvcha.2006.01.006

Pianosi, F., K. Beven, J. Freer, J. W. Hall, J. Rougier, D. B. Stephenson, and T. Wagener. 2016. Sensitivity analysis of environmental models: a systematic review with practical workflow. Environmental Modelling and Software 79:214-232. https://doi.org/10.1016/j.envsoft.2016.02.008

Pouladi, P., A. Afshar, M. H. Afshar, A. Molajou, and H. Farahmand. 2019. Agent-based socio-hydrological modeling for restoration of Urmia Lake: application of theory of planned behavior. Journal of Hydrology 576:736-748. https://doi. org/10.1016/j.jhydrol.2019.06.080

Ridolfi, E., F. Albrecht, and G. Di Baldassarre. 2020. Exploring the role of risk perception in influencing flood losses over time. Hydrological Sciences Journal 65(1):12-20. https://doi. org/10.1080/02626667.2019.1677907

Sahin, O., R. S. Siems, R. A. Stewart, and M. G. Porter. 2016. Paradigm shift to enhanced water supply planning through augmented grids, scarcity pricing and adaptive factory water: a system dynamics approach. Environmental Modelling and Software 75:348-361. https://doi.org/10.1016/j.envsoft.2014.05.018

Sandman, P. M. 1989. Hazard versus outrage in the public perception of risk. Pages 45-49 in V. T. Covello, D. B. McCallum, and M. T. Pavlova, editors. Effective risk communication: the role and responsibility of government and nongovernment organizations. Springer, Boston, Massachusetts, USA. https:// doi.org/10.1007/978-1-4613-1569-8_6 
Sarmento Buarque, A. C., N. Bhattacharya-Mis, M. C. Fava, F. A. A. de Souza, and E. M. Mendiondo. 2020. Using historical source data to understand urban flood risk: a socio-hydrological modelling application at Gregório Creek, Brazil. Hydrological Sciences Journal 65:1075-1083. https://doi.org/10.1080/02626667.2020.1740705

Schlüter, M., B. Müller, and K. Frank. 2019. The potential of models and modeling for social-ecological systems research: the reference frame ModSES. Ecology and Society 24(1):31. https:// doi.org/10.5751/es-10716-240131

Scolobig, A., B. De Marchi, and M. Borga. 2012. The missing link between flood risk awareness and preparedness: findings from case studies in an Alpine Region. Natural Hazards 63 (2):499-520. https://doi.org/10.1007/s11069-012-0161-1

Scott, C. A. 2011. The water-energy-climate nexus: resources and policy outlook for aquifers in Mexico. Water Resources Research 47(6). https://doi.org/10.1029/2011WR010805

Seqwater. 2011. Flood event: report on the operation of Somerset Dam and Wivenhoe Dam. Seqwater, Brisbane, Queensland, Australia. [online] URL: http://www.floodcommission.qld.gov. au/ data/assets/pdf file/0017/4292/QFCI Exhibit 24 January2011_Flood_Event_Report_on_the_Operation_of_Somerset_and Wivenhoe.pdf

Seqwater. 2017. Water for life South East Queensland's Water Security Program. Seqwater, Brisbane, Queensland, Australia. [online] URL: https://www.seqwater.com.au/sites/default/files/2019-08/ Water $\% 20$ for $\% 20$ life Water $\% 20$ Security $\% 20$ Program.pdf

Seqwater. 2019. Wivenhoe Dam and Somerset Dam: manual of operational procedures for flood mitigation. Seqwater, Brisbane, Queensland, Australia.

Shahid, S., and H. Behrawan. 2008. Drought risk assessment in the western part of Bangladesh. Natural Hazards 46(3):391-413. https://doi.org/10.1007/s11069-007-9191-5

Shiau, J.-T. 2009. Optimization of reservoir hedging rules using multiobjective genetic algorithm. Journal of Water Resources Planning and Management 135(5):355-363. https://doi. org/10.1061/(ASCE)0733-9496(2009)135:5(355)

Shiau, J.-T. 2011. Analytical optimal hedging with explicit incorporation of reservoir release and carryover storage targets. Water Resources Research 47(1). https://doi.org/10.1029/2010WR009166

Shih, J.-S., and C. ReVelle. 1994. Water-supply operations during drought: continuous hedging rule. Journal of Water Resources Planning and Management 120(5):613-629. https://doi. org/10.1061/(asce)0733-9496(1994)120:5(613)

Slovic, P. 1987. Perception of risk. Science 236(4799):280-285. https://doi.org/10.1126/science.3563507

Slovic, P., M. L. Finucane, E. Peters, and D. G. MacGregor. 2004. Risk as analysis and risk as feelings: some thoughts about affect, reason, risk, and rationality. Risk Analysis 24(2):311-322. https:// doi.org/10.1111/j.0272-4332.2004.00433.X

Smith, I., and C. McAlpine. 2014. Estimating future changes in flood risk: case study of the Brisbane River, Australia. Climate Risk Management 6:6-17. https://doi.org/10.1016/j.crm.2014.11.002
Smyth, C., and L. Toombes. 2015. Data, rating curve and historical flood review report. Brisbane River catchment flood study - comprehensive hydrologic assessment. State of Queensland, Department of Natural Resources, Brisbane, Queensland, Australia. [online] URL: https://www.publications. qld.gov.au/dataset/brisbane-river-catchment-flood-study/ resource/8f6782fd-676b-4526-a524-d577fb233e 5d? truncate $=30 \&$ inner span $=$ True

Srinivasan, V., S. M. Gorelick, and L. Goulder. 2010. A hydrologic-economic modeling approach for analysis of urban water supply dynamics in Chennai, India. Water Resources Research 46(7). https://doi.org/10.1029/2009WR008693

Sterle, K., B. J. Hatchett, L. Singletary, and G. Pohll. 2019. Hydroclimate variability in snow-fed river systems: local water managers' perspectives on adapting to the new normal. Bulletin of the American Meteorological Society 100(6):1031-1048. https://doi.org/10.1175/BAMS-D-18-0031.1

Sterle, K., and L. Singletary. 2017. Adapting to variable water supply in the Truckee-Carson River system, Western USA. Water 9(10):768. https://doi.org/10.3390/w9100768

Sterman, J. 2002. System dynamics: systems thinking and modeling for a complex world. Working Paper. Massachusetts Institute of Technology, Engineering Systems Division, Cambridge, Massachusetts, USA. [online] URL: https://dspace. mit.edu/handle/1721.1/102741

Su, Y., F. Zhao, and L. Tan. 2015. Whether a large disaster could change public concern and risk perception: a case study of the $7 / 21$ extraordinary rainstorm disaster in Beijing in 2012. Natural Hazards 78(1):555-567. https://doi.org/10.1007/s11069-015-1730$\underline{x}$

Thieken, A., S. Kienzler, H. Kreibich, C. Kuhlicke, M. Kunz, B. Mühr, M. Müller, A. Otto, T. Petrow, S. Pisi, and K. Schröter. 2016. Review of the flood risk management system in Germany after the major flood in 2013. Ecology and Society 21(2):51. https://doi.org/10.5751/es-08547-210251

Tonn, G. L., and S. D. Guikema. 2018. An agent-based model of evolving community flood risk. Risk Analysis 38(6):1258-1278. https://doi.org/10.1111/risa.12939

Van den Honert, R. C., and J. McAneney. 2011. The 2011 Brisbane floods: causes, impacts and implications. Water 3(4):1149-1173. https://doi.org/10.3390/w3041149

van Dijk, A. I. J. M., H. E. Beck, R. S. Crosbie, R. A. M. de Jeu, Y. Y. Liu, G. M. Podger, B. Timbal, and N. R. Viney. 2013. The Millennium Drought in southeast Australia (2001-2009): natural and human causes and implications for water resources, ecosystems, economy, and society. Water Resources Research 49 (2):1040-1057. https://doi.org/10.1002/wrcr.20123

van Emmerik, T. H. M., Z. Li, M. Sivapalan, S. Pande, J. Kandasamy, H. H. G. Savenije, A. Chanan, and S. Vigneswaran. 2014. Socio-hydrologic modeling to understand and mediate the competition for water between agriculture development and environmental health: Murrumbidgee River basin, Australia. Hydrology and Earth System Sciences 18(10):4239-4259. https:// doi.org/10.5194/hess-18-4239-2014 
Van Loon, A. F., T. Gleeson, J. Clark, A. I. J. M. Van Dijk, K. Stahl, J. Hannaford, G. Di Baldassarre, A. J. Teuling, L. M. Tallaksen, R. Uijlenhoet, D. M. Hannah, J. Sheffield, M. Svoboda, B. Verbeiren, T. Wagener, S. Rangecroft, N. Wanders, and H. A. J. Van Lanen. 2016. Drought in the Anthropocene. Nature Geoscience 9(2):89-91. https://doi.org/10.1038/ngeo2646

Viglione, A., G. Di Baldassarre, L. Brandimarte, L. Kuil, G. Carr, J. L. Salinas, A. Scolobig, and G. Blöschl. 2014. Insights from socio-hydrology modelling on dealing with flood risk - roles of collective memory, risk-taking attitude and trust. Journal of Hydrology 518:71-82. https://doi.org/10.1016/j.jhydrol.2014.01.018

Vörösmarty, C. J., C. Pahl-Wostl, S. E. Bunn, and R. Lawford. 2013. Global water, the anthropocene and the transformation of a science. Current Opinion in Environmental Sustainability 5 (6):539-550. https://doi.org/10.1016/j.cosust.2013.10.005

Wallington, K., and X. Cai. 2020. Feedback between reservoir operation and floodplain development: implications for reservoir benefits and beneficiaries. Water Resources Research 56(4): e24524. https://doi.org/10.1029/2019WR026610

Wang, J., T. Hu, X. Zeng, and M. Yasir. 2018. Storage targets optimization embedded with analytical hedging rule for reservoir water supply operation. Water Supply 18(2):622-629. https://doi. org/10.2166/ws.2017.145

Wens, M., J. M. Johnson, C. Zagaria, and T. I. E. Veldkamp. 2019. Integrating human behavior dynamics into drought risk assessment - a sociohydrologic, agent-based approach. WIREs Water 6(4):e1345. https://doi.org/10.1002/wat2.1345

Wind, H. G., T. M. Nierop, C. J. de Blois, and J. L. de Kok. 1999. Analysis of flood damages from the 1993 and 1995 Meuse Floods. Water Resources Research 35(11):3459-3465. https://doi. org/10.1029/1999WR900192

Winder, N., B. S. McIntosh, and P. Jeffrey. 2005. The origin, diagnostic attributes and practical application of co-evolutionary theory. Ecological Economics 54(4):347-361. https://doi. org/10.1016/j.ecolecon.2005.03.017

Winsemius, H. C., J. C. J. H. Aerts, L. P. H. van Beek, M. F. P. Bierkens, A. Bouwman, B. Jongman, J. C. J. Kwadijk, W. Ligtvoet, P. L. Lucas, D. P. van Vuuren, and P. J. Ward. 2016. Global drivers of future river flood risk. Nature Climate Change 6(4):381-385. https://doi.org/10.1038/nclimate2893

You, J.-Y., and X. Cai. 2008. Hedging rule for reservoir operations: 1. a theoretical analysis. Water Resources Research 44(1). https:// doi.org/10.1029/2006wr005481

Yu, D., H. Chang, T. T. Davis, V. Hillis, L. T. Marston, W. S. Oh, M. Sivapalan, and T. M. Waring. 2020. Socio-hydrology: an interplay of design and self-organization in a multilevel world. Ecology and Society 25(4):22. https://doi.org/10.5751/es-11887-250422

Yu, D. J., N. Sangwan, K. Sung, X. Chen, and V. Merwade. 2017. Incorporating institutions and collective action into a sociohydrological model of flood resilience. Water Resources Research 53(2):1336-1353. https://doi.org/10.1002/2016WR019746
Zhao, J., X. Cai, and Z. Wang. 2011. Optimality conditions for a two-stage reservoir operation problem. Water Resources Research 47(8). https://doi.org/10.1029/2010WR009971 


\section{Appendix 1}

\section{Contents of this file}

1. Mean monthly and maximum monthly and daily river flow of the historical and synthetic series

2. Percent error in the variation and discrepancy coefficient between observed water level $(\mathrm{WL})$, reservoir volume $(\mathrm{P})$, and population $(\mathrm{P})$ with the simulated ones.

3. Maximum monthly and daily river flow of additional six river flow scenarios

4. Results of the analyses with the additional six river flow scenarios

5. Mean values of model outcomes with the additional six river flow scenarios 


\section{Mean monthly and maximum daily river flow of the historical and synthetic series}
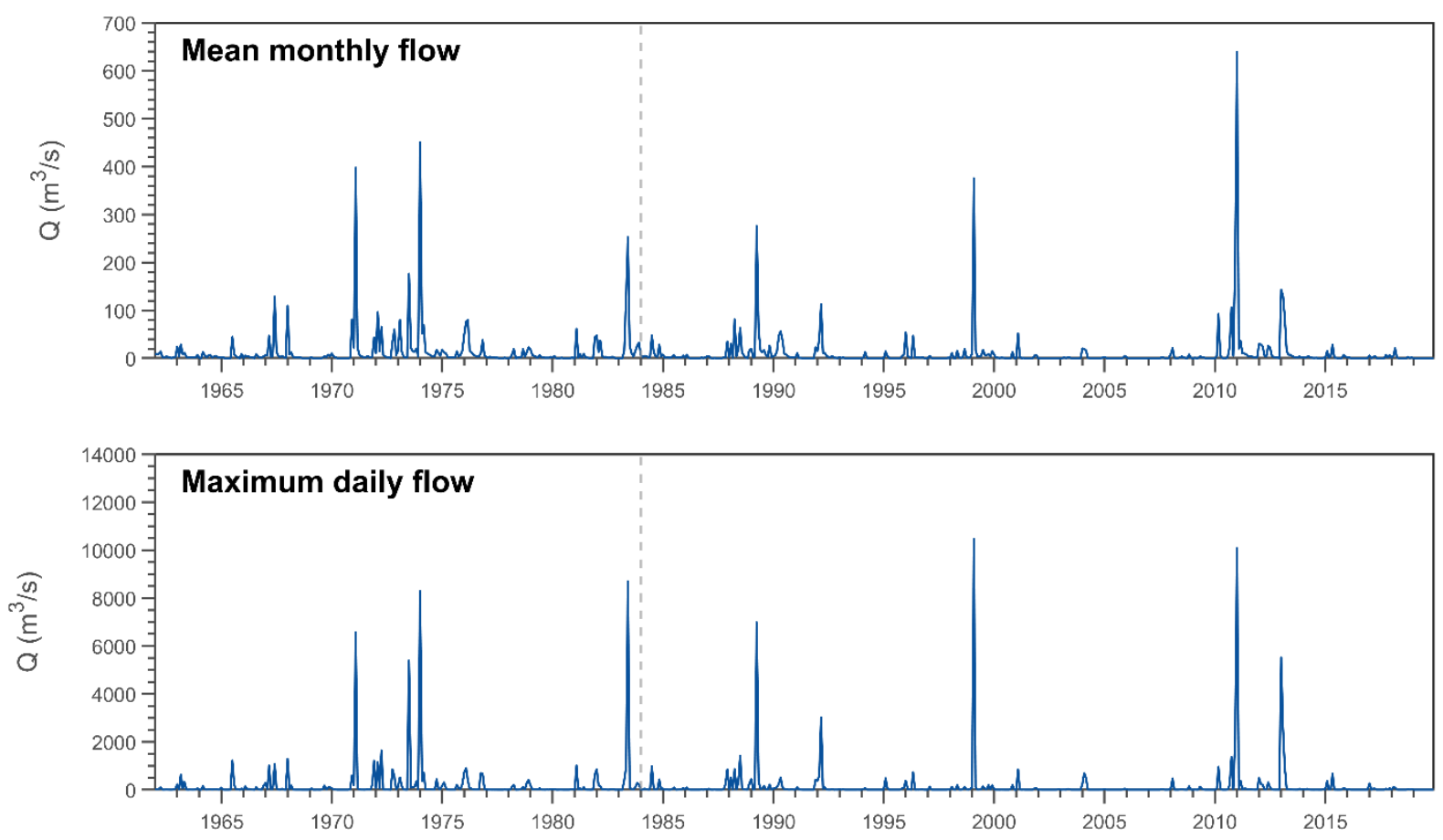

Figure A1. Mean monthly (top) and maximum daily (top) observed inflow hydrographs of the Brisbane River at Gregors Creek. The dashed line indicates the construction of the Wivenhoe Dam.
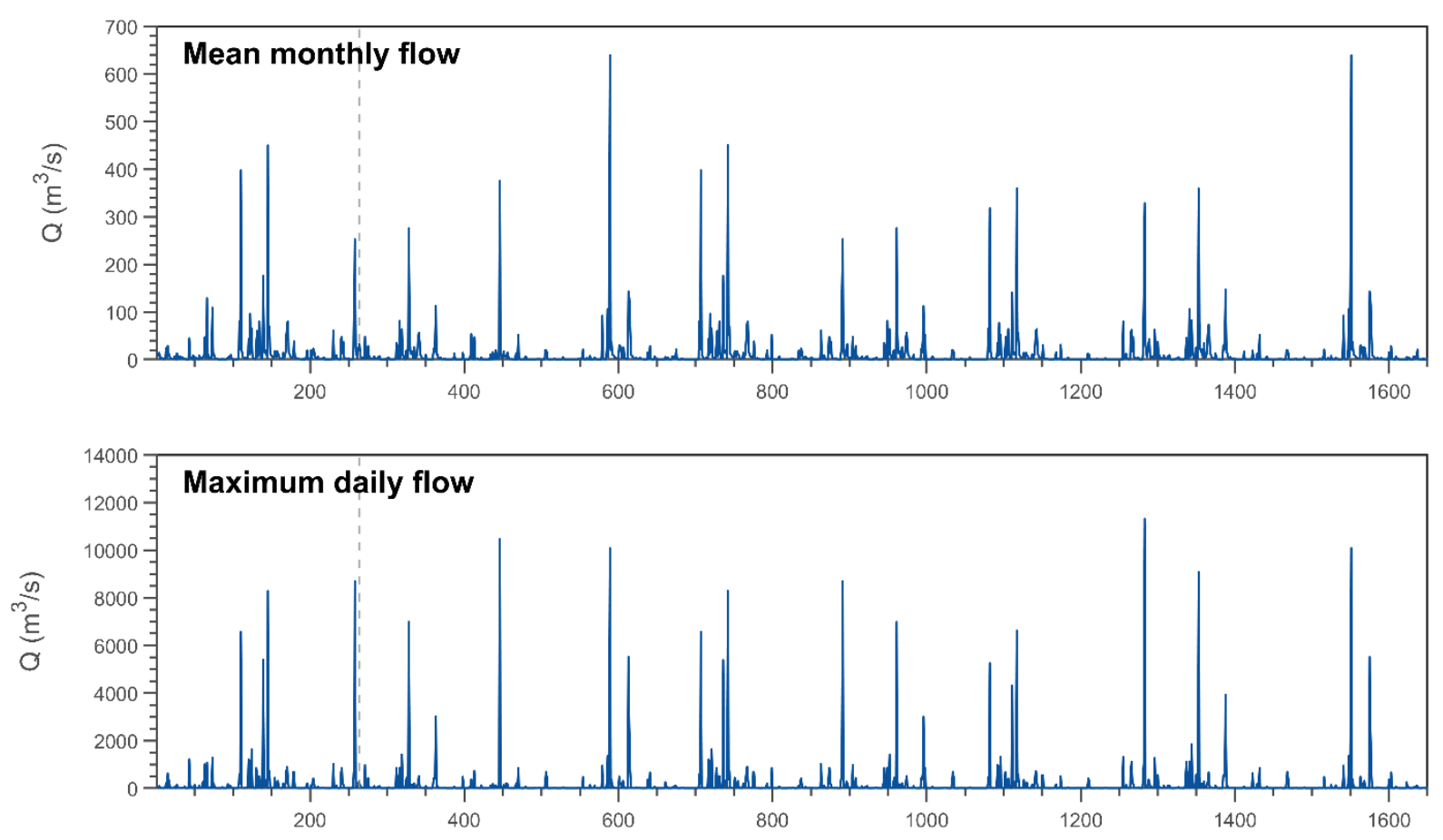

Figure A2. Mean monthly (top) and maximum daily (bottom) synthetic inflow hydrographs. The dashed line indicates the construction of the Wivenhoe Dam. 
Percent Error in the variation (PE), and Discrepancy Coefficient (DC) between observed water level (WL), reservoir volume (P), and population $(P)$ with the simulated ones.

Table A1. Percent error in the variation and discrepancy coefficient values of water level (WL), reservoir volume $(P)$, and population $(P)$ for the different water management strategies $(N A$ : No Actions; FF: Fighting Floods; WC: Water Conservation; WE: Water Exploitation)

\begin{tabular}{ccccccccc}
\hline & \multicolumn{4}{c}{ Percent error in the variation } & \multicolumn{3}{c}{ Discrepancy coefficient } \\
\hline Model variable & NA & FF & WC & WE & NA & FF & WC & WE \\
\hline W $\boldsymbol{L}$ & 0.66 & 0.64 & 0.63 & 0.67 & 0.75 & 0.74 & 0.73 & 0.75 \\
$\boldsymbol{V}$ & 0.12 & 0.01 & 0.22 & 0.18 & 0.44 & 0.45 & 0.43 & 0.44 \\
$\boldsymbol{P}$ & 0.08 & 0.12 & 0.00 & 0.08 & 0.06 & 0.06 & 0.09 & 0.06 \\
\hline
\end{tabular}




\section{Maximum monthly and daily river flow of additional six river flow scenarios}
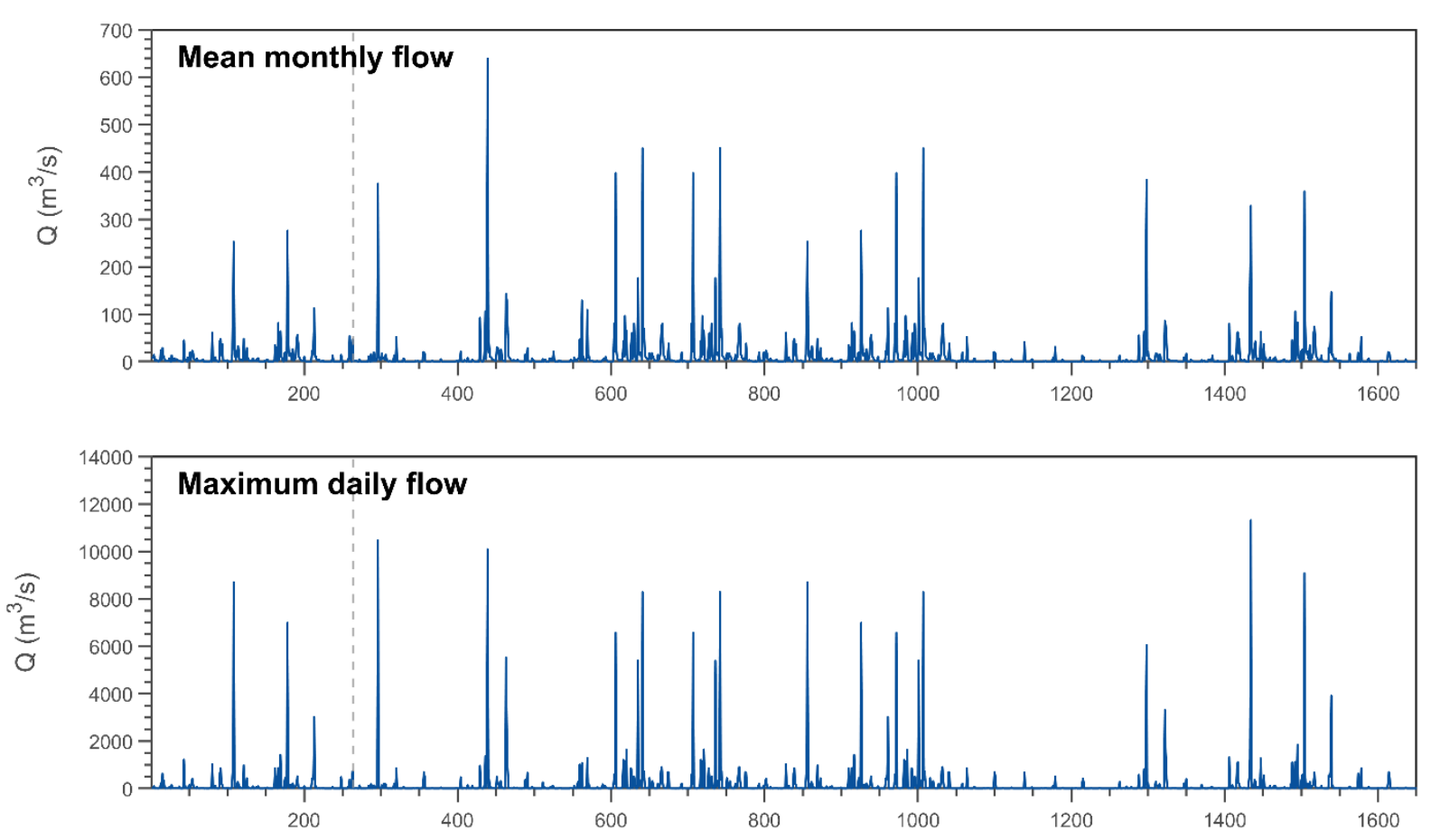

Figure A3. Mean monthly (top) and maximum daily (bottom) synthetic inflow hydrographs of additional scenario \#1. The dashed line indicates the construction of the Wivenhoe Dam.
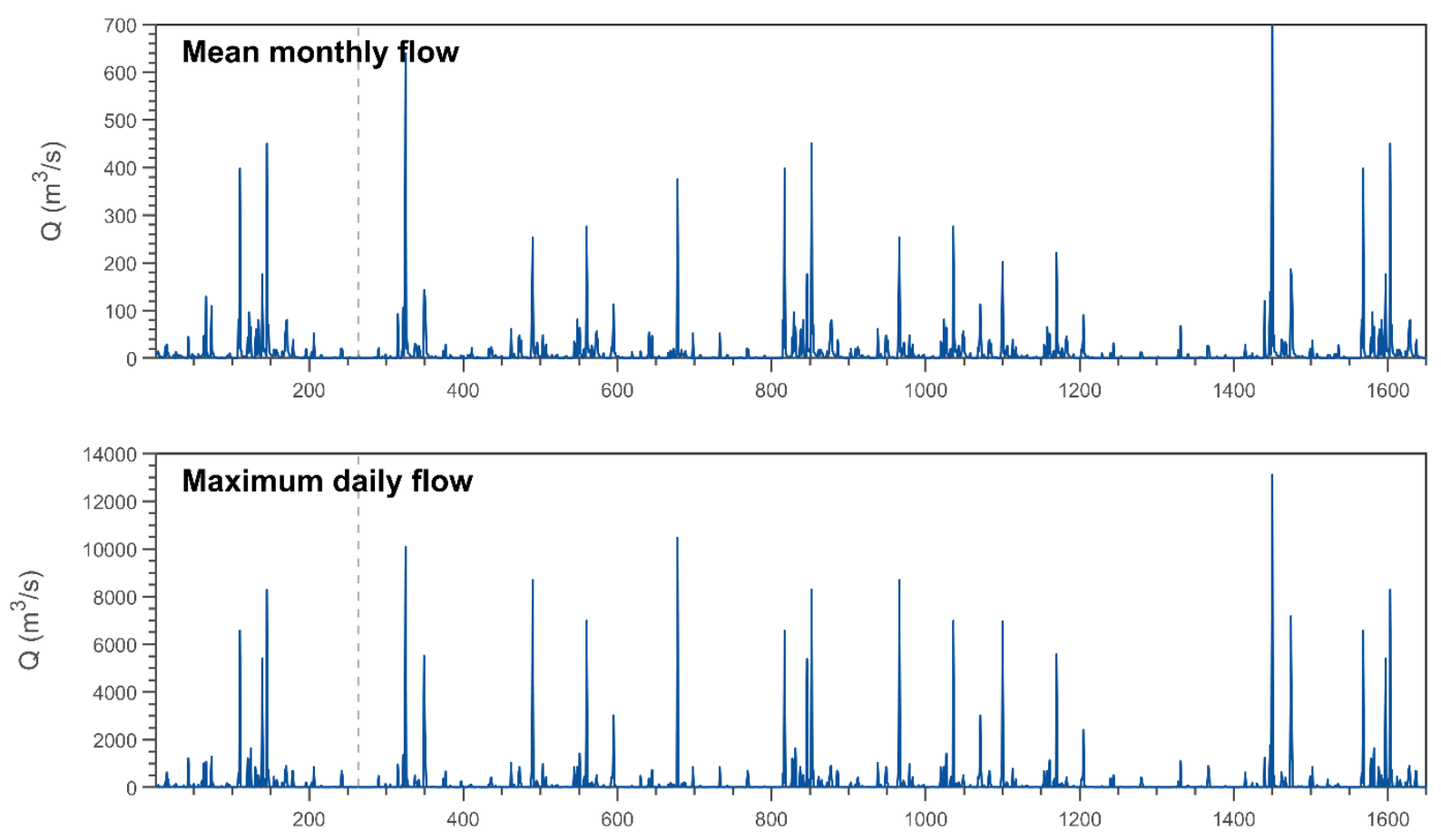

Figure A4. Mean monthly (top) and maximum daily (bottom) synthetic inflow hydrographs of additional scenario \#2. The dashed line indicates the construction of the Wivenhoe Dam. 

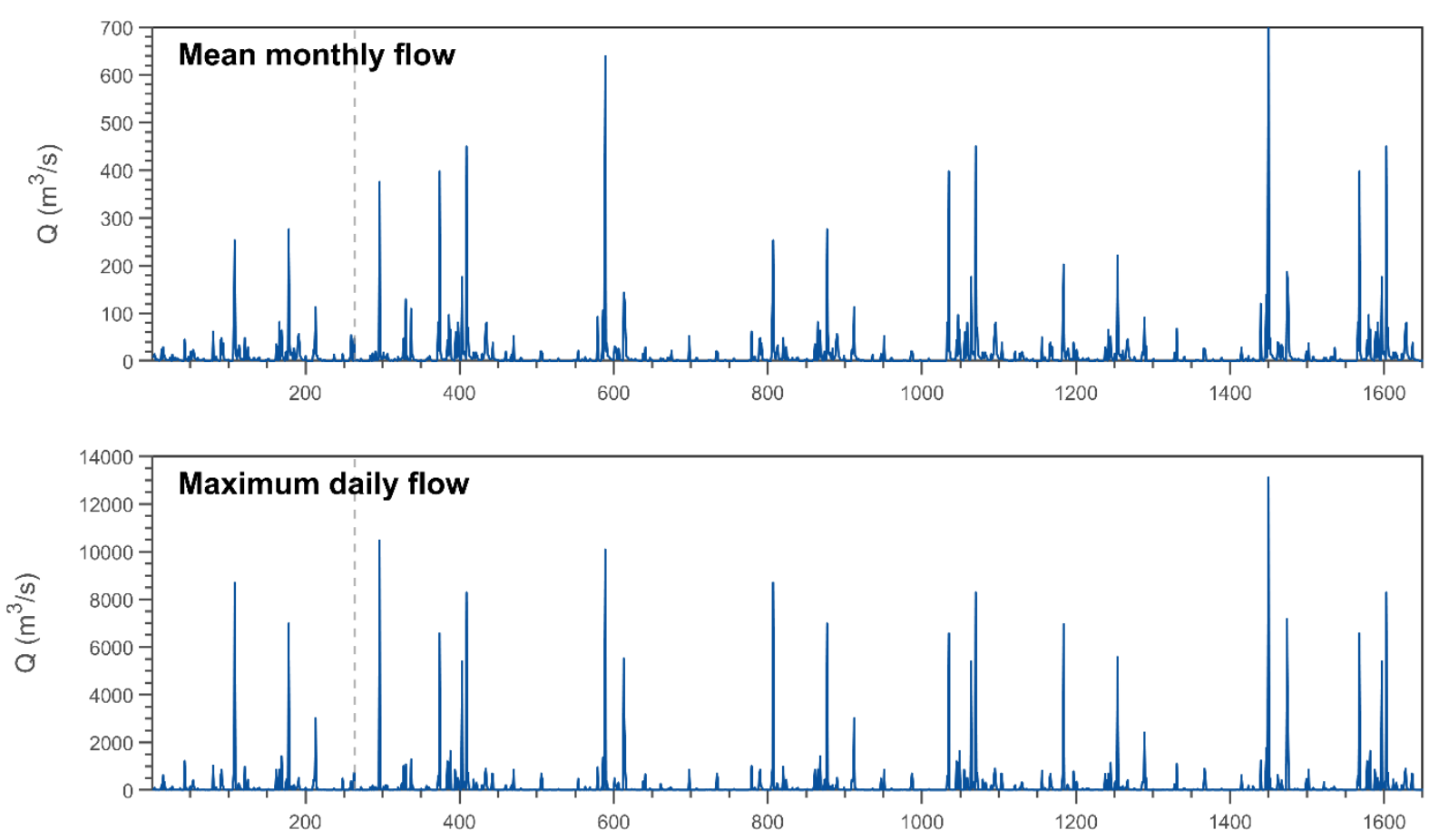

Figure A5. Mean monthly (top) and maximum daily (bottom) synthetic inflow hydrographs of additional scenario \#3. The dashed line indicates the construction of the Wivenhoe Dam.
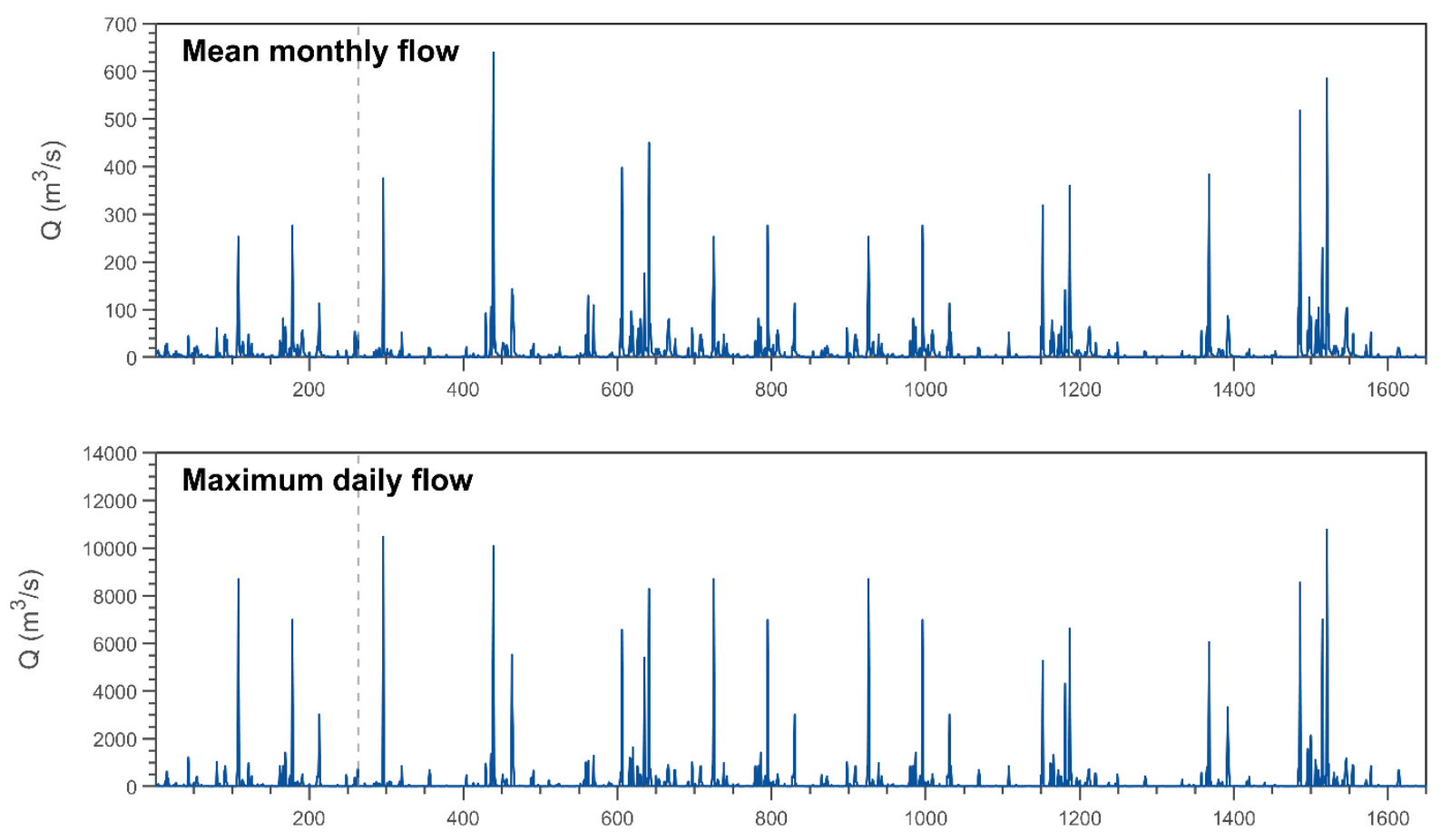

Figure A6. Mean monthly (top) and maximum daily (bottom) synthetic inflow hydrographs of additional scenario \#4. The dashed line indicates the construction of the Wivenhoe Dam. 

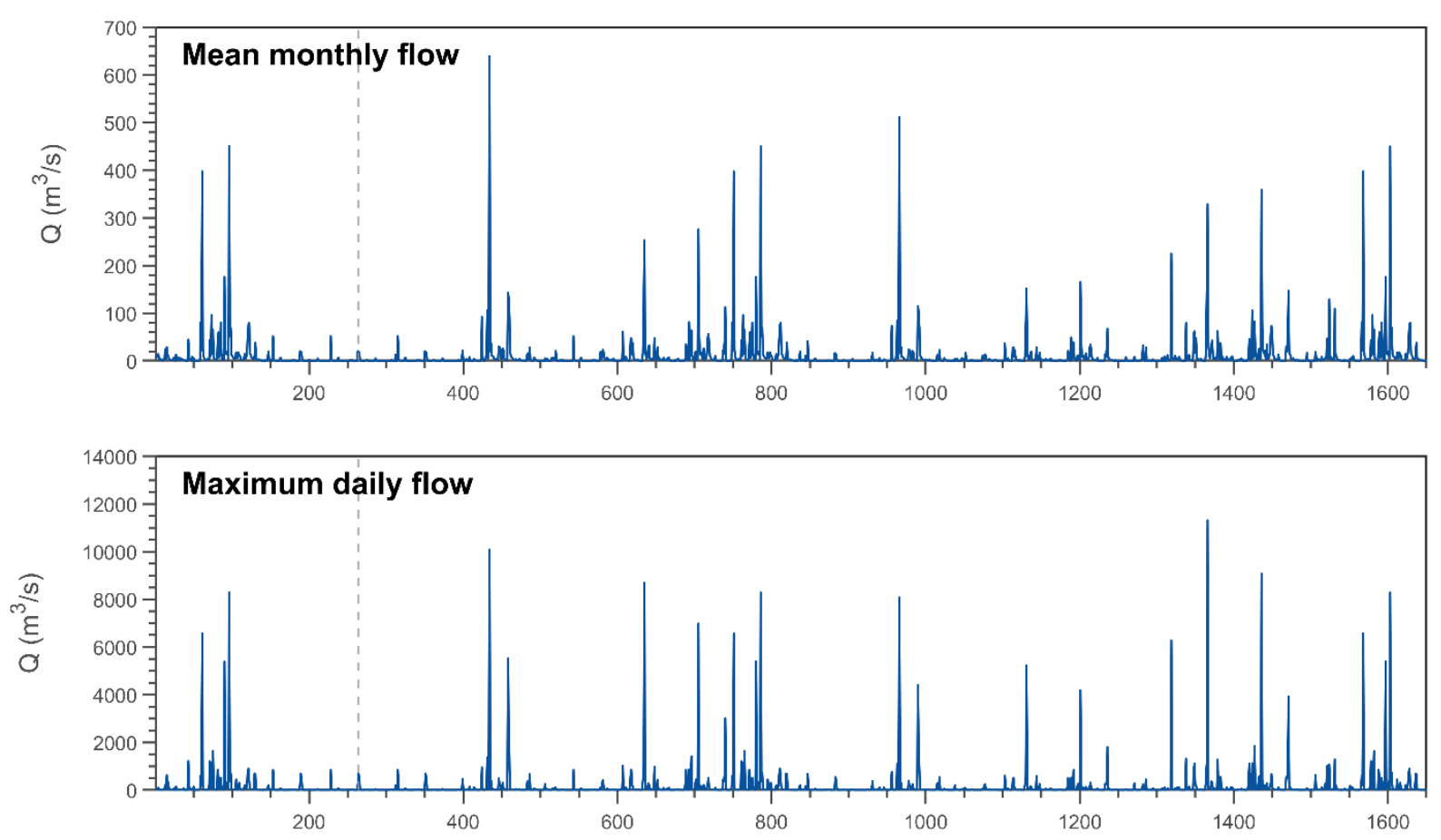

Figure A7. Mean monthly (top) and maximum daily (bottom) synthetic inflow hydrographs of additional scenario \#5. The dashed line indicates the construction of the Wivenhoe Dam.
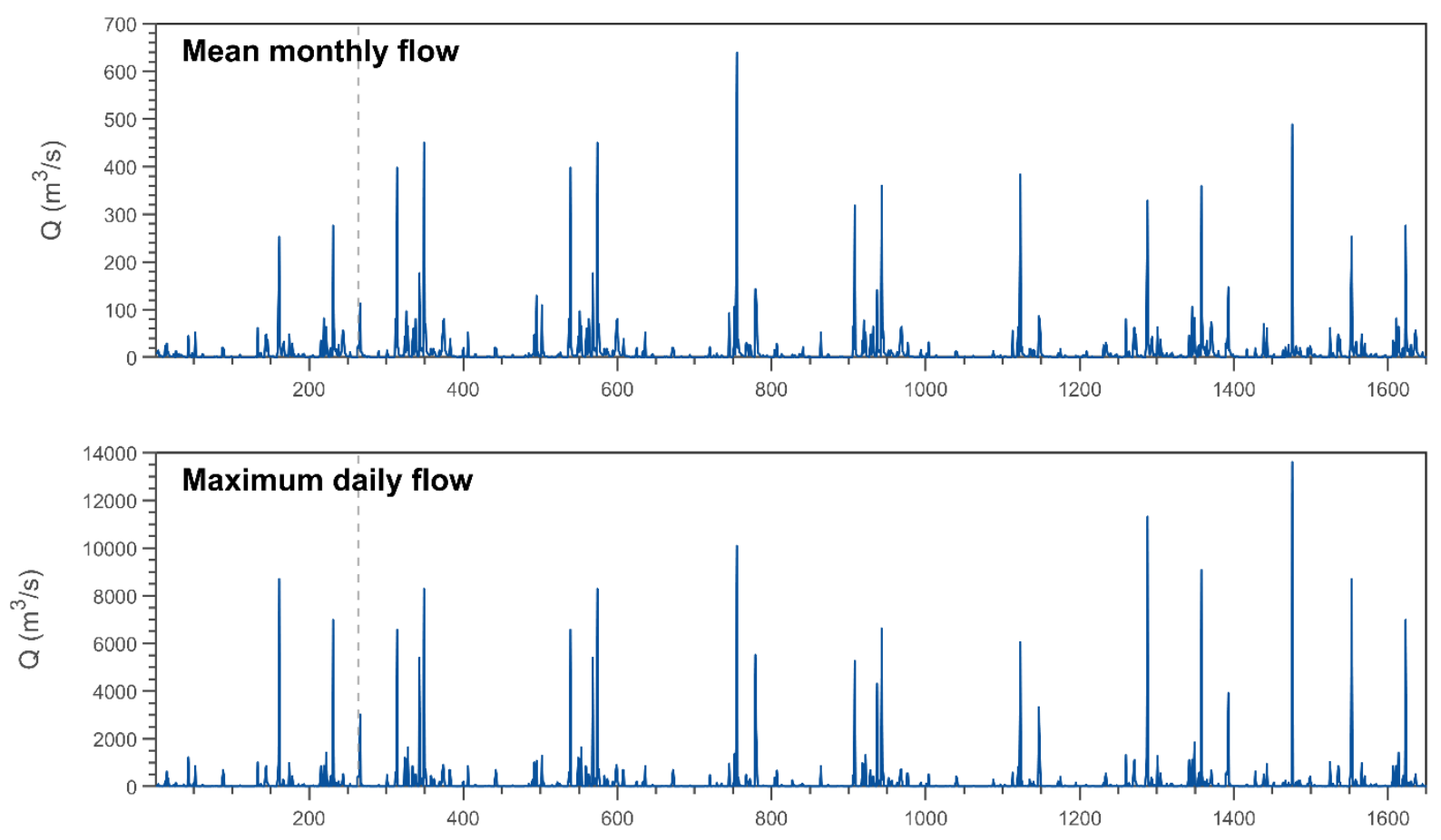

Figure A8. Mean monthly (top) and maximum daily (bottom) synthetic inflow hydrographs of additional scenario \#6. The dashed line indicates the construction of the Wivenhoe Dam. 


\section{Results of the analyses with the additional six river flow scenarios}
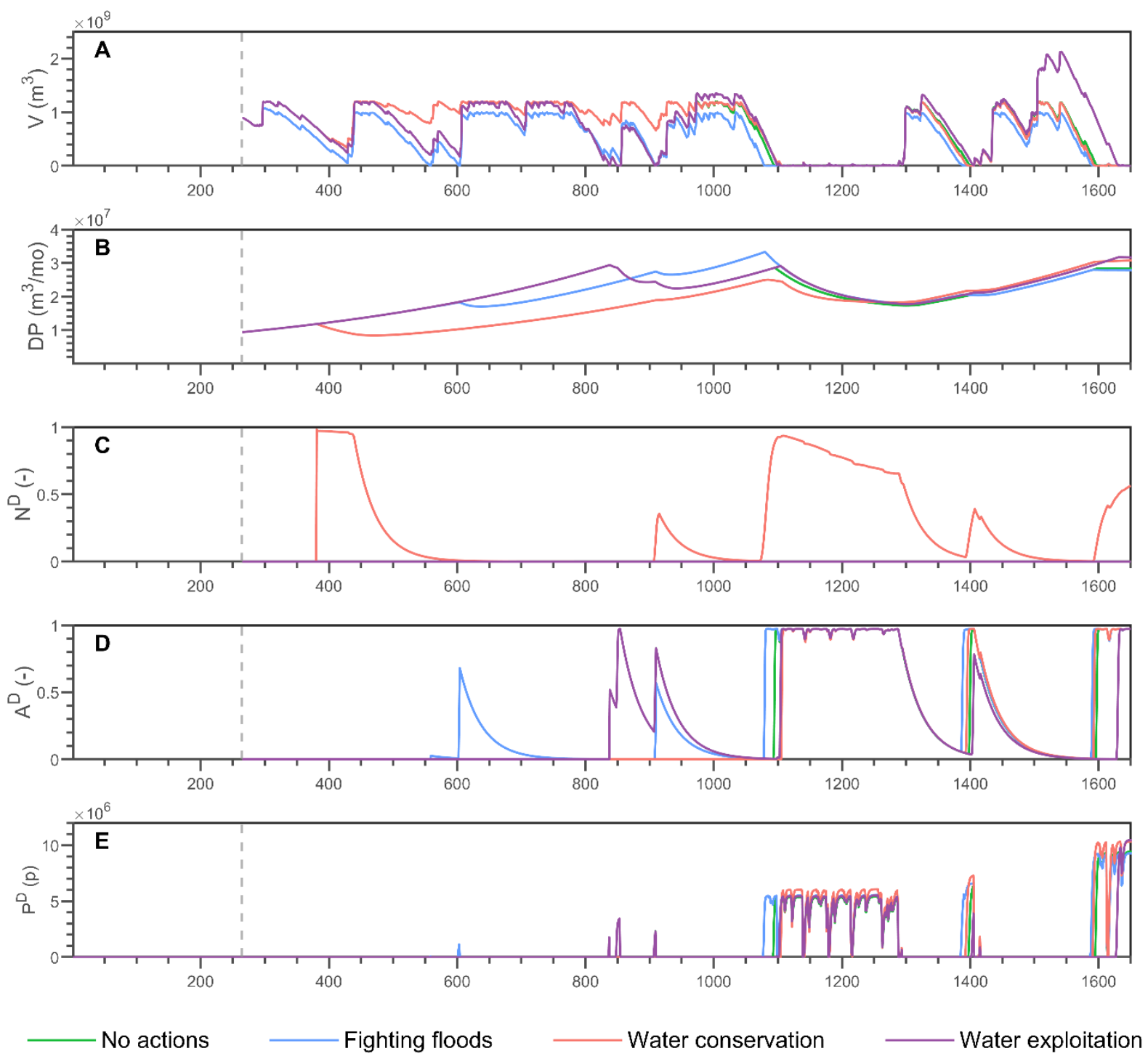

Figure A9. Water shortage-based variables of the synthetic experiments additional scenario \#1 considering dam construction and human-flood interactions with the four water management strategies introduced in this study. (A) reservoir volume (V), (B) total water demand (DP), $(C)$ willingness to the new per-capita demand (ND), (D) drought awareness $(A D)$, and $(E)$ population affected by droughts $(P D)$. The grey dashed line indicates the construction of the Wivenhoe Dam. 

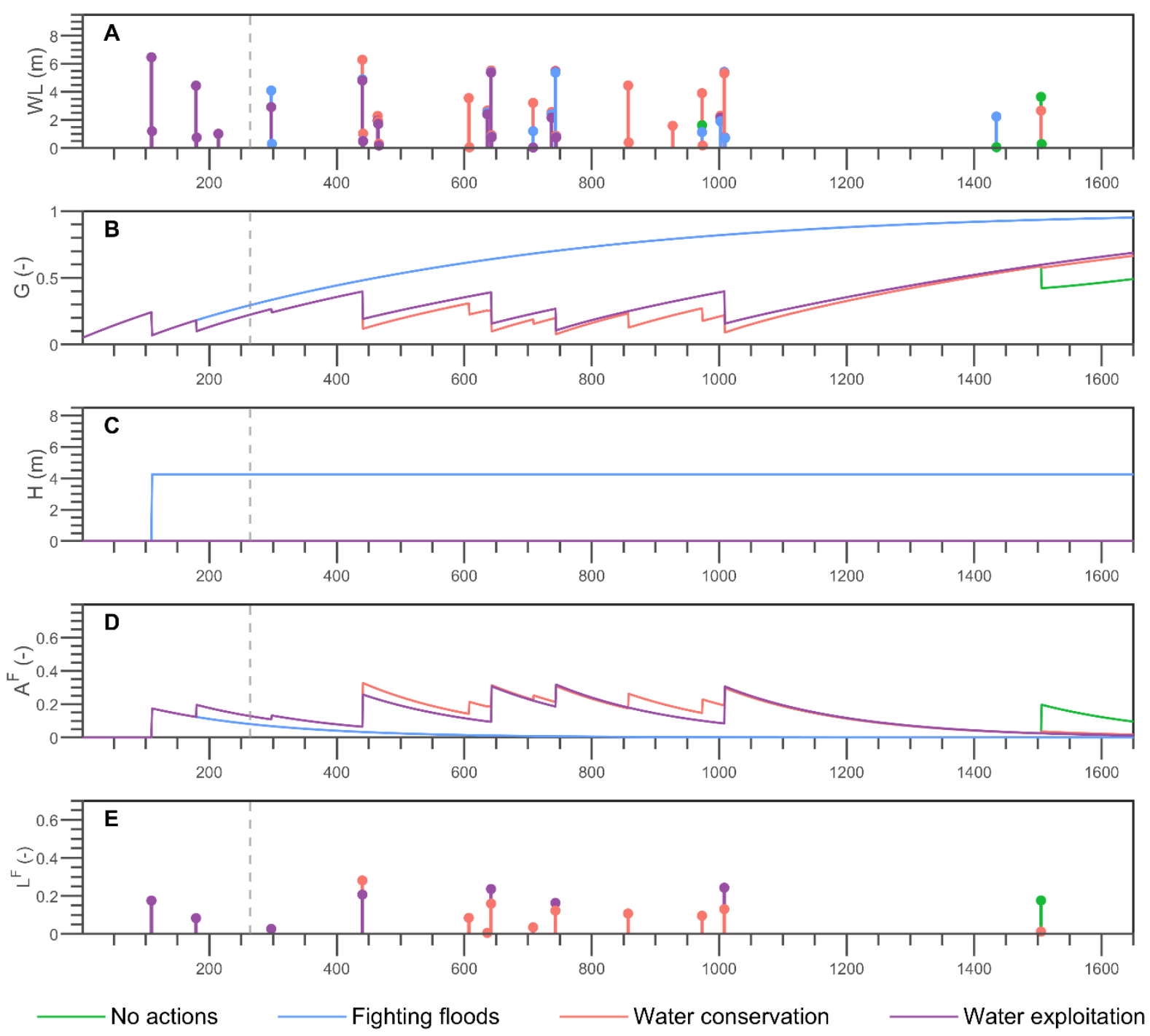

Figure A10. Flooding-based variables of the synthetic experiments additional scenario \#1 considering dam construction and human-flood interactions with the four water management strategies introduced in this study. (A) Water level (WL), (B) proportion of population in floodplain $(G),(C)$ levee height $(H)$, (D) flood awareness $(A F)$, and (E) flood losses $(L F)$. The grey dashed line indicates the construction of the Wivenhoe Dam. 

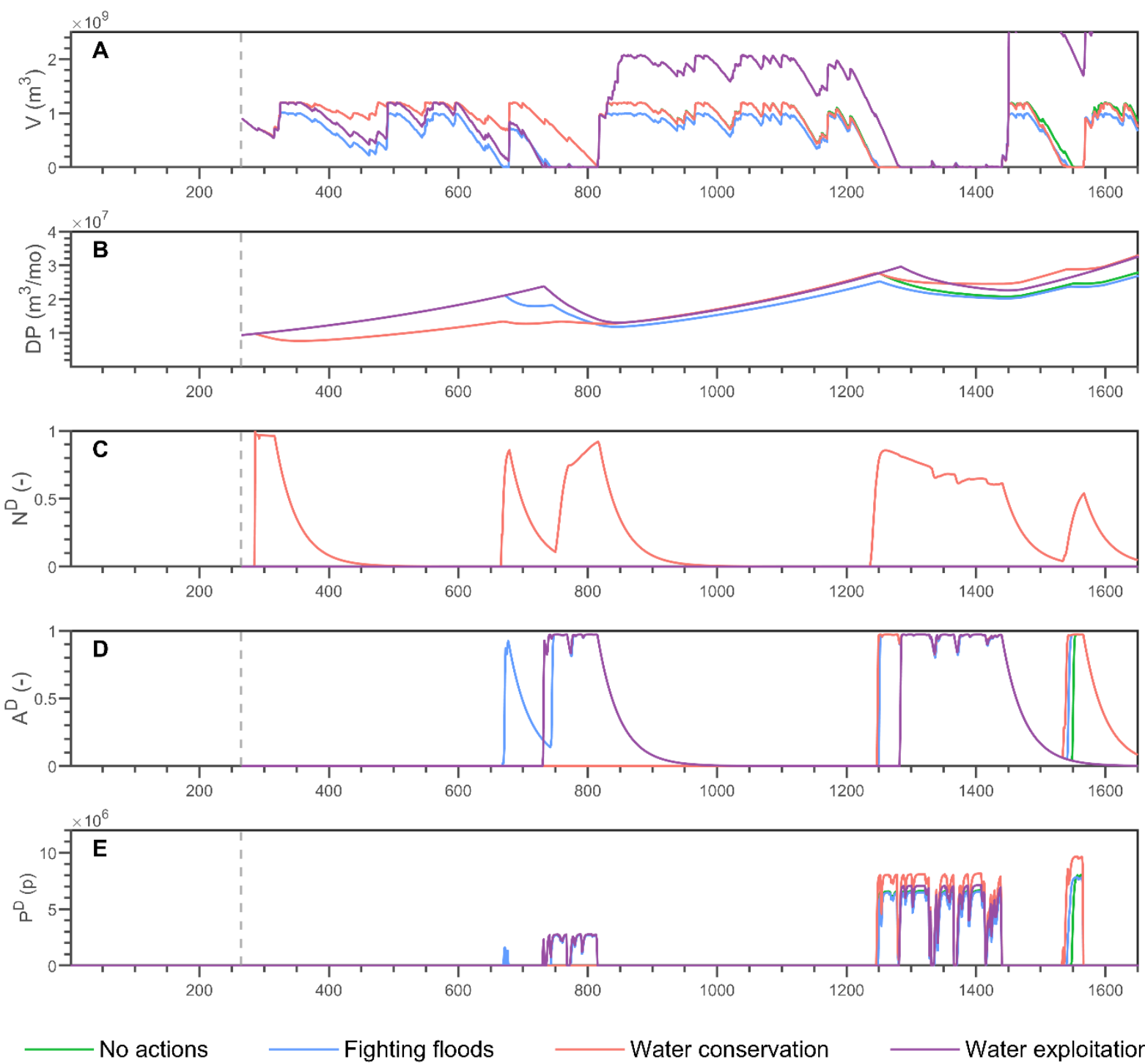

Fighting floods

- Water conservation

Water exploitation

Figure A11. Water shortage-based variables of the synthetic experiments additional scenario \#2 considering dam construction and human-flood interactions with the four water management strategies introduced in this study. (A) reservoir volume (V), (B) total water demand (DP), (C) willingness to the new per-capita demand (ND), (D) drought awareness $(A D)$, and $(E)$ population affected by droughts $(P D)$. The grey dashed line indicates the construction of the Wivenhoe Dam. 

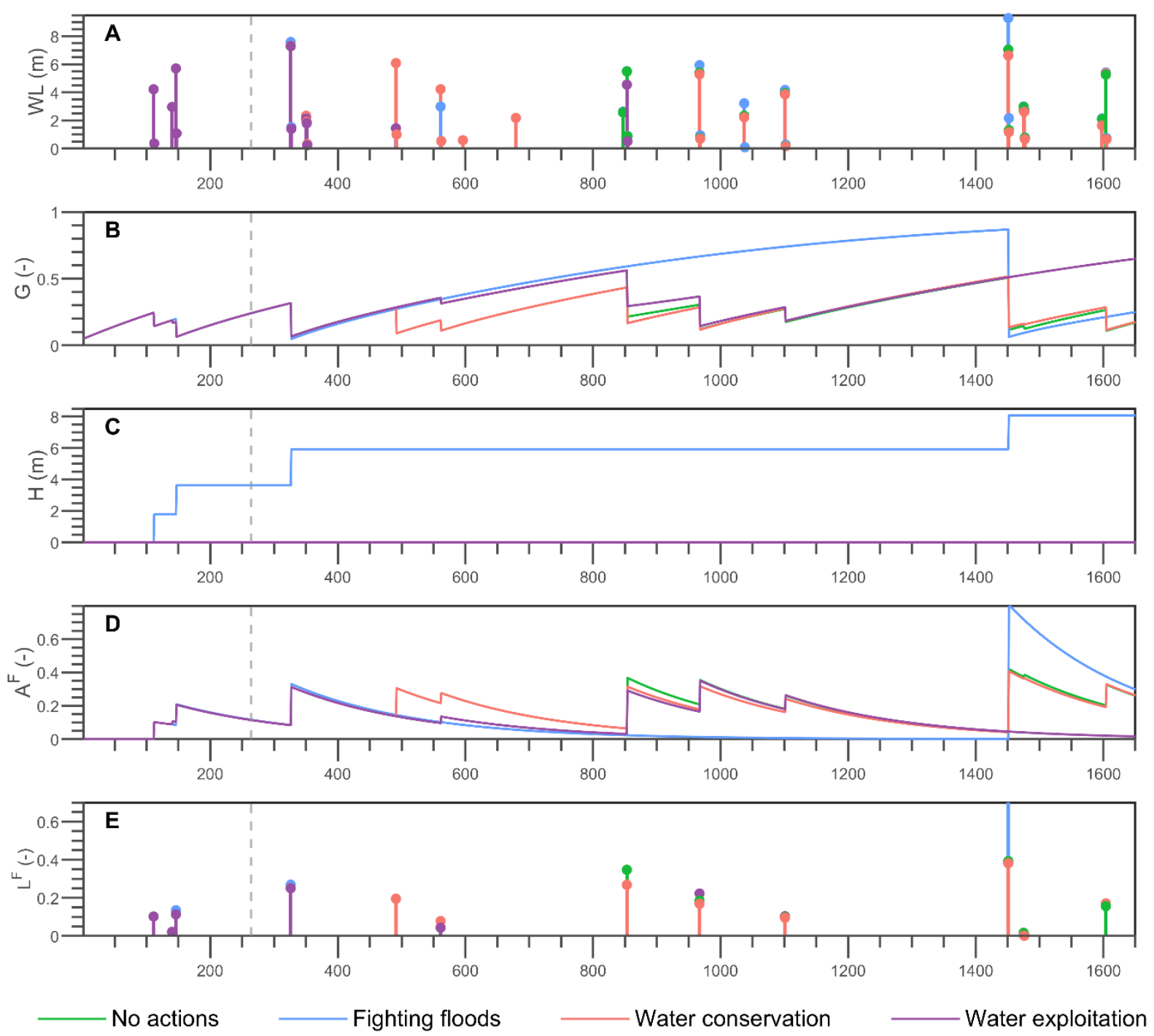

Figure A12. Flooding-based variables of the synthetic experiments additional scenario \#2 considering dam construction and human-flood interactions with the four water management strategies introduced in this study. (A) Water level (WL), (B) proportion of population in floodplain $(G),(C)$ levee height $(H)$, (D) flood awareness $(A F)$, and (E) flood losses $(L F)$. The grey dashed line indicates the construction of the Wivenhoe Dam. 

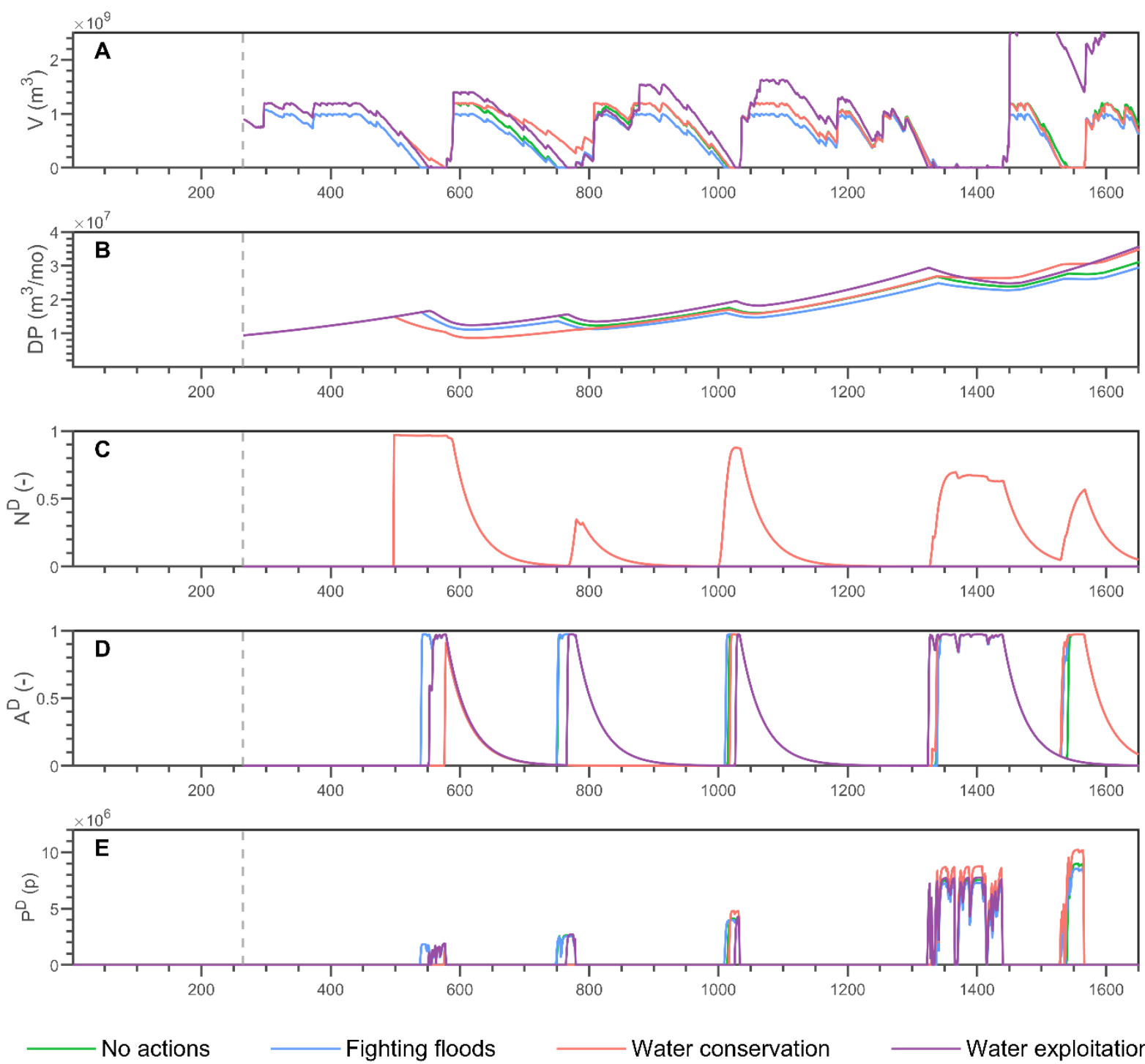

Fighting floods

- Water conservation

Water exploitation

Figure A13. Water shortage-based variables of the synthetic experiments additional scenario \#3 considering dam construction and human-flood interactions with the four water management strategies introduced in this study. (A) reservoir volume (V), (B) total water demand (DP), (C) willingness to the new per-capita demand (ND), (D) drought awareness $(A D)$, and $(E)$ population affected by droughts $(P D)$. The grey dashed line indicates the construction of the Wivenhoe Dam. 

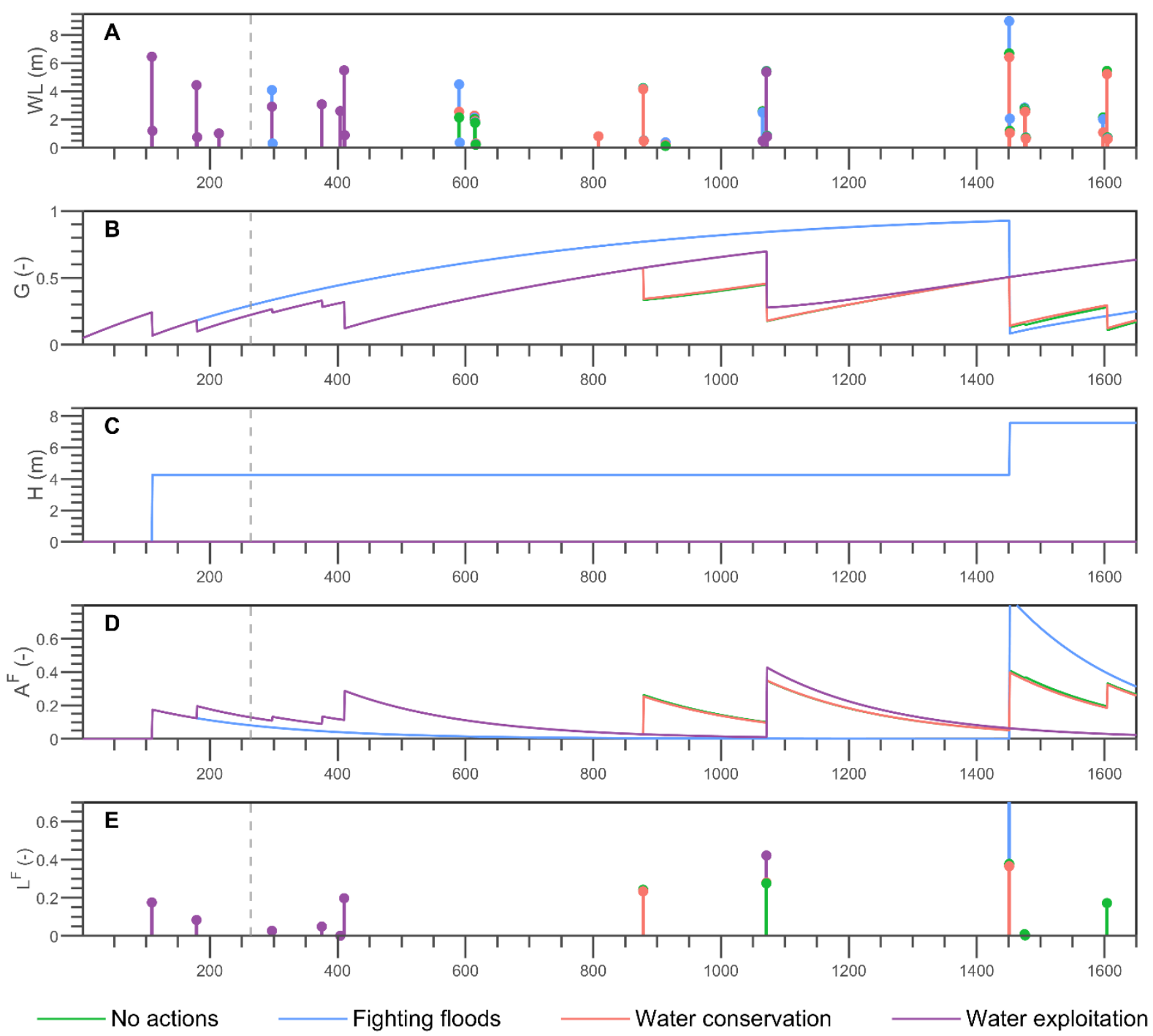

Figure A14. Flooding-based variables of the synthetic experiments additional scenario \#3 considering dam construction and human-flood interactions with the four water management strategies introduced in this study. (A) Water level (WL), (B) proportion of population in floodplain $(G),(C)$ levee height $(H)$, (D) flood awareness $(A F)$, and (E) flood losses $(L F)$. The grey dashed line indicates the construction of the Wivenhoe Dam. 

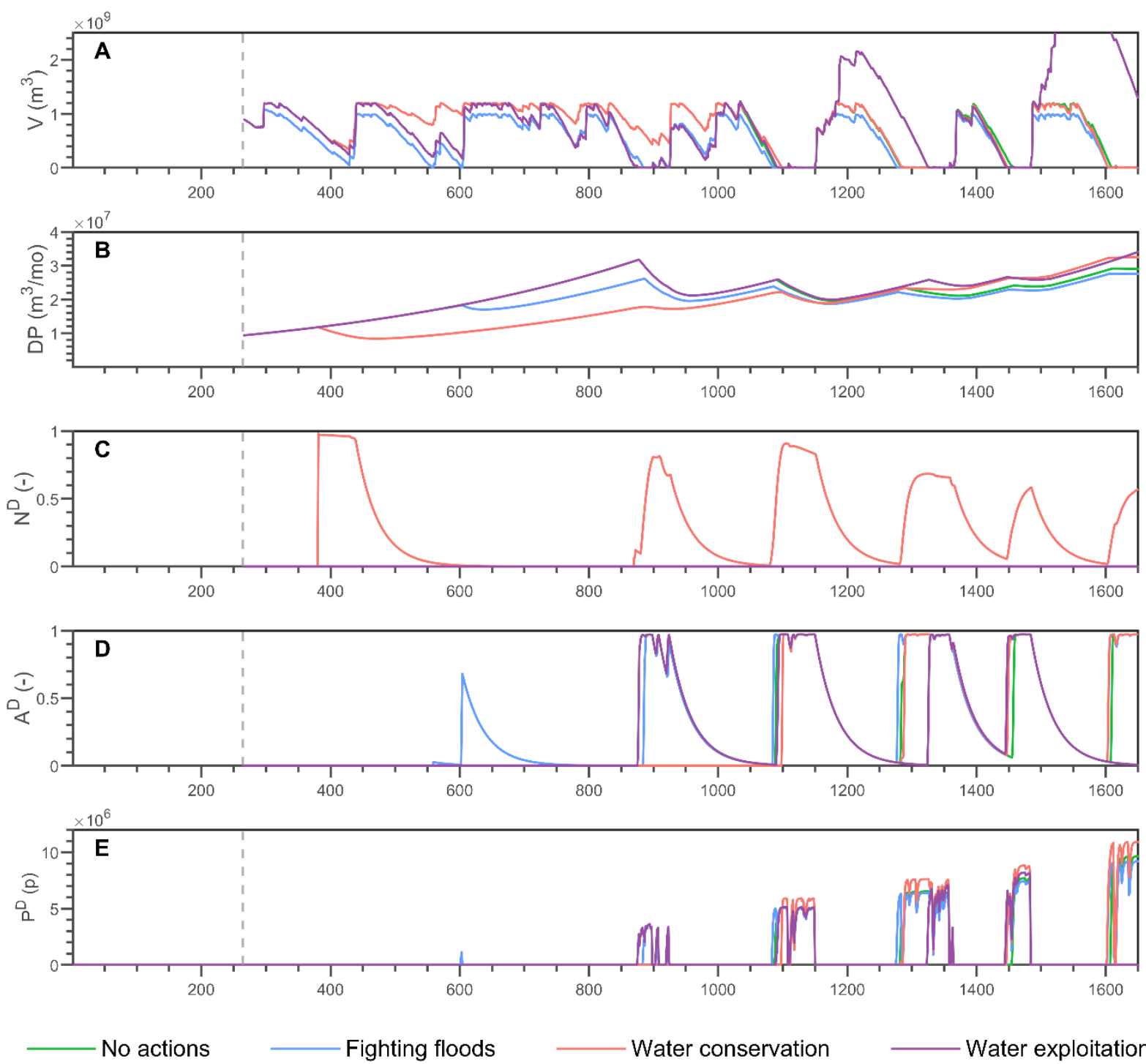

Fighting floods

- Water conservation

Water exploitation

Figure A15. Water shortage-based variables of the synthetic experiments additional scenario \#4 considering dam construction and human-flood interactions with the four water management strategies introduced in this study. (A) reservoir volume (V), (B) total water demand (DP), (C) willingness to the new per-capita demand (ND), (D) drought awareness $(A D)$, and $(E)$ population affected by droughts $(P D)$. The grey dashed line indicates the construction of the Wivenhoe Dam. 

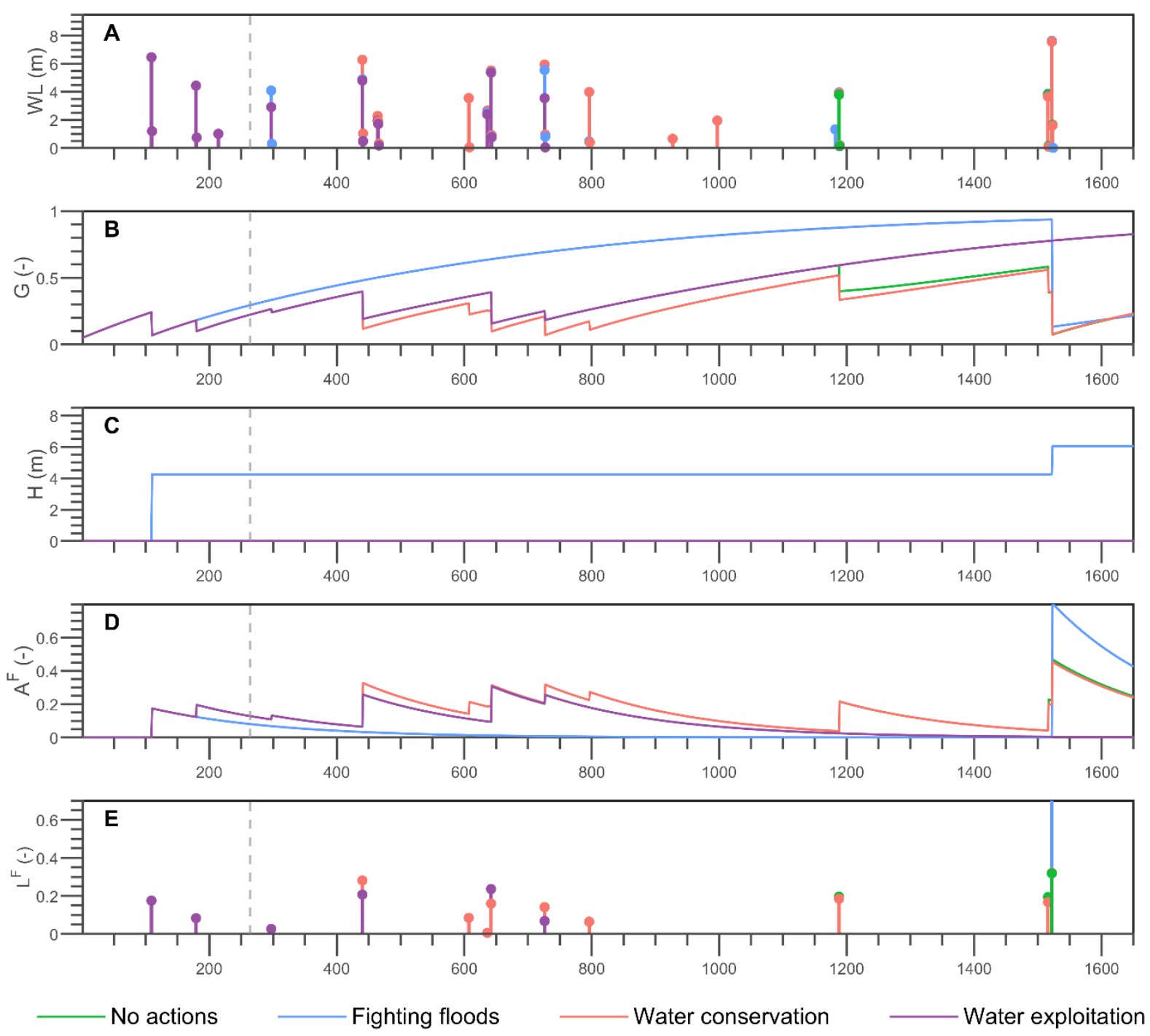

Figure A16. Flooding-based variables of the synthetic experiments additional scenario \#4 considering dam construction and human-flood interactions with the four water management strategies introduced in this study. (A) Water level (WL), (B) proportion of population in floodplain $(G),(C)$ levee height $(H)$, (D) flood awareness $(A F)$, and (E) flood losses $(L F)$. The grey dashed line indicates the construction of the Wivenhoe Dam. 

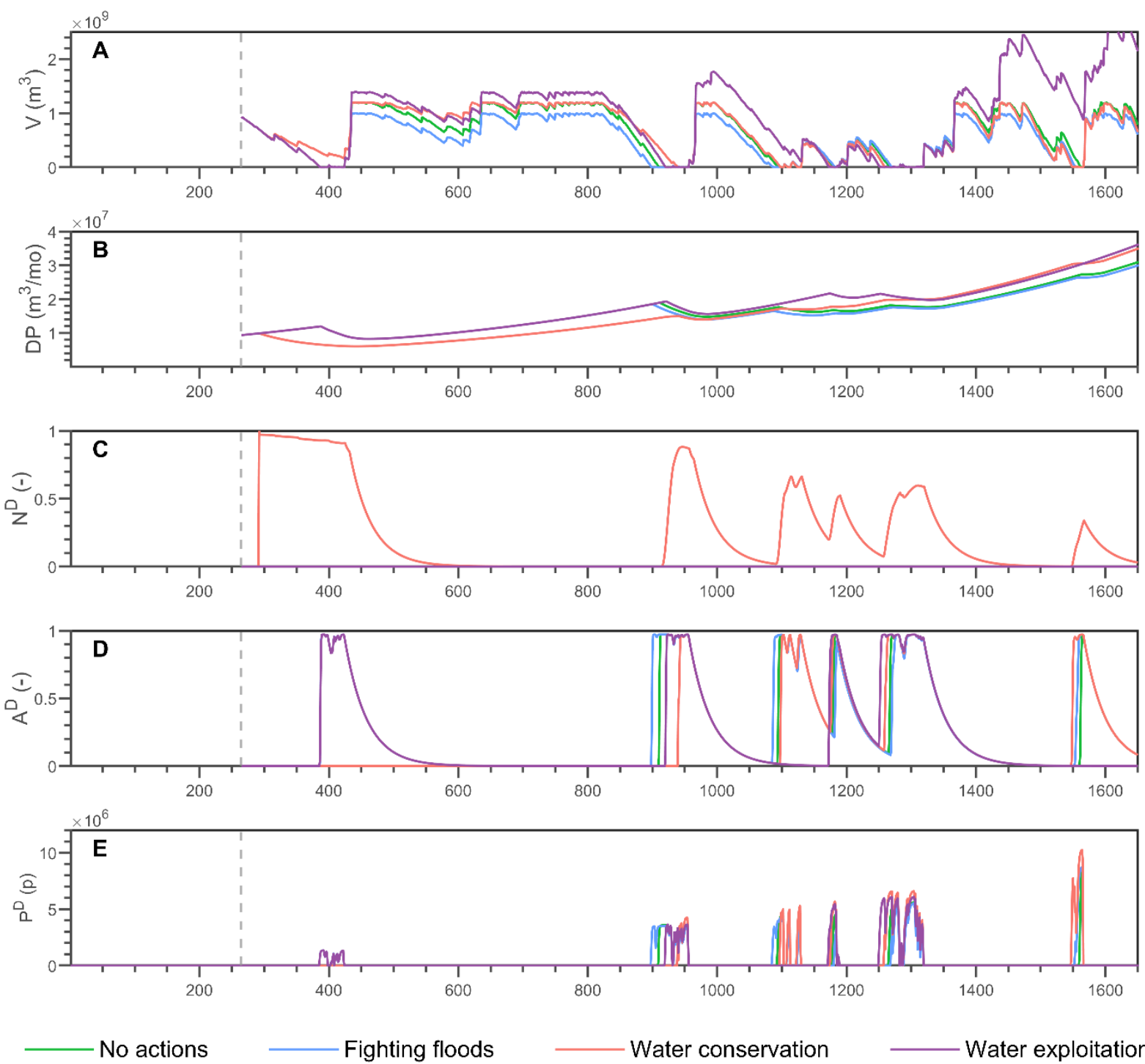

Fighting floods

- Water conservation

Water exploitation

Figure A17. Water shortage-based variables of the synthetic experiments additional scenario \#5 considering dam construction and human-flood interactions with the four water management strategies introduced in this study. (A) reservoir volume (V), (B) total water demand (DP), (C) willingness to the new per-capita demand (ND), (D) drought awareness $(A D)$, and $(E)$ population affected by droughts $(P D)$. The grey dashed line indicates the construction of the Wivenhoe Dam. 

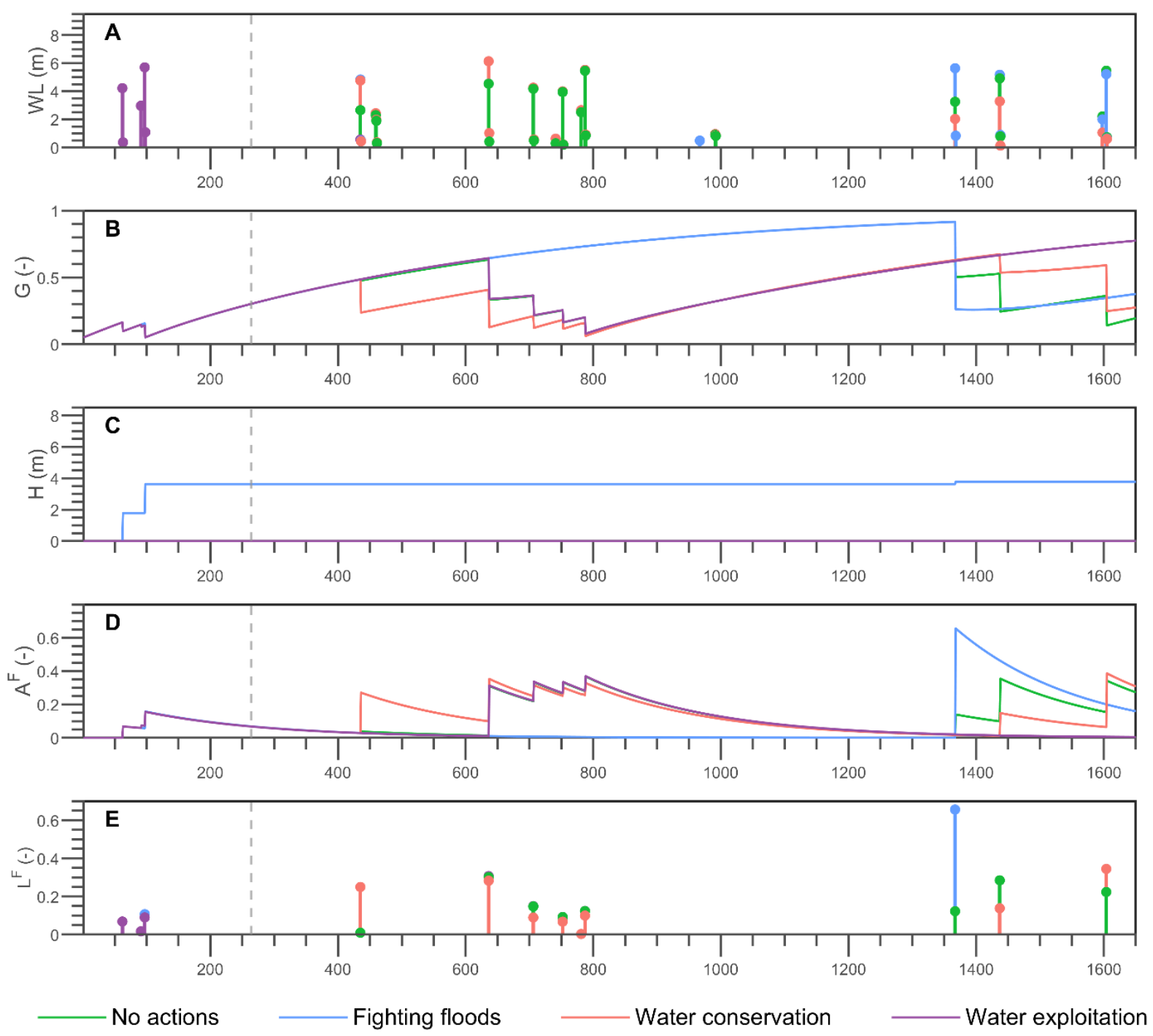

Figure A18. Flooding-based variables of the synthetic experiments additional scenario \#5 considering dam construction and human-flood interactions with the four water management strategies introduced in this study. (A) Water level (WL), (B) proportion of population in floodplain $(G),(C)$ levee height $(H)$, (D) flood awareness $(A F)$, and (E) flood losses $(L F)$. The grey dashed line indicates the construction of the Wivenhoe Dam. 

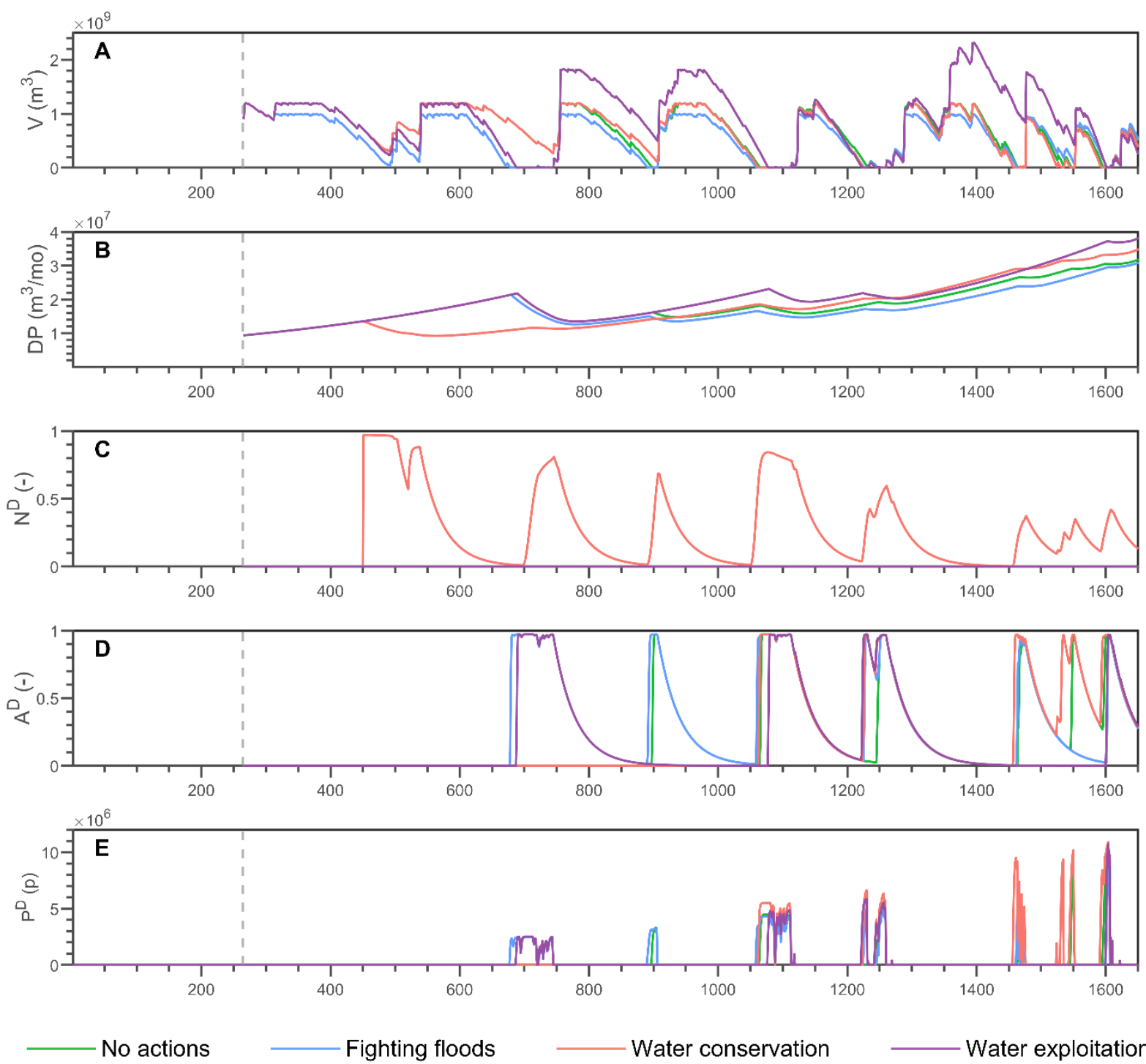

Fighting floods

- Water conservation

Water exploitation

Figure A19. Water shortage-based variables of the synthetic experiments additional scenario \#6 considering dam construction and human-flood interactions with the four water management strategies introduced in this study. (A) reservoir volume (V), (B) total water demand (DP), (C) willingness to the new per-capita demand (ND), (D) drought awareness $(A D)$, and $(E)$ population affected by droughts $(P D)$. The grey dashed line indicates the construction of the Wivenhoe Dam. 

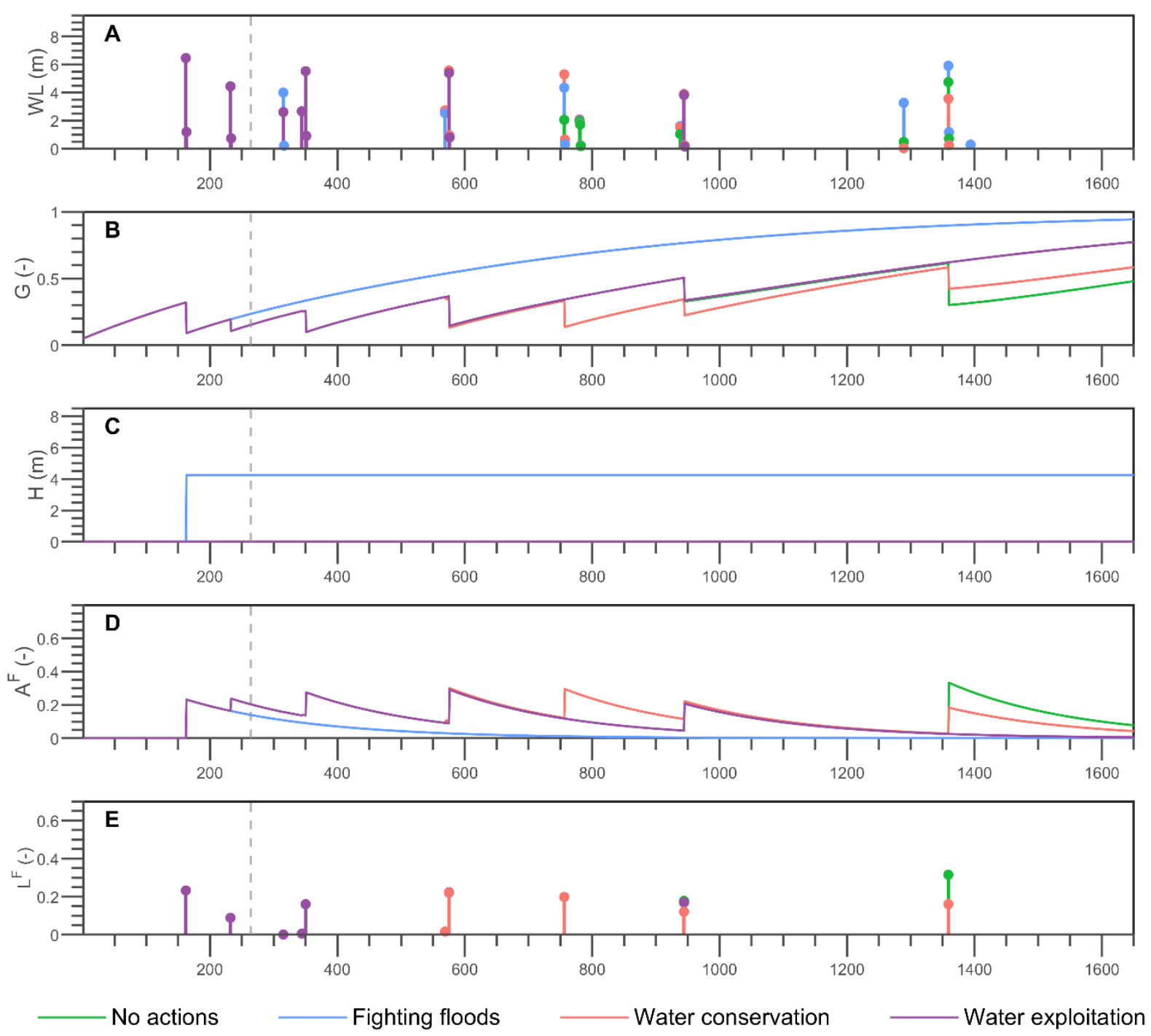

Figure A20. Flooding-based variables of the synthetic experiments additional scenario \#6 considering dam construction and human-flood interactions with the four water management strategies introduced in this study. (A) Water level (WL), (B) proportion of population in floodplain $(G),(C)$ levee height $(H)$, (D) flood awareness $(A F)$, and (E) flood losses $(L F)$. The grey dashed line indicates the construction of the Wivenhoe Dam. 


\section{Mean values of model outcomes with the additional six river flow scenarios}

Table A2. Average values of different model variables obtained for the synthetic experiment additional scenario \#1 with dam construction and four water management strategies (NA: No Actions; FF: Fighting Floods; WC: Water Conservation; WE: Water Exploitation)

\begin{tabular}{ccccc}
\hline Model variable & NA & FF & WC & WE \\
\hline $\boldsymbol{W} \boldsymbol{L}$ & 2.27 & 2.36 & 2.59 & 2.44 \\
$\boldsymbol{V}$ & $6.3 \cdot 10^{8}$ & $5.1 \cdot 10^{8}$ & $7.5 \cdot 10^{8}$ & $7.2 \cdot 10^{8}$ \\
$\boldsymbol{D}$ & 202.90 & 198.49 & 151.63 & 203.52 \\
$\boldsymbol{G}$ & 0.31 & 0.65 & 0.29 & 0.33 \\
$\boldsymbol{H}$ & 0.00 & 3.97 & 0.00 & 0.00 \\
$\boldsymbol{A}^{\boldsymbol{F}}$ & 0.13 & 0.02 & 0.14 & 0.12 \\
$\boldsymbol{A}^{\boldsymbol{D}}$ & 0.27 & 0.28 & 0.23 & 0.24 \\
$\boldsymbol{L}^{\boldsymbol{F}}$ & 0.16 & 0.18 & 0.10 & 0.16 \\
$\boldsymbol{L}^{\boldsymbol{D}}$ & 0.81 & 0.83 & 0.83 & 0.80 \\
$\boldsymbol{P}^{\boldsymbol{F}}$ & $2.2 \cdot 10^{5}$ & $3.2 \cdot 10^{4}$ & $6.6 \cdot 10^{4}$ & $1.3 \cdot 10^{5}$ \\
\hline
\end{tabular}

Table A3. Average values of different model variables obtained for the synthetic experiment additional scenario \#2 with dam construction and four water management strategies (NA: No Actions; FF: Fighting Floods; WC: Water Conservation; WE: Water Exploitation)

\begin{tabular}{ccccc}
\hline Model variable & NA & FF & WC & WE \\
\hline $\boldsymbol{W} \boldsymbol{L}$ & 2.72 & 2.83 & 2.66 & 2.60 \\
$\boldsymbol{V}$ & $6.9 \cdot 10^{8}$ & $5.7 \cdot 10^{8}$ & $7.8 \cdot 10^{8}$ & $1.3 \cdot 10^{9}$ \\
$\boldsymbol{D}$ & 188.46 & 181.29 & 141.86 & 189.55 \\
$\boldsymbol{G}$ & 0.28 & 0.44 & 0.24 & 0.33 \\
$\boldsymbol{H}$ & 0.00 & 5.46 & 0.00 & 0.00 \\
$\boldsymbol{A}^{\boldsymbol{F}}$ & 0.16 & 0.12 & 0.17 & 0.12 \\
$\boldsymbol{A}^{\boldsymbol{D}}$ & 0.27 & 0.28 & 0.20 & 0.21 \\
$\boldsymbol{L}^{\boldsymbol{F}}$ & 0.14 & 0.33 & 0.14 & 0.14 \\
$\boldsymbol{L}^{\boldsymbol{D}}$ & 0.83 & 0.81 & 0.82 & 0.83 \\
$\boldsymbol{P}^{\boldsymbol{F}}$ & $2.3 \cdot 10^{5}$ & $1.2 \cdot 10^{6}$ & $2.4 \cdot 10^{5}$ & $1.3 \cdot 10^{5}$ \\
\hline
\end{tabular}


Table A4. Average values of different model variables obtained for the synthetic experiment additional scenario \#3 with dam construction and four water management strategies (NA: No Actions; FF: Fighting Floods; WC: Water Conservation; WE: Water Exploitation)

\begin{tabular}{ccccc}
\hline Model variable & NA & FF & WC & WE \\
\hline $\boldsymbol{W} \boldsymbol{L}$ & 2.54 & 2.62 & 2.43 & 2.47 \\
$\boldsymbol{V}$ & $7.1 \cdot 10^{8}$ & $6.0 \cdot 10^{8}$ & $7.5 \cdot 10^{8}$ & $1.1 \cdot 10^{9}$ \\
$\boldsymbol{D}$ & 172.09 & 166.36 & 149.75 & 176.23 \\
$\boldsymbol{G}$ & 0.30 & 0.56 & 0.31 & 0.39 \\
$\boldsymbol{H}$ & 0.00 & 4.39 & 0.00 & 0.00 \\
$\boldsymbol{A}^{\boldsymbol{F}}$ & 0.15 & 0.09 & 0.15 & 0.11 \\
$\boldsymbol{A}^{\boldsymbol{D}}$ & 0.25 & 0.27 & 0.20 & 0.20 \\
$\boldsymbol{L}^{\boldsymbol{F}}$ & 0.13 & 0.51 & 0.16 & 0.14 \\
$\boldsymbol{L}^{\boldsymbol{D}}$ & 0.81 & 0.80 & 0.80 & 0.76 \\
$\boldsymbol{P}^{\boldsymbol{F}}$ & $2.5 \cdot 10^{5}$ & $2.9 \cdot 10^{6}$ & $3.4 \cdot 10^{5}$ & $2.1 \cdot 10^{5}$ \\
\hline
\end{tabular}

Table A5. Average values of different model variables obtained for the synthetic experiment additional scenario \#4 with dam construction and four water management strategies (NA: No Actions; FF: Fighting Floods; WC: Water Conservation; WE: Water Exploitation)

\begin{tabular}{ccccc}
\hline Model variable & NA & FF & WC & WE \\
\hline $\boldsymbol{W} \boldsymbol{L}$ & 2.51 & 2.38 & 2.58 & 2.38 \\
$\boldsymbol{V}$ & $6.4 \cdot 10^{8}$ & $5.4 \cdot 10^{8}$ & $7.7 \cdot 10^{8}$ & $9.5 \cdot 10^{8}$ \\
$\boldsymbol{D}$ & 204.31 & 191.58 & 148.86 & 205.28 \\
$\boldsymbol{G}$ & 0.33 & 0.59 & 0.28 & 0.42 \\
$\boldsymbol{H}$ & 0.00 & 4.12 & 0.00 & 0.00 \\
$\boldsymbol{A}^{\boldsymbol{F}}$ & 0.14 & 0.07 & 0.15 & 0.09 \\
$\boldsymbol{A}^{\boldsymbol{D}}$ & 0.27 & 0.30 & 0.22 & 0.21 \\
$\boldsymbol{L}^{\boldsymbol{F}}$ & 0.17 & 0.49 & 0.14 & 0.13 \\
$\boldsymbol{L}^{\boldsymbol{D}}$ & 0.82 & 0.81 & 0.83 & 0.79 \\
$\boldsymbol{P}^{\boldsymbol{F}}$ & $3.3 \cdot 10^{5}$ & $2.9 \cdot 10^{6}$ & $2.6 \cdot 10^{5}$ & $7.2 \cdot 10^{4}$ \\
\hline
\end{tabular}


Table A6. Average values of different model variables obtained for the synthetic experiment additional scenario \#5 with dam construction and four water management strategies (NA: No Actions; FF: Fighting Floods; WC: Water Conservation; WE: Water Exploitation)

\begin{tabular}{ccccc}
\hline Model variable & NA & FF & WC & WE \\
\hline $\boldsymbol{W} \boldsymbol{L}$ & 2.35 & 2.33 & 2.30 & 2.23 \\
$\boldsymbol{V}$ & $6.6 \cdot 10^{8}$ & $5.5 \cdot 10^{8}$ & $7.0 \cdot 10^{8}$ & $9.7 \cdot 10^{8}$ \\
$\boldsymbol{D}$ & 158.13 & 156.91 & 122.83 & 161.08 \\
$\boldsymbol{G}$ & 0.35 & 0.55 & 0.35 & 0.42 \\
$\boldsymbol{H}$ & 0.00 & 3.48 & 0.00 & 0.00 \\
$\boldsymbol{A}^{\boldsymbol{F}}$ & 0.13 & 0.08 & 0.12 & 0.09 \\
$\boldsymbol{A}^{\boldsymbol{D}}$ & 0.25 & 0.26 & 0.19 & 0.19 \\
$\boldsymbol{L}^{\boldsymbol{F}}$ & 0.13 & 0.28 & 0.13 & 0.12 \\
$\boldsymbol{L}^{\boldsymbol{D}}$ & 0.67 & 0.68 & 0.67 & 0.69 \\
$\boldsymbol{P}^{\boldsymbol{F}}$ & $2.7 \cdot 10^{5}$ & $1.2 \cdot 10^{6}$ & $3.2 \cdot 10^{5}$ & $9.6 \cdot 10^{4}$ \\
\hline
\end{tabular}

Table A7. Average values of different model variables obtained for the synthetic experiment additional scenario \#6 with dam construction and four water management strategies (NA: No Actions; FF: Fighting Floods; WC: Water Conservation; WE: Water Exploitation)

\begin{tabular}{ccccc}
\hline Model variable & NA & FF & WC & WE \\
\hline $\boldsymbol{W} \boldsymbol{L}$ & 2.40 & 2.50 & 2.43 & 2.57 \\
$\boldsymbol{V}$ & $6.7 \cdot 10^{8}$ & $5.6 \cdot 10^{8}$ & $7.1 \cdot 10^{8}$ & $9.2 \cdot 10^{8}$ \\
$\boldsymbol{D}$ & 180.87 & 177.21 & 146.35 & 186.52 \\
$\boldsymbol{G}$ & 0.34 & 0.63 & 0.32 & 0.39 \\
$\boldsymbol{H}$ & 0.00 & 3.84 & 0.00 & 0.00 \\
$\boldsymbol{A}^{\boldsymbol{F}}$ & 0.13 & 0.03 & 0.13 & 0.10 \\
$\boldsymbol{A}^{\boldsymbol{D}}$ & 0.25 & 0.26 & 0.19 & 0.18 \\
$\boldsymbol{L}^{\boldsymbol{F}}$ & 0.15 & 0.23 & 0.12 & 0.13 \\
$\boldsymbol{L}^{\boldsymbol{D}}$ & 0.72 & 0.73 & 0.68 & 0.72 \\
$\boldsymbol{P}^{\boldsymbol{F}}$ & $2.4 \cdot 10^{5}$ & $6.3 \cdot 10^{4}$ & $1.4 \cdot 10^{5}$ & $8.7 \cdot 10^{4}$ \\
\hline
\end{tabular}

